\title{
Copyright
}

by

Tracie McDonald Majors

2013 
The Dissertation Committee for Tracie McDonald Majors Certifies that this is the approved version of the following dissertation:

\section{Communicating Measurement Uncertainty: An Experimental Study of Financial Reporting Implications for Managers and Investors}

\section{Committee:}

Steven J. Kachelmeier, Supervisor

$$
\text { William R. Kinney }
$$

Lisa L. Koonce

Rajagopal Raghunathan

Michael G. Williamson 
Communicating Measurement Uncertainty: An Experimental Study of Financial Reporting Implications for Managers and Investors

by

Tracie McDonald Majors, B.S.; M.S.Acc.

\author{
Dissertation \\ Presented to the Faculty of the Graduate School of \\ The University of Texas at Austin \\ in Partial Fulfillment \\ of the Requirements \\ for the Degree of \\ Doctor of Philosophy
}

The University of Texas at Austin

December 2013 


\section{Dedication}

To my husband, Ed, my parents, Ed and Cindy, and my sister, Meredith

Honoring the memory of Maylon (Grandpa) McDonald, my role model in scholarly pursuits and life, and Dot (Granny) Avera, who was the most selfless person I have ever known. 


\section{Acknowledgements}

I am very grateful for the extraordinary guidance of my committee, composed of Steve Kachelmeier (chair) Bill Kinney, Lisa Koonce, Raj Raghunathan, and Michael Williamson. Stimulating conversations with Bill began even before my start of the doctoral program, and his support, encouragement, and advice throughout the doctoral program has been tremendous. I would like to thank Lisa for always becoming available at a moment's notice to give me wise advice about research and any dilemma that might be arising. I hope that as a professor, I can exhibit Raj's creativity, curiosity, and passion. Coauthoring with Michael has been great, and I really appreciate all that I have learned from him during our many conversations throughout the years.

I am also fortunate to have wonderful colleagues in the doctoral program. In particular, Brett Cantrell, Brent Lao, Erin Towery, Chris Yust, Marcy Shepardson, James Smith, and Todd Thornock have been wonderful colleagues, and I also appreciate their friendship very much. I would especially like to thank Erin - our Starbucks runs and outings at the AT\&T center were very fun, her racing to find experimental participants when I was running short was the utmost sign of friendship, and I know we will be lifelong friends.

I would like to express my appreciation to Mark Wimby, for his help in the McCombs laboratory. Helping me navigate z-Tree unexpectedly crashing and conversations while I was testing late in the night were much appreciated. I would also like to thank Bill Swann for directing me to the Dark Triad and for thoughtful discussions during his seminars.

I express my deepest gratitude to my mentor, dissertation chair, and friend, Steve Kachelmeier. I view Steve as the best researcher, teacher, and editor imaginable, and I have learned tremendously from him ever since I first sat in his office to interview for the doctoral program. His energy, passion, caring for others, and commitment are truly admirable, and I am grateful for the (many!) hours of conversations about this dissertation we have had in his office. Working on The Accounting Review with Steve was a "once in a lifetime" experience that I both learned from tremendously and enjoyed very much. When a dilemma or question arose throughout my time in the doctoral program, from my decision to pursue experimental research in January of the first year of the doctoral program, to the excitement of job market experiences, Steve has always been there for me and been a valued confidante and advisor.

Finally, I would like to thank my husband, Ed Majors. Spending Saturdays testing z-Tree in the McCombs laboratory, helping me troubleshoot programming problems, discussing dissertation ideas, reading drafts of this dissertation, providing valuable advice, and the many other things he has done have all been amazing. Most importantly, his unwavering love, enthusiasm, and support in sharing this journey throughout the doctoral program with me has been tremendous, and I look forward to our future adventures together. 


\title{
Communicating Measurement Uncertainty: An Experimental Study of Financial Reporting Implications for Managers and Investors
}

\author{
Tracie McDonald Majors, Ph.D. \\ The University of Texas at Austin, 2013
}

Supervisor: Steven J. Kachelmeier

\begin{abstract}
Range disclosures of estimates, whether in an expanded auditor's report or by managers, would be intended to communicate measurement uncertainty to investors. Knowing this information should enhance investors' ability to identify aggressive reporting, thereby possibly increasing investor actions taken against managers. In a laboratory experiment, I find that students in a managerial reporting role (hereafter, managers) report less aggressive estimates of an asset's value when ranges of possible estimates accompany their point estimates reported to students in an investor role (hereafter, investors), such that investor actions against managers do not increase when ranges are disclosed. However, this decline in aggressiveness is concentrated in managers with a greater degree of association with one or more of the following personalities: psychopathy, narcissism, and Machiavellianism (collectively deemed the "Dark Triad" in psychology). Notably, this result occurs because, in a regime of no range disclosure, these managers report relatively aggressive estimates to investors, irrespective of their private information about the asset's true value, while managers exhibiting low association with any of these personalities report estimates that more accurately reflect their private information. Range disclosure disciplines the former group of managers, which suggests that requiring range disclosure would discipline the reporting of the vi
\end{abstract}


managers who are the most prone to take advantage of investors absent the communication of this information. 


\section{Table of Contents}

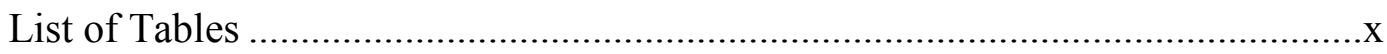

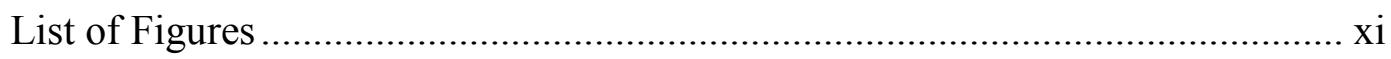

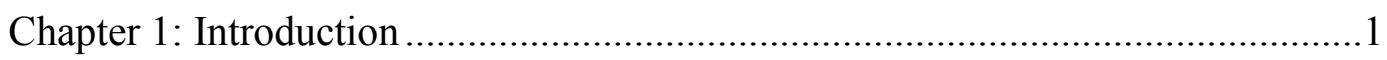

Chapter 2: Theory and Hypotheses Development: Range Disclosure....................12

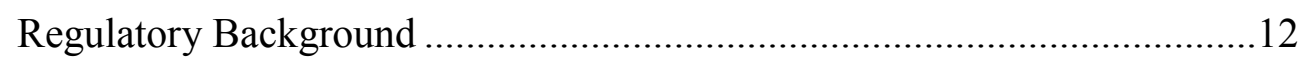

Hypotheses Development for Managers and Investors .................................17

Chapter 3: Theory and Hypothesis Development: The Interaction Between Range

Disclosure and the Dark Triad ..................................................................26

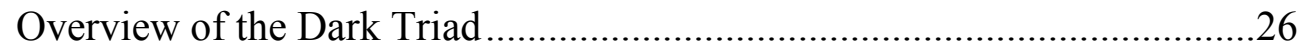

Dark Triad Managers in Reporting Environments..........................................31

The Dark Triad in a Regime of No Range Disclosure..................................33

The Effect of Range Disclosure and the Dark Triad......................................40

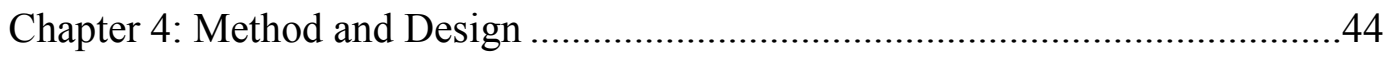

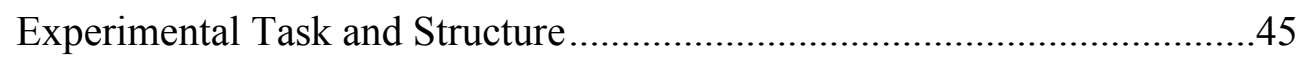

Measuring the Dark Triad........................................................................48

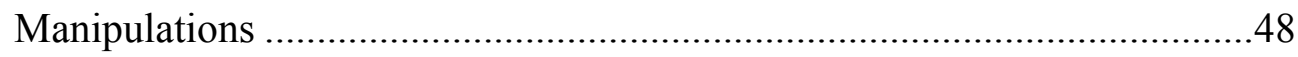

Chapter 5: Results and Analysis ……………………...................................50

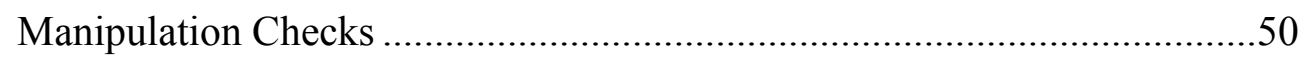

Distribution of Dark Triad Personality Scores..............................................51

Primary Results for Managers ................................................................51

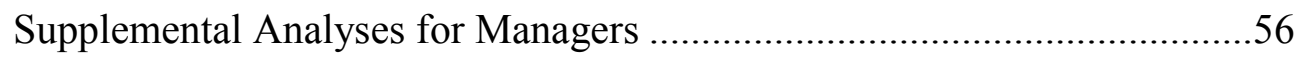

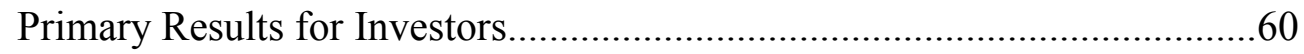

Supplemental Analyses for Investors.........................................................65

Chapter 6: Conclusions and Opportunities for Future Research ............................68

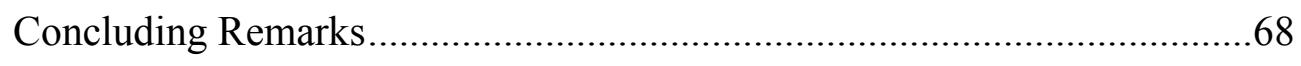

Limitations and Future Research Opportunities ............................................70 


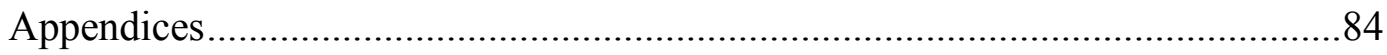

Appendix A: Experimental Instructions for Managers ..................................84

Appendix B: Experimental Instructions for Investors ..................................96

Appendix C: Z-Tree Screens for Managers and Investors............................108

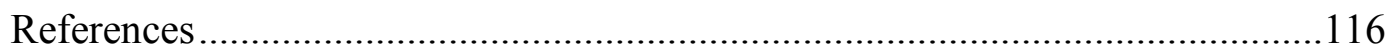

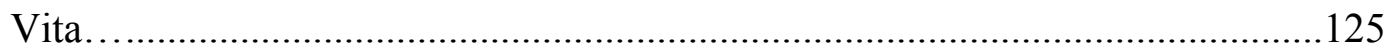




\section{List of Tables}

Table 1: $\quad$ Repeated-Measures Analysis of Variance for Managers...................82

Table 2: $\quad$ Mixed-Effects Model for Treatment Effects on Investors ................83 


\section{List of Figures}

Figure 1: $\quad$ Short Dark Triad (SD3) Questionnaire ......................................... 74

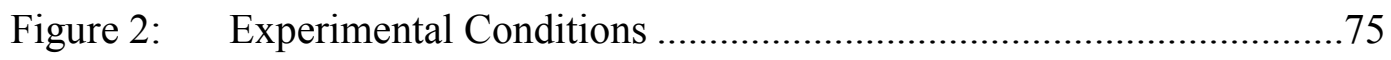

Figure 3: Frequency Distributions of Dark Triad Mean Scores .......................76

Figure 4: $\quad$ Range Disclosure and the Dark Triad by Personality Type..............77

Figure 5: Range Disclosure and the Dark Triad by Number of Personalities ..78

Figure 6: Range Disclosure and the Dark Triad ..........................................79

Figure 7: Range Disclosure and the Dark Triad by Private Information .........80

Figure 8: Investor Actions Taken Against Managers.....................................81 


\section{Chapter 1: Introduction}

The extent of uncertainty inherent in estimates of financial statement items with subjective values, such as assets and liabilities with "Level 2" and "Level 3" fair value inputs, has recently commanded heightened scrutiny from investors, regulators, auditors, and academics (e.g., Christensen et al. 2012; Bratten et al. 2013). One way to communicate the extent of measurement uncertainty in these estimates would be through range disclosures, to accompany managers' point estimates reported to investors. This potential regulatory action could materialize in several forms, including mandated disclosure of ranges by managers for estimates with high measurement uncertainty (e.g., Bell and Griffin 2012), or by auditors choosing to comment on reasonable ranges of estimates in an expanded auditor's report (e.g., IAASB 2013). The possibility of range disclosures prompts the question of how such an action could influence behavior. Specifically, could the disclosure of a range of possible estimates cause investors to react to managers' reported point estimates differently than they would otherwise? Could the anticipation that ranges must be disclosed to investors cause managers to report different point estimates than they would if range disclosures were not imposed?

Answers to these questions are important because measurement uncertainty is a frequent topic in regulatory discussions of potential changes to the auditor's report. A prominent theme in PCAOB and IAASB discussions and proposed standards about potential changes to the auditor's report is auditor communication to investors about areas of significant management judgment, including accounting estimates and the 
uncertainty in these estimates (Blake et al. 2012; PCAOB 2012, 2013; IAASB 2012b, 2013). The SEC and roundtable participants have also discussed the importance of communicating measurement uncertainty to investors, possibly in the form of range disclosures of estimates made by a firm's management or by the auditor (SEC 2011). Therefore, whether provided to investors by a firm's manager or auditor (or both), the possibility of range disclosures of estimates to investors is a timely and important potential regulatory requirement for which ex ante evidence on the consequences would be informative.

In addition to informing investors of the extent of measurement uncertainty in estimates, range disclosures could also potentially discourage managers from biasing estimates (Bell and Griffin 2012). A key premise underlying this possibility is that managers take advantage of investors' limited knowledge in a regime of no range disclosure by reporting relatively more aggressive estimates. However, as discussed next, literature in psychology based on personality characteristics conditions this premise.

Specifically, Paulhus and Williams (2002) refer to a "Dark Triad" of personality, comprised of psychopathy, narcissism, and Machiavellianism. Although these personalities are conceptually distinct, they have been shown to overlap empirically, sharing an "indifference to the harm they cause to others in the course of achieving their goals" (Jones and Paulhus 2011, p. 253), which Jones and Paulhus (2011) characterize as exploitive tendencies. Drawing from this literature, I posit that managers who do not exhibit association with any of the Dark Triad personalities (hereafter, "non-Dark Triad" 
managers) are less prone to report particularly aggressive estimates when ranges are not disclosed, due to their concern for the harm imposed on investors. In contrast, I posit that managers who exhibit association with one or more members of the Dark Triad (hereafter, "Dark Triad" managers) are more prone to report particularly aggressive estimates when ranges are not disclosed, due to their relative lack of concern for the harm imposed on investors. Jointly, these predictions imply that there should be a stronger disciplining effect of the regulatory scrutiny introduced by range disclosures on Dark Triad managers because there is more aggressiveness to discipline.

Importantly, recognizing individual differences in manager behavior acknowledges that regulators care about who they are regulating. Individuals with personalities in the Dark Triad are well represented in the corporate world. Babiak et al. (2010) find in a sample of corporate managers that most managers with higher levels of psychopathic traits hold high ranking executive positions, concluding that "it is likely that the sour cream will continue to rise to the top" (p. 192). Narcissistic individuals are often charismatic visionaries, filling positions of leadership and seeking positions of power and influence over others (Maccoby 2000; Chatterjee and Hambrick 2007). Research has also demonstrated that high Machiavellians gravitate to management and leadership positions, tending to seek business careers, particularly in which they can control and manipulate others and have access to widespread resources (Fehr et al. 1992; Corzine 1997; Judge et al. 2009). 
Because individuals associating with the Dark Triad tend to prioritize their material welfare, there is reason to believe that Dark Triad managers might be disciplined by the imposition of range disclosures that could expose their aggressive reporting, thereby provoking punitive investor actions if they do not respond strategically to such disclosures by reducing their aggressiveness in anticipation of these actions. Yet, there are other characteristics of Dark Triad managers, such as their belief that they have superior abilities to deceive others (Giammarco et al. 2013), that make it unclear ex ante if they will even be disciplined by range disclosure. To be effective, reporting regulation must discipline those managers who would report the most aggressively in the absence of regulation. However, regulation ideally should also not impose on managers who are not reporting aggressively absent such regulation. By examining how individuals respond to range disclosure differently, depending on their association with Dark Triad personality characteristics (which I theorize will be predictive of aggressive reporting), my study directly tests this question.

I design an interactive laboratory experiment, in which student participants make decisions in roles analogous to those of managers and investors (hereafter, managers and investors), interacting in manager-investor dyads. Each manager is given a reasonable range of estimates of an asset's value and is asked to report an estimate within this range to the investor with whom s/he is paired. Managers are incentivized to report higher estimates within the reasonable range, as they receive compensation tied to the estimates they report. However, investors have a vested interest in the true asset value, as their 
compensation is tied to the realized asset value, and they directly bear the cost of any aggressive bias in managers' reported estimates, defined as the excess of the reported estimate over the realized asset value. After viewing the manager's reported estimate, but without knowledge of the realized asset value, investors have the option to take a costly action against the manager. This action can be analogized to various forms of shareholder activism (see Gillan and Starks 2007), in addition to investors exerting selling pressure on a firm's stock in a way that drives the stock price downward and imposes costs on both managers and investors.

To operationalize reporting regimes with and without range disclosure, a mandatory disclosure of the reasonable range of estimates accompanies the manager's point estimate to the investor in one condition, while in the other condition, only the manager's point estimate is disclosed to the investor. Managers are informed whether the reasonable range of estimates will be disclosed to investors, thereby capturing managers' reporting decisions in anticipation of the presence or absence of range disclosure.

Because managers are not permitted to manipulate the reasonable range of estimates, the range disclosure in this study represents the auditor's independently developed range or management's range that has been verified by an auditor. ${ }^{1}$ While in practice there are factors that can give managers discretion over such a range of

\footnotetext{
${ }^{1}$ As the range in this study represents either a range chosen by the auditor to disclose or a mandatory disclosure made by management, this study fundamentally differs from literature on management's voluntary disclosure of ranges, such as studies examining management earnings forecasts (e.g., Hirst et al. 1999). In contrast to this study's focus on management's reporting of point estimates, either in isolation or with disclosure of an accompanying range (that the manager cannot manipulate), the voluntary disclosure literature explores management's choice to disclose either a point estimate or range (e.g., Kennedy, Mitchell, and Sefcik 1999).
} 
estimates, such as management pressure on auditors or substandard auditing, this study abstracts from these factors by investigating how managers strategically respond to the disclosure of a range over which they have no discretion. Abstracting from these factors enables this study to answer the fundamental question of how managers' reporting of estimates changes in response to the imposition of a range disclosure to accompany such estimates, with a ceteris paribus comparison between regimes with or without range disclosure. Another key feature of this study's design is that managers are consistently restricted to report estimates within the range, irrespective of whether the range is disclosed to investors, representing the fact that auditors accept management's estimate only if it falls within the reasonable range of possible asset values. ${ }^{2}$

Range disclosure is only meaningful if there is variety in the ranges that are disclosed. Considering an extreme example, if the range consistently has the same lower and upper bounds, disclosure of the range provides no incremental information. To incorporate such variety, the experimental design also includes two within-participants manipulations. Specifically, I manipulate (1) the location of the range within the context of the possible asset values, via manipulating the midpoint of the range and (2) the precision of the asset value being estimated, via manipulating the width of the range. Manipulating the location of the range and the precision of the asset's value enhances the extent to which range disclosures communicate information about the asset's value that is

\footnotetext{
${ }^{2}$ In practice, if management's estimate falls outside of the reasonable range, auditors would consider the difference between management's estimate and the closest bound to be a misstatement. If the auditor considers this misstatement qualitatively or quantitatively material, management's estimate would be rejected. For simplifying purposes, my experimental design assumes that any value outside of the reasonable range is rejected by the auditor.
} 
incremental to information available to investors when ranges are not disclosed. Manipulating the precision of the asset's value also captures the institutional reality that managers make estimates of asset values that vary in precision (e.g., Level 2 vs. Level 3). I also manipulate, within-participants, the manager's private information about where the asset's value lies within the range. Manipulating the manager's private information ensures that disclosure of the range is not equivalent to fully revealing the manager's private information. Overall, these three manipulations are intended to more effectively capture the primary, between-participants manipulation of regimes with and without range disclosure.

My findings indicate that, on average, managers report less aggressively in a regime of range disclosure than in a regime of no range disclosure, such that investor actions against managers do not increase in response to range disclosure. This result is consistent with managers engaging in first-order strategic reasoning (e.g., Stahl and Wilson 1995; Zimbelman and Waller 1999; Bowlin 2011), as they respond to the mandating of range disclosures by anticipating the enhanced ability to detect aggressive reporting that such disclosures afford to investors, leading managers to reduce aggressive reporting in order to pre-empt an increase in harmful investor actions. ${ }^{3}$ However, the disciplining effect of range disclosure is concentrated in Dark Triad managers. This result occurs because, in a regime of no range disclosure, Dark Triad managers report relatively aggressive estimates, while non-Dark Triad managers report estimates that more

${ }^{3}$ First-order strategic reasoning occurs when a decision-maker considers not only conditions directly impacting his decision, but also factors directly impacting the other party's decision (e.g., Zimbelman and Waller 1999). 
accurately reflect their private information about where the asset's value lies within the reasonable range. Range disclosure disciplines Dark Triad managers, such that there is no discernible difference in reporting aggressiveness between non-Dark Triad and Dark Triad managers in a regime of range disclosure, implying that this regulatory action would effectively discipline those managers most likely to report aggressively in the absence of range disclosure. Importantly, non-Dark Triad managers exhibit no change in reporting in response to range disclosure, suggesting that such a regulatory action would not unduly impact such managers.

This experiment is conducted in the experimental economics tradition, such that undergraduate student participants receive explicit monetary incentives and act in roles analogous to those held by managers and investors in practice. This style of experimentation utilizes abstract settings often with student participants, and as such, does not afford the degree of realism of experiments conducted in the judgment and decision-making tradition, which often elicit judgments from experienced professionals and utilize context-rich case materials. Nonetheless, an experimental economics design does proffer the noteworthy advantages of meaningful incentives, measures of actual behavior, and rich strategic interactions (e.g., Kachelmeier and King 2002).

In particular, a key advantage of the interactive experimental design in this study is that reported estimates are determined endogenously by strategic managers. An experiment with managers selecting estimates is important because determining investor actions when ranges are and are not disclosed hinges on the ability to determine how 
managers report in each regime. Specifically, the interactive design enables observance of how managers report estimates, with both the economic incentive to report aggressively and the knowledge that investors can take actions against them. The fact that investor actions do not increase in response to range disclosure highlights that endowing investors with greater ability to identify aggressive reporting will not necessarily increase investor actions against managers, so long as managers (and in particular, Dark Triad managers) sufficiently adjust their reporting to avoid provoking investor actions. In essence, such a design enables this experiment to determine if managers successfully engage in first-order strategic reasoning (e.g., Zimbelman and Waller 1999; Bowlin 2011) when range disclosures are imposed, by pre-empting an increase in investor actions when range disclosures are imposed.

Evidence in this study complements recent archival research by Ramanna and Watts (2012), who examine the motives of managers who are estimating goodwill fair values to determine impairment decisions. These authors find evidence that managers opportunistically use the discretion allowed in SFAS 142 to fulfill their agency-based motives, which is consistent with my study's finding that managers (and in particular, Dark Triad managers) report aggressive estimates to increase their personal welfare when range disclosures are not imposed. Ramanna and Watts (2012, p. 753) conclude that "our evidence suggests that fair values, when extended to assets with unauditable valuations, are likely to compromise financial reporting's role as a management control system." Results of this dissertation suggest that imposing disclosure of a range of reasonable 
estimates to investors, in a fashion such that the range is not manipulated by managers, could rein in opportunistic behavior such as that observed by Ramanna and Watts (2012), and in a sense, serve as an alternative management control system. My study also investigates managerial attributes that give rise to different manager motives, showing that not all managers take advantage of the discretion allowed in reporting estimates, and that mandating range disclosures could rein in those managers who are taking advantage of such discretion.

In particular, this study contributes insights regarding how the regulatory action of range disclosure could differentially influence managers depending on their attributes. Psychopathy expert Robert Hare states that “...psychopathic entrepreneurs and risktakers tend to gravitate toward financial watering holes, particularly those that are enormously lucrative and poorly regulated" (Hare 2012). The "poorly regulated" element of this statement seems to hint that, in an environment of more stringent regulation, managers with psychopathic tendencies may not bear as much of an advantage over their counterparts. This study's finding that aggressive reporting from Dark Triad managers is indeed disciplined by range disclosure supports this conjecture. This study also shows that Dark Triad managers successfully engage in first-order strategic reasoning and preempt an increase in investor actions when ranges are disclosed, thereby contributing to the literature in accounting examining strategic reasoning in various contexts (e.g., Zimbelman and Waller 1999; Bowlin 2011). Moreover, by investigating how managers' personalities influence their reporting decisions, this study also adds to the emerging 
literature in accounting examining the effect of managers' attributes on their reporting decisions (e.g., Bamber et al. 2010; Hales et al. 2012; Murphy 2012). 


\section{Chapter 2: Theory and Hypotheses Development: Range Disclosure}

This chapter begins with a discussion of regulatory initiatives relevant to measurement uncertainty and the potential role of range disclosures to communicate such uncertainty. The following sections motivate hypotheses for how range disclosures could influence manager reporting and investor actions taken against managers.

\section{Regulatory Background}

Range disclosures to investors would be intended to communicate the extent of measurement uncertainty in estimates and the range of other acceptable estimates (SEC 2011; PCAOB 2011; Bell and Griffin 2012). Measurement uncertainty is defined as ambiguity in valuing or developing a point estimate of a financial statement item (e.g., Bratten et al. 2013). Examples include imprecision in estimating fair values, goodwill, or bad debts, among others. Measurement uncertainty could be communicated to investors by either a firm's auditor or management (SEC 2011). Recent regulatory developments suggest that either (or both) of these possibilities could materialize.

For auditing, the PCAOB and IAASB have both issued proposed standards to make the auditor's report more informative for investors. In the following subsections, I discuss the content of each proposed standard and elements of each standard that are most relevant to this study. This section closes with a discussion of the alternative possibility that range disclosures could materialize in the form of required disclosures made by management. 


\section{The PCAOB's Proposed Standard}

In the United States, the PCAOB has proposed a standard entitled "The Auditor's Report on an Audit of Financial Statements When the Auditor Expresses an Unqualified Opinion," which illustrates a proposed approach to increase the informativeness and transparency of the auditor's report for investors (PCAOB 2013). The essence of the proposed standard is requiring the auditor to communicate "critical audit matters" in the auditor's report. The PCAOB specifies that critical audit matters are areas of the audit that prompted particularly complex, difficult, or subjective judgments, presented relatively greater difficulty for the auditor in acquiring appropriate and sufficient evidence, or most generally, caused the auditor the most difficulty in forming the financial statement opinion (PCAOB 2013). The PCAOB also suggests that critical audit matters, due to their relative importance to the audit, would be typically be items disclosed in communications with the audit committee, included in the engagement completion document, or reviewed by the quality review partner (PCAOB 2013).

More specific factors in the proposed standard to aid the auditor in identifying critical audit matters include the subjectivity in establishing audit procedures and evaluating the accompanying results, the nature and degree of required audit effort, the nature and amount of evidence and difficulty in obtaining evidence, and any changes made to the auditor's planned procedures or risk assessment (PCAOB 2013). The PCAOB also suggests that factors such as the severity of related control deficiencies, the quantitative and qualitative nature and significance of related corrected and uncorrected 
misstatements, the degree of specialized knowledge warranted, and consultations made outside of the engagement team would be relevant information in deeming an area a critical matter (PCAOB 2013).

Of key relevance to this study, areas involving estimates with high measurement uncertainty would often introduce issues such as the PCAOB's recommended areas of consideration discussed above. As just a few examples, auditors often consult specialists to assist with auditing estimates (e.g., Griffith et al. 2013), and areas of high measurement uncertainty would certainly qualify as areas in which determination of appropriate audit procedures is often subjective in nature and sufficient and appropriate evidence can be difficult to obtain (Christensen et al. 2012; Bratten et al. 2013). ${ }^{4}$ In fact, one of the PCAOB's three illustrative examples of a critical audit matter is an estimate with high measurement uncertainty - specifically, the fair value of fixed maturity securities that are held as investments and not actively traded (PCAOB 2013, A5-74). When auditors disclose critical audit matters in an expanded auditor's report, disclosure of a range of reasonable estimates independently determined by the auditor could potentially be a part of this communication.

\section{The IAASB's Proposed Standard}

Internationally, the IAASB unanimously approved their proposed International Standard On Auditing (ISA) 701, "Communicating Key Audit Matters in the Independent Auditor's Report" to release for comment (IAASB 2013). The proposed standard requires

\footnotetext{
${ }^{4}$ Indeed, in its proposed standard (PCAOB 2013), the PCAOB actually cites estimates as an example of an area in which these considerations are particularly likely to arise.
} 
auditors to communicate key audit matters to investors in a new section of the auditor's report. The standard further defines key audit matters as "those matters that, in the auditor's professional judgment, were of most significance in the audit of the financial statements of the current period...[and] communicated with those charged with governance" (IAASB 2013, p. 2). Of particular interest to this study is that the topic of estimates is prominently highlighted within the standard.

Specifically, the IAASB communicates how the auditor should determine which items are of most significance, suggesting that significant qualitative or quantitative factors related to the area, such as high magnitude or user interest in the area, areas in which the auditor spent the most effort, or areas requiring significant judgment by management or the auditor, among others, could constitute key audit matters. Because estimates with high uncertainty could certainly relate to such factors, such estimates are a good candidate to be considered a key audit matter. Indeed, as the standard elaborates, "Accounting estimates with high estimation uncertainty are of interest to users of the financial statements because, among other things, they are highly dependent on judgment, may require involvement of both a management's expert and an auditor's expert, and may be identified as significant risks. As a result, these areas of the audit may be considered key audit matters" (IAASB 2013, p. 8).

Auditors in an enhanced auditor's report might directly communicate about reasonable ranges of estimates. Alternatively, in an attempt to avoid disclosing original information about the client, the auditor might discuss a range disclosure made by 
management, potentially even encouraging management to provide the disclosure if one does not currently exist (IAASB 2013). Proposed ISA 701 states that "the auditor may draw attention to the disclosure of key assumptions and other sources of estimation uncertainty, the disclosure of the range of possible outcomes [emphasis added], and other qualitative and quantitative disclosures relating to key sources of estimation uncertainty or critical accounting estimates, as part of explaining why the matter was important to the audit" (IAASB 2013, p. 13). Irrespective of whether the auditor is in a position prompting their disclosure of a range, which the standard suggests occurs "if in the auditor's judgment, the additional information...is critical to the auditor's description of the key audit matter" (IAASB 2013, p. 12) and management has not disclosed such information, or the auditor is discussing management's disclosure, this regulatory development indicates that range disclosures are likely to be prominent within the enhanced auditor's report.

\section{Range Disclosures Made by Management}

In addition to the possibility of auditors disclosing ranges, range disclosures could also materialize in the form of mandatory disclosures made by management. In a roundtable on measurement uncertainty, the SEC and roundtable participants discussed possible ways to communicate such uncertainty, one of which entailed range disclosures of reasonable estimates to investors, made by a firm's management or auditor (SEC 2011). In principle, auditor verification that disclosed ranges are reasonable would ensure 
such ranges are not manipulated by managers. In this spirit, Bell and Griffin (2012, p.

151) recommend disclosing reasonable ranges of estimates to investors, stating:

An effective fair value accounting accountability system should create incentives that encourage management to develop the most accurate and unbiased estimates possible...these incentives will be reinforced when...quantitative disclosures of estimated levels of inherent measurement uncertainty are made mandatory [emphasis added]... and by an independent audit of, and auditor communications about, these disclosures.

As indicated by these discussions, range disclosures by a firm's management or auditor is an important topic in expanding the auditor's report and potential improvements to financial reporting. Next, I turn to developing hypotheses for the effects of range disclosures on manager reporting and investor actions taken against managers.

\section{Hypotheses Development for Managers and Investors}

Research in economics (e.g., Nagel 1995; Stahl and Wilson 1995) and accounting (e.g., Zimbelman and Waller 1999; Bowlin 2011) has characterized decision-making in strategic settings within a framework of differing levels of iterative reasoning. Because this study's setting involves strategic interactions between managers and investors, I develop predictions for their behavior using this framework. I incorporate predictions drawing from zero-order and first-order reasoning. Zero-order reasoning occurs when decision-makers only consider factors directly influencing their decision, and do not consider factors facing the other party. This lack of consideration of the other party has been characterized in a variety of forms, such as only considering factors directly impacting one's personal decision (e.g., Zimbelman and Waller 1999), focusing on factors that seem most salient (e.g., Nagel 1995), or even choosing at random (e.g., Nagel 
1995; Stahl and Wilson 1995). In contrast, first-order reasoning occurs when decisionmakers, in addition to considering factors directly influencing their decision, also consider factors directly influencing the other party's decision (e.g., Zimbelman and Waller 1999).

\section{The Influence of Range Disclosure on Manager Reporting}

Below, I develop a prediction for how managers are likely to report differently in regimes of no range disclosure vs. range disclosure. This prediction draws from zeroorder reasoning and first-order reasoning, which I discuss in the subsections below.

\section{Zero-order reasoning: Managers}

In this study, I employ a definition of zero-order reasoning that is closest to Zimbelman and Waller (1999, p. 142), who define a decision-maker employing zeroorder reasoning as one who only "considers conditions that directly affect his choice." For example, Zimbelman and Waller (1999) predict that if managers engage in zero-order reasoning, they will misstate more as their incentive to misstate increases. In the current study, zero-order reasoning by managers would result in managers reporting the most aggressive estimates possible in both regimes of no range disclosure and range disclosure, because they gain monetary benefits from reporting higher estimates. Such a self-centric focus, however, would preclude managers from considering how investors might perceive their reporting decisions differently in regimes of no range disclosure and range disclosure. 
Note that managers' reporting decisions under zero-order reasoning are consistent with how managers would make reporting decisions if they consider investors to be rational in a strict economic sense. That is, this study captures the tension behind investor actions that are costly for both investors and managers. Examples include investors engaging in various forms of shareholder activism (e.g., Gillan and Starks 2007), or exerting selling pressure on the firm's stock in a way that drives the stock price downward. In contrast to other types of shareholder actions, such as lawsuits, these actions do not provide investors with direct monetary benefits and also impose costs on investors and managers. Accordingly, if managers believe that investors are rational in a strict economic sense, managers will believe that investors will be unwilling to incur the costs of taking such actions, even if they suspect aggressive reporting by managers. If managers hold this belief, they will report to the most aggressive extent possible, irrespective of whether or not ranges are disclosed to investors, because they do not believe investor actions are a credible threat.

\section{First-order reasoning: Managers}

First-order reasoning occurs when decision-makers consider factors directly influencing the other party's decisions and assume that the other party engages in zeroorder reasoning (e.g., Zimbelman and Waller 1999). In the current study, I posit that firstorder reasoning will prompt managers to reduce the aggressiveness of reported estimates when range disclosure is imposed, in order to avoid provoking investor actions. 
More precisely, because investors have limited knowledge of the range of reasonable estimates when ranges are not disclosed, and presumably will have difficulty identifying aggressive reporting, I posit that managers will report most aggressively in a regime of no range disclosure. Manager reporting aggressiveness when range disclosures are not mandated is consistent with evidence from Ramanna and Watts (2012) that managers estimate goodwill fair values to fulfill their agency-based motives, rather than convey their private information. Moreover, this prediction follows from either zeroorder reasoning or first-order reasoning because, in a regime of no range disclosure, managers would likely infer that investors have limited ability to identify their aggressive reporting and so have little rationale for taking actions. Range disclosures, however, should enhance investors' ability to identify aggressive reporting. Managers engaging in first-order reasoning, in anticipation of investors' enhanced ability to identify (and presumably, punish) aggressive reporting in a regime of range disclosure, should report less aggressively than they would in a regime of no range disclosure, to avoid provoking costly investor actions.

In short, first-order reasoning motivates the prediction that managers should report less aggressively in a regime of range disclosure than in a regime of no range disclosure. This line of reasoning motivates a directional hypothesis that managers will reduce reporting aggressiveness when range disclosure is imposed, as formally stated below:

H1: Managers will report less aggressively in a regime of range disclosure than in a regime of no range disclosure. 


\section{The Influence of Range Disclosure on Investor Actions}

In practice, if investors identify aggressive reporting by managers, they have the opportunity to take actions against managers. In the following subsections, I explore how investors could take actions against managers differently in regimes of no range disclosure vs. range disclosure. I discuss predictions for investor actions in response to the imposition of range disclosure, motivated from zero-order and first-order reasoning, in turn. I then revisit managers' predicted reporting behavior, as how manager reporting differs between regimes of no range disclosure and range disclosure is a pivotal driver of how investor actions might differ between the two regimes.

\section{Zero-order reasoning: Investors}

Investors engaging in zero-order reasoning will only consider direct factors influencing their decision of what extent to take actions against managers. In the most fundamental sense, if investors only consider the impact of taking actions on their personal payoff, they will not take actions against managers because the actions explored in the current study are costly and do not confer direct monetary benefits. It is important, however, to consider the frequent observation that "subjects' utility functions have arguments other than money" (Thaler 1988, p. 202). For example, there is a rich literature on the ultimatum game, showing that individuals will incur costs in order to punish unfair behavior (Roth 1995). Accordingly, I consider zero-order reasoning in this setting to manifest in investors taking actions based on the implications of managers' reported estimates for their perceived welfare, rather than the cost of taking actions. 
Investors in a regime of range disclosure might use the location of the reported estimate within the range as a cue to assess aggressiveness, taking more actions against managers as reported estimates lie higher in the disclosed range because aggressive reporting detracts from their welfare. Nevertheless, investors have incentives to prefer higher reported estimates if the realized values are also high (which is most likely to occur if the manager's private information indicates the asset value is likely to be high), because conservative reporting by managers does not increase investors' welfare. Instead, conservative reporting simply minimizes the possibility of incurring a loss from aggressive reporting. Due to the well-established salience of loss aversion (cf., Tversky

and Kahneman 1991), however, I predict that investors engaging in zero-order reasoning when ranges are disclosed will focus on the possibility of loss when estimates lie higher within the range, prompting them to take more actions against managers as reported estimates are higher within the disclosed range.

\section{First-order reasoning: Investors}

Investors engaging in first-order reasoning will, in addition to considering factors directly influencing their decisions, also consider factors influencing managers' reporting decisions. Research in psychology and accounting suggests that investors considering the manager's perspective will view reported estimates with increasing skepticism when such estimates more consistently reflect management's incentives. Specifically, studies examining persuasion (e.g., Eagly and Chaiken 1975; Eagly et al. 1978) show that people view communications as less credible and more likely to reflect strategic motives when 
such communications are aligned with the communicator's incentives. In the accounting literature, Hirst et al. (1995) find that users of an analyst report view information that is consistent with the analyst's incentives to be more biased than information that is inconsistent with the analyst's incentives. Hodge et al. (2006) find that, when a company is close to violating a debt covenant, users view equity classification of a hybrid security as less credible than liability classification, because the equity classification allows management to avoid violating the debt covenant. Extrapolated to disclosed estimates, results from these studies suggest that investors will view reports that are higher within the reasonable range (and hence, reflect management's incentives), as opportunistic reporting.

In short, I expect investors engaging in first-order reasoning to infer that estimates toward the upper end of the disclosed range reflect opportunistic reporting by managers, rather than legitimate optimistic beliefs held by managers. Recall that zero-order reasoning predicts the same end result - that investors will view estimates that are higher within the range as reflecting greater aggressiveness, but in that case, such beliefs arise from the harm that such estimates can (if aggressive) inflict on investor welfare. Consequently, irrespective of whether investors engage in zero-order or first-order reasoning, I expect investors to take more actions against managers as managers' reported estimates increase within the disclosed range.

Note that this setting of range disclosure, in essence, precludes investors from the possibility of engaging in even higher order reasoning. To see this point, consider the 
premise that investors engaging in higher order reasoning would anticipate managers' reduction in reporting aggressiveness to avoid provoking investor actions (as predicted in H1). Consequently, if investors view a reported estimate in a regime of range disclosure that is higher within the range, they might infer by higher order reasoning that managers are signaling that their private information indicates that the asset value is high, which is consistent with investors' incentives. Yet, this argument cannot hold because, by definition, investors cannot observe managers' private information. That is, investors viewing a reported estimate high within the range cannot distinguish between managers with high private information and managers with low or medium private information reporting the same as a manager with high private information. Moreover, if investors engage in such higher order reasoning, managers engaging in even higher order reasoning could then exploit such a strategy by reporting aggressively, because they know such attempts would be successful, implying that such an equilibrium would not be sustainable.

In sum, I predict that investors will view reports higher within the disclosed range as more aggressive, which is consistent with both zero-order reasoning and first-order reasoning. In a regime of no range disclosure, investors have limited insight into the range of reasonable estimates, precluding them from using such a cue to assess aggressiveness. Understanding the impact of range disclosures on investor actions, however, hinges on understanding how managers' reporting aggressiveness will differ between regimes with or without range disclosure, as I explore next. 


\section{Implications for effect of range disclosure}

Overall, range disclosures communicate measurement uncertainty, providing investors with a richer information set within which to understand the position of the manager's reported estimate relative to other possible estimates the manager could have reported. Drawing from earlier arguments, in a regime of range disclosure, investors will take more actions against managers as reported estimates are closer to the upper bound of the range. This prediction implies that, because range disclosure reveals higher reports to investors, investors actions taken against managers could increase when ranges are disclosed vs. not disclosed. However, if managers anticipate this reaction from investors and reduce reported estimates accordingly (as predicted in H1), investors' greater insight might not expose reported estimates higher in the range because managers would have adjusted reports downward in anticipation. This line of reasoning motivates the null hypothesis that investor actions will not differ between regimes of no range disclosure and range disclosure, as stated formally below: ${ }^{5}$

H2: Investors will take no more actions against managers in a regime of range disclosure than in a regime of no range disclosure.

\footnotetext{
5 To emphasize, H2 is a null prediction because, if H1 holds, managers' adjustments of reporting aggressiveness downward should be sufficient to avoid provoking incremental investor actions, implying that there should be no difference in investor actions between regimes of no range disclosure and range disclosure. I acknowledge, however, that there can be heterogeneity in the extent to which managers sufficiently adjust their reporting downward. To address this, in supplemental analyses in Chapter 5, I test investor actions conditional on the aggressiveness of managers' reported estimates.
} 


\section{Chapter 3: Theory and Hypothesis Development: The Interaction Between Range Disclosure and the Dark Triad}

The premise of $\mathrm{H} 1$ is that managers, engaging in first-order reasoning, will reduce reporting aggressiveness in a regime of range disclosure because investors will have greater ability to detect aggressive reporting in such a regime. A key premise underlying this prediction is that managers report more aggressive estimates to investors in a regime of no range disclosure, necessitating a downward adjustment of reported estimates in a regime of range disclosure to avoid provoking investor actions. Such a premise, however, is based on the general notion of managers increasing their utility purely via wealth maximization, abstracting from their individual attributes and preferences. I explore in this chapter the potential for meaningful and systematic individual differences in the aggressiveness of managerial reporting in a regime in which ranges are not disclosed, along with corresponding differences in responses to range disclosure. I draw from literature in psychology on the Dark Triad (Paulhus and Williams 2002) to develop theoretical support for when these individual differences are likely to emerge.

\section{Overview of the Dark Triad}

This section discusses the three personalities in the Dark Triad, providing a backdrop against which this study's prediction about the influence of the Dark Triad on manager reporting can be viewed. I begin by discussing Machiavellianism, which was established as a personality trait molded from writings of Niccolo Machiavelli, a political advisor for the Medici family in Italy. Contrary to Machiavellianism's origins as a personality trait, narcissism and psychopathy originated from clinical personality 
disorders observed in psychiatry patients (e.g., Raskin and Hall 1979; Hare 1985). Subsequent research suggests that these clinical personality disorders also are manifested in milder forms in subclinical or "normal" populations, which are the personalities examined in this study. Subclinical versions of these disorders have been shown to influence behavior, but are mild enough to allow individuals associating with these personalities to function in everyday society (e.g., Furnham et al. 2013).

\section{Machiavellianism}

Drawing from the $16^{\text {th }}$ century writings of Niccolo Machiavelli, Christie and Geis (1970) established the personality trait of Machiavellianism, which embodies the philosophy of the phrase "the end justifies the means" (e.g., Jones and Paulhus 2009). Machiavelli's most prominently known writing is his collection of his philosophies on maintaining political control, published in 1513, entitled The Prince. Machiavelli's writings illustrate his view that people tend to be malicious, self-interested, and not trustworthy, advising that a ruler must employ deceitful and exploitative tactics to hold power (Fehr et al. 1992). Christie and Geis (1970) put forth the idea that individuals differ on the extent to which they endorse Machiavelli's philosophies, developing the Mach-IV scale to measure this trait in individuals. The three dimensions of Machiavellianism, which are measured in the Mach-IV scale, include (1) advocating for manipulative tactics, such as those involving deceit and flattery, (2) holding cynical views that others are self-interested, weak, and not to be trusted, and (3) showing a disdain for conventional standards of morality (Christie 1970; Fehr and Paulhus 1992). 
Individuals exhibiting Machiavellianism also tend to prioritize agentic goals such as power, money, and competition (e.g., McHoskey 1999; Stewart and Stewart 2006; Jones and Paulhus 2009).

\section{Narcissism}

The origins of narcissism date back to the writings of Sigmund Freud (e.g., Raskin and Terry 1988; Swann and Bosson 2010). Perhaps reflecting his tendency to derive inspiration from Greek mythology (e.g., Downing 1975), Freud derived the term "narcissism" based on the mythological figure of Narcissus, who was in love with his own reflection. Freud viewed narcissism as a personality disorder that occurs when individuals allocate too much "psychic energy" to the self, at the expense of allocating energy to others, causing narcissists to have excessive admiration of the self and a deficit of love for others (Swann and Bosson 2010). Eventually, narcissism evolved into being viewed not just as a clinical disorder that one either does or does not have, but also a personality trait that can vary in normal populations (e.g., Raskin and Hall 1979; Robins and Paulhus 2001). Individuals with higher levels of narcissism tend to be grandiose and self-absorbed, with a sense of entitlement and superiority (Paulhus and Williams 2002).

Raskin and Hall (1979) developed the Narcissistic Personality Inventory to measure the extent of narcissism present in individuals. Narcissism can be separated into four dimensions (Emmons 1984). As defined in Emmons (1984), the first dimension is leadership and authority, which broadly reflects the narcissist's perception of themselves as a leader, combined with their dominant and extroverted nature, warmth, and boldness. 
The second dimension involves self-absorption and self-admiration, which is consistent with the most common portrayal of narcissism. The third dimension is superiority and arrogance, reflecting both the narcissist's grandiose self-view and independence. The fourth dimension is exploitativeness and entitlement, which is considered the maladaptive aspect of narcissism, because it is associated with troubling factors such as suspiciousness, anxiety, and neuroticism and is related to narcissists' propensity to manipulate others (Emmons 1984).

\section{Psychopathy}

Similar to narcissism, psychopathy originated as a clinical personality disorder. Psychiatrist Hervey Cleckley identified the clinical construct of psychopathy based on observations of patients with whom he and fellow psychiatrists particularly struggled and experienced difficulty treating (Cleckley 1941/1976). He compiled his observations of these patients and the disorder of psychopathy in a book aptly titled "The Mask of Sanity" (Cleckley 1941/1976), as these individuals often appeared quite normal, even charming and pleasant, in superficial or initial impressions (e.g., Babiak and Hare 2006). The clinical disorder of psychopathy gradually evolved from Cleckley's work and the work of other clinicians, such as William and Joan McCord (e.g., Hare and Neumann 2008). Individuals high in psychopathy tend to be impulsive, lack empathy for others, and exhibit a propensity to seek thrills and lack anxiety (e.g., Paulhus and Williams 2002).

In later work, psychologist Robert Hare developed the empirical construct of psychopathy. Specifically, Hare (1980) developed the Psychopathy Checklist (PCL) to 
measure psychopathy in individuals (a score exceeding 30 is considered a clinical psychopath), followed by the Psychopathy Checklist Revisited (PCL-R) (Hare 1991). As described by Furnham et al. (2013), Ray and Ray (1982) foreshadowed the introduction of the subclinical form of psychopathy, with later researchers developing reliable scales to measures subclinical psychopathy, such as the Self-Report Psychopathy (SRP-I) scale (Hare 1985), which through a series of adjustments has been refined to the current SRPIII scale (Paulhus et al. in press). To address emerging interest in the role of psychopathy in corporate environments, Mathieu et al. (2013) developed the B-Scan 360, a scale tailored to corporate psychopathy with which individuals rate other members of the organization, such as supervisors, peers, and subordinates.

Psychopathy can be classified into four dimensions (Williams et al. 2007; Hare and Neumann 2008). The interpersonal dimension involves grandiose views of one's self, superficial charm, deceptive tactics, and a manipulative nature (Williams et al. 2007). Shallow emotions, callous nature, lack of experiencing guilt or remorse for negative actions, and unwillingness to take responsibility comprise the affective dimension (Williams et al. 2007). The third dimension, lifestyle, consists of impulsivity, desire for stimulation and propensity toward boredom, parasitic nature, and lack of realistic goals (Williams et al. 2007). Finally, the antisocial dimension is manifested by criminal acts, early age behavioral problems, and a lack of self-control (Williams et al. 2007). The literature has also characterized psychopathy at a higher level as having a two factor structure, in which the interpersonal and affective dimensions jointly comprise primary 
psychopathy, and the lifestyle and antisocial dimensions jointly comprise secondary psychopathy (e.g., Hare and Neumann 2008). Next, I discuss how managers associated with the Dark Triad (hereafter, "Dark Triad" managers) would likely approach the decision of which estimate to report in a setting with reporting discretion.

\section{Dark Triad Managers in Reporting Environments}

In practice, the decision of which estimate to report, given a subjectively valued financial statement item, is likely made by multiple individuals. The question arises how Dark Triad managers could achieve the goal of reporting aggressively, given the possibility that other involved parties could have different, possibly less opportunistic, goals. One possibility is that, because Dark Triad managers often emerge as leaders and occupy high ranking positions, they are likely to possess reporting authority. But even Dark Triad managers not occupying such positions could achieve control over reported estimates, by skillfully manipulating those possessing reporting authority so as to report the aggressive estimates they desire. I now discuss research supporting each of these premises, in turn.

One example of a study finding that Dark Triad individuals tend to emerge as leaders is Brunell et al. (2008). Using both student and MBA samples, these authors observe that narcissistic individuals are more prone than non-narcissistic individuals to emerge as the group leader. They find that power-seeking of narcissistic individuals is one possible mechanism behind this result, also theorizing that narcissists' extraverted nature and overconfidence likely prompt them to speak up more in the group. 
Researchers have also shown that individuals high in psychopathy are prone to be identified as candidates for corporate leadership positions. For example, Babiak et al. (2010) study 203 managers, from seven companies, who are identified as having high potential within the organization by virtue of their selection to participate in a management development program. These authors find that individuals high in psychopathy are perceived as having high levels of creativity, charisma, communication skills, and strategic thinking; however, they also are perceived as failing to be a "team player," exhibiting weak overall accomplishments, and lacking good management skills (Babiak et al. 2010). Yet, in spite of these negative attributes, they were chosen to participate in a program intended for managers with high potential, who are expected to rise within the ranks.

However, even Dark Triad managers who are not in positions of reporting authority could skillfully manipulate the manager who does possess such authority. To this end, Jonason et al. (2012) examine how Dark Triad individuals achieve agentic goals in the workplace. They find that Dark Triad individuals adopt both hard tactics, such as aggressive behavior or obvious manipulation, and soft tactics, such as subtly persuading others that the desired behavior is in their best interest, or even developing superficial friendships to take advantage of and charm others. In short, I posit that because Dark Triad managers often occupy top ranking positions, and successfully employ soft and hard tactics to achieve their workplace goals, my assumption that such managers can control reported estimates seems reasonable. 


\section{The Dark Triad in a Regime of No Range Disclosure}

Although the three Dark Triad personalities are conceptually distinct, they are empirically overlapping, and can be broadly characterized as all entailing a "socially malevolent character with behavioral tendencies toward self-promotion, emotional coldness, duplicity, and aggressiveness" (Paulhus and Williams 2002, p. 557). I posit that these particular traits common to the Dark Triad characterize managers who would report particularly aggressively in an environment in which aggressiveness is unlikely to be detected, without concern for the negative consequences imposed on investors. As such, in a regime of no range disclosure, I expect managers associated with one or more of the Dark Triad traits (hereafter, "Dark Triad" managers) to take advantage of investors' lack of knowledge, reporting aggressively for their personal gain. In contrast, I expect managers exhibiting none of the Dark Triad traits (hereafter, "non-Dark Triad" managers) to be less prone to take advantage of the fact that investors do not have knowledge of the range of possible estimates, leading them to report less aggressively than Dark Triad managers in a regime of no range disclosure.

Next, I present theoretical support for this study's assumption that the key driver

of differences in manager reporting will be association with one or more of the Dark Triad traits or with none. Subsequently, I discuss theory and literature motivating this study's prediction that Dark Triad managers will report more aggressively in a regime of no range disclosure than non-Dark Triad managers. 


\section{The Dark Triad - One or Three Constructs?}

Notwithstanding the distinct origins of Machiavellianism, narcissism, and psychopathy, there are commonalities between the three personalities, prompting Paulhus and Williams (2002) to name the collective of the personalities the Dark Triad. In

particular, although the three personalities do differ in some facets, they exhibit a nontrivial overlap; as noted by Furnham et al. (2013, p. 1), "at the subclinical [emphasis added] level of functioning, the three concepts share a conceptual resemblance and their common measures overlap empirically." In fact, there has even been debate in the literature questioning if the Dark Triad personalities in subclinical form are distinguishable from each another. Some researchers believe that the three Dark Triad personalities represent the same latent construct (e.g., Jonason and Webster 2010) and use a composite measure to represent the three personalities (e.g., Jonason et al. 2010a).

Nevertheless, other researchers conclude that the Dark Triad personalities exemplify three distinct constructs that are significantly and positively correlated. These researchers assert that this positive correlation is likely driven by a common core overlapping among the three personalities. Furnham et al. (2013) review the possible common cores of the Dark Triad, which include lack of agreeableness (e.g., Jakobwitz and Egan 2006), propensity for social exploitation (e.g., Jonason et al. 2009), callousness or lack of empathy (e.g., Jones and Paulhus 2011), interpersonal antagonism (e.g., Lynam and Derefinko 2005), or manipulation and callousness (Jones and Figueredo, in press). 
Of particular significance to this study is that these potential underlying elements common to the three Dark Triad personalities could all predict aggressive reporting. For example, managers who would report aggressively to increase their personal wealth at the expense of investors' welfare could be driven by the lack of empathy put forth by Jones and Paulhus (2011) as a common core. To this end, in an investigation of how the Dark Triad relates to various personality traits, Jonason et al. (2010b, p. 112) state that "disagreeableness may predispose people to not valuing others much, which may facilitate the pursuit of selfish ends." In a corporate setting, those "selfish ends" could certainly materialize into extracting wealth from shareholders.

Overall, because traits common to the three Dark Triad personalities are also likely to be associated with aggressive reporting, I examine the effect of the Dark Triad on manager reporting by classifying managers as associated with one or more of the Dark Triad personalities or with none. This classification treatment is independent of the aforementioned debate in psychology. In other words, irrespective of whether the Dark Triad personalities represent one latent construct or three overlapping constructs, I expect association with any of the personalities to predict aggressive reporting in managers because I expect an element that is common among the three to drive such behavior. Because the three personalities also differ in some key facets, however, I perform analyses in the discussion of results in Chapter 5 to examine the robustness of my primary findings to each of these three personality types. Next, I discuss literature providing theoretical support for this study's premise that Dark Triad managers will be 
prone to report particularly aggressively in a regime of no range disclosure, in which such aggressiveness is likely to be undetected.

\section{The Dark Triad and Reporting Aggressively}

Researchers have discerned connection between the Dark Triad and one's propensity to engage in opportunistic, or self-interested, behavior. Although aggressive reporting in my experiment is "legal," and therefore captures a sense of the discretion permitted by GAAP, it is certainly true that aggressive reporting benefits managers' personal welfare and is opportunistic, in the sense that it extracts wealth from investors. Overall, a discussion of the influence of the Dark Triad on various forms of selfinterested behavior is prudent to understand how the case of opportunistic reporting in the current study fits in the broader literature in this area examining the Dark Triad and opportunism.

\section{$\underline{\text { Research in psychology and economics }}$}

Researchers in psychology and economics have found evidence that Dark Triad individuals are willing to behave opportunistically, if it benefits their personal welfare. For example, in a hypothetical decision-making task, Jones and Kavanagh (1996) find that high Machiavellians are more willing than low Machiavellians to overreport expenses to an employer. Using the classic trust game (Berg et al. 1995) with a "oneshot" structure and anonymous interaction, Gunnthorsdottir et al. (2002) find that high Machiavellians are less likely to reciprocate trust than low Machiavellians. These authors conjecture that high Machiavellians behave in this way because the "one-shot" and 
anonymous nature of the interaction cause lack of reciprocation to be most profitable, given that there is no chance of retaliation from the first mover.

Researchers using functional magnetic resonance imaging (fMRI) technology have examined unique aspects of neural activity exhibited by Dark Triad individuals facing situations in which opportunism is possible. For example, in an ultimatum game setting, Spitzer et al. (2007) find that high Machiavellians are more successful than low Macahiavellians because they propose unfair offers when rejection is not possible but propose fairer offers when rejection is possible. In conditions in which punishment is possible, they find that high Machiavellians experience greater activation in areas of the brain associated with emotional arousal, which they conjecture could be negative emotion incurred by punishment being possible, and neural areas relating to evaluating punishment threat.

Using the trust game and fMRI technology, Bereczkei et al. (2013) find that high Machiavellians transfer less money (i.e., trust less), are less likely to reciprocate trust, and earn more money in the experiment. The fMRI technology reveals that high Machiavellians exhibit a stronger increase in brain activity from rest to the trust game than low Machiavellians, with this activity concentrated in areas of the brain associated with making inferences, reward-seeking, and anticipating risky conditions. They conclude that high Machiavellians exhibit unique neural patterns that enable them to successfully exploit others and predict outcomes in risky situations. Results of these studies support the current study's premise that Dark Triad managers will report 
aggressively in a regime of no range disclosure, because aggressiveness benefits their welfare and is unlikely to be detected by investors.

\section{Studies in the accounting literature}

There are also studies in accounting exploring the influence of the Dark Triad on opportunistic actions. Ghosh and Crain (1996) find that high Machiavellians, when facing a hypothetical decision about tax compliance, indicate greater willingness to underreport their tax liability, with this effect being most pronounced for high Machiavellians perceiving that the probability of IRS audit is low. Hartmann and Maas (2010) find in an experiment that high Machiavellian controllers are more likely to succumb to pressure to create budgetary slack when they are involved in business unit decision making, while low Machiavellians are more likely to succumb to such pressure when they are not involved in business unit decision making. They theorize that this result occurs because involvement in the business unit triggers high Machiavellians to associate creating slack with their self-interest, while such involvement prompts low Machiavellians to focus on the unethical ramifications of creating slack.

Brown et al. (2013) theorize and find that high Machiavellians have less need for rationalizing unethical actions that would financially harm a hypothetical third party than low Machiavellians, consistent with high Machiavellians viewing their actions from a utilitarian (rather than moral) perspective. Murphy (2012) finds, in a setting in which penalties are not possible, that high Machiavellians misreport earned income to the experimenter to a greater extent than low Machiavellians and do not experience guilt 
when committing this infraction. Moreover, Bailey (2013) identifies a positive relationship between accounting students' levels of primary psychopathy and endorsement of unethical corporate practices, such as depositing a check for a company account that has been written off in one's personal bank account.

With respect to narcissism, Hales et al. (2012) find that narcissists inflate reported performance on a Graduate Management Admissions Test (GMAT) task when they consider the task to be important. My theoretical development of the dark side of narcissism as a driver of aggressive reporting is consistent with the finding in Hales et al. (2012) that participants who rate high on the exploitativeness and entitlement aspect of narcissism are the most prone to inflate their performance. Although Hales et al. (2012) examine a task in which inflating performance does not harm the welfare of other experimental participants (while biasing estimates does harm the welfare of investors in this study), I do not expect that the thought of reducing the welfare of other participants would deter these individuals from reporting aggressively, as the very nature of extracting rents from others hinges on a lack of regard for others' welfare. In fact, knowing that they are taking welfare from another person by reporting aggressively could even give these individuals additional utility by reinforcing their sense of entitlement.

In related archival research, Rijsenbilt and Commandeur (2012) discern a positive association between CEO narcissism and likelihood of fraud, proxied for by issuance of an Accounting and Auditing Enforcement Release by the SEC. Indeed, Johnson et al. (2013) show that auditors are even attuned to indicators of narcissism when performing 
risk assessments. They find that auditors assess fraud risk to be higher when client management exhibits narcissistic behavior, and audit managers and partners explicitly classify narcissism as a significant fraud attitude risk factor.

Overall, results from studies in accounting support the premise that Dark Triad managers in this study will report more aggressively in a regime of no range disclosure than their non-Dark Triad counterparts. Next, I turn to discussion of how the imposition of range disclosure could influence managers differently, depending on their association with the Dark Triad.

\section{The Effect of Range Disclosure and the Dark Triad}

If Dark Triad managers and non-Dark Triad managers report differently in a regime of no range disclosure, implementing range disclosure should influence them differently. Specifically, if non-Dark Triad managers report less aggressively than Dark Triad managers in a regime of no range disclosure, there is less aggressiveness in nonDark Triad managers to be disciplined by range disclosure. Correspondingly, if Dark Triad managers report more aggressively than non-Dark Triad managers in a regime of no range disclosure, there should be a relatively stronger disciplining effect of range disclosure for Dark Triad managers. I now turn to theoretical support for why I expect range disclosure to discipline the reporting aggressiveness of Dark Triad managers.

Overall, as individuals associated with the Dark Triad can collectively be characterized as desiring to achieve personal gain at others' expense, I expect the threat of provoking costly investor actions to prompt Dark Triad managers to reduce reporting 
aggressiveness in response to range disclosure, since punitive investor actions reduce their personal welfare. For example, high Machiavellians are characterized as strategic, tactical, and exhibiting a rational decision-making style of considering costs and benefits (Jones and Paulhus 2011). Indeed, philosopher Sun Tzu, who produced the earliest writings reflecting the concept of Machiavellianism in 500 B.C., characterizes this philosophy as "the wise leader in his deliberations always blends consideration of gain and harm [emphasis added]" (Jones and Paulhus 2011, p. 254), suggesting that high Machiavellians should incorporate the threat of investor actions in a regime of range disclosure into their reporting decisions.

Shultz (1993) finds that high Machiavellian brokers working for a loosely structured firm exhibit superior performance, greater earned income, and greater number of clients maintained because they push bounds and exploit their environment to gain an advantage over others, while low Machiavellians do not engage in such behaviors. High Machiavellians working for tightly structured firms did not outperform low Machiavellians, however, because the constraints imposed by such a firm cause the high Machiavellian to, "having fewer opportunities to wheel and deal, [display] perfunctory performance and occasionally apathy" (Shultz 1993, p. 479). Curiously, Shultz's (1993) examination of a loose vs. tight organizational structure might be analogized to the influence of a regime of no range disclosure vs. range disclosure in this study. Consistent with earlier discussion, in a regime of no range disclosure, high Machiavellians might test the bounds of aggressive reporting due to a lack of imposed limits, while low 
Machiavellians are likely to "assume unstated limits" (Shultz 1993, p. 479). Imposing the structure of range disclosure might prompt high Machiavellians to report less aggressively, but prompt no change in the reporting behavior of low Machiavellians, who will likely continue to report within the limits of aggressive reporting.

Similarly, while individuals associated with psychopathy can be manipulative, deceitful, and relatively callous to the welfare of others, Babiak and Hare (2006) note that these individuals "can be surprisingly successful in dealing with others...[and] are adept at reading situations and people and then modifying their approach to best influence those around them" (p. 187), suggesting that these managers should modify their reporting aggressiveness in a regime of range disclosure to circumvent anticipated investor actions. Likewise, if managers high in narcissism anticipate that investors have enhanced ability to identify aggressive reporting in a regime of range disclosure, they are likely to reduce aggressive reporting in such a regime, in an effort to avoid provoking investor actions taken against them that could threaten their sense of grandiosity. As noted by Judge et al. (2009, p. 870$)$, “...to reduce ego-threatening conflicts, narcissistic leaders may modify the nature and pattern of interpersonal interactions to preserve (and control) the positive impressions they seek to make on others."

However, the above reasoning is not self-evident, as it is unclear how Dark Triad individuals might react to the (potentially) constraining force of an imposed range disclosure to investors. For example, research finds that Dark Triad individuals believe that they are better than others at deceiving (Giammarco et al. 2013), which suggests that 
Dark Triad managers might believe that they can continue reporting aggressively even when ranges are disclosed because they will be able to circumvent detection by investors. Dark Triad individuals engage in exploitive behaviors because their sense of entitlement leads them to believe they should receive liberties at others' expense (Jones and Paulhus 2011), and this sense of entitlement could be impervious to the threat of actions from investors. Moreover, researchers (e.g., Lee and Ashton 2005) have identified a strong negative association between the Dark Triad and the Honesty-Humility dimension of the HEXACO model of personality, suggesting that Dark Triad managers exhibit low degrees of humility and honesty. Such lack of humility might prompt them to infer they "are above" being detected by investors when ranges are disclosed, with the honesty facet reinforcing their rationale to report aggressively.

On balance, I expect the threat of provoking costly investor actions in a regime of range disclosure to dominate, prompting Dark Triad managers, engaging in first-order reasoning, to reduce reporting aggressiveness when faced with such a regime. I expect less of a reduction in reporting aggressiveness for non-Dark Triad managers because there is less aggressiveness to be disciplined by range disclosure. Jointly, these two effects motivate an interactive hypothesis of range disclosure and the Dark Triad on reporting aggressiveness, as stated formally below:

H3: Managers' reduction in reporting aggressiveness in response to range disclosure will be more pronounced for Dark Triad managers than for non-Dark Triad managers. 


\section{Chapter 4: Method and Design}

Using the "Z-tree" program for computerized interactive experiments (Fischbacher 2007), I structure an 18-period laboratory experiment in which undergraduate business student volunteers make decisions in roles analogous to managers $(\mathrm{n}=48)$ and investors $(\mathrm{n}=48)$. As explained in more detail in a subsequent subsection, 18 periods are necessary to administer all possible within-participants treatment conditions to each manager. In the first period of the experiment, managers and investors are paired randomly and anonymously, with pairings randomly rotated each subsequent period.

Upon arriving to the experimental session, each participant is randomly assigned to the manager or investor role. To minimize influences of role playing, I do not use contextually rich terms such as "manager" or "investor" to identify roles (Haynes and Kachelmeier 1998). Rather, I identify managers as "A Players" and investors as "B Players" in the experiment. For ease of exposition, I refer to A Players and B Players as managers and investors, respectively. I conduct eight experimental sessions, each 75 minutes in length, with six managers and six investors in each session. The experiment begins after participants read through the instructions and complete a quiz to ensure comprehension of the experimental procedures. The computer program requires participants to indicate the correct answer to a question before moving to the next question. Appendix A and Appendix B display instructions provided to managers and 
investors, respectively. Appendix C displays screens of the Z-tree program for managers and investors.

\section{Experimental Task and Structure}

In the experiment, all participants are aware that there is an asset valued between 1 and 100, with only integer values possible. Managers learn a narrower reasonable range within the possible asset values of 1 to 100 points, within which the asset's true value lies. For ease of exposition, I refer to the range as a "reasonable range," but in the experimental sessions, the term "range" was used. Managers also receive private information about where, within the reasonable range, the asset's value is likely to lie (e.g., lower end, middle, or upper end of the reasonable range). Each manager then sends a report about the value of the asset to his/her paired investor. The only restriction is that reports must be within the reasonable range. Managers receive the following payoff:

20 points + Reported Value - Any reduction to payoff imposed by the paired investor.

As evidenced by this payoff structure, managers are incentivized to report higher values, as higher reports yield higher payoffs. However, if the report is greater than the realized true asset value, the investor bears the full cost of the aggressive reporting (i.e., any positive difference between the report and the true asset value is a wealth transfer from the investor to the manager). Conversely, if the report is conservative (i.e., less than the true asset value), no wealth transfer occurs, and the investor and manager both receive the reported asset value. As such, the investor's payoff is as follows: 
If the Reported Value is greater than or equal to the True Asset Value, 20 points + True Asset Value - Excess, if any, of the Reported Value over the True Asset Value - Cost to reduce the paired manager's payoff, if any.

If the Reported Value is less than the True Asset Value,

20 points + Reported Value - Cost to reduce the paired manager's payoff, if any.

Note that managers and investors both receive an endowment of 20 points, in order to minimize instances of a negative payoff in a period (though a negative payoff in a period is unlikely, it is possible). After viewing the reported value, the investor has the option to pay a cost to reduce the manager's payoff.

When deciding the extent, if any, to reduce a paired manager's payoff, investors are aware of the report, but are unaware of the manager's private information about where the asset's value is likely to lie within the reasonable range or the realized asset value. If an investor elects to reduce his/her paired manager's payoff, for every one point the investor spends, the manager's payoff is reduced by four points. Investors can spend from a minimum of zero points to a maximum of ten points when reducing their paired manager's payoff. As such, each manager's payoff can be reduced by a minimum of zero points to a maximum of 40 points. I select a ratio of one to four because research in experimental economics (Nikiforakis and Normann 2008) has shown that this ratio is the most effective in optimizing welfare outcomes. This reduction in payoffs can be analogized to forms of shareholder activism (e.g., Gillan and Starks 2007), in addition to investors exerting selling pressure that drives the stock price downward and imposes costs on both managers and investors. Each period, managers learn how much, if any, their paired investor decided to reduce their payoff. Investors do not learn how their 
paired manager's report compared to the true asset value until the end of the experiment, thus capturing the institutional reality that there is often a considerable delay between the reporting of fair-valued financial statement items and other estimates and the associated realization (e.g., Bratten et al. 2013).

At the end of the experimental session, the computer program determines the realized asset values and informs participants of their points earned for each of the 18 periods. To determine realized asset values, the computer program uses the following procedure. If private information is low (high), the true asset value is in the lower (upper) part of the reasonable range with 0.80 probability, middle of the reasonable range with 0.15 probability, and upper (lower) part of the reasonable range with 0.05 probability. If private information is medium, the true asset value is in the middle of the reasonable range with 0.80 probability and in the lower or upper part of the reasonable range with 0.10 probability each.

After points earned are revealed, I compensate participants for six of the 18 total periods, which I determine by asking a volunteer participant to randomly select six chips out of a container holding 18 chips (numbered $1-18$ ). Although this method can have the limitation of magnifying participants' risk preferences (see Hobson and Kachelmeier 2005 for a discussion), I would not expect risk preferences to interact with my hypothesized pattern of results for managers or investors. Participants' points are then converted to dollars at a rate of $\$ 0.06$ per point, ranging from $\$ 18.00$ to $\$ 34.00$, with an average payoff of $\$ 26.25$. I also administer a risk preference exercise, adapted from 
Boylan and Sprinkle (2001), at the conclusion of the experimental session before payoffs are revealed. Depending on the participant's selections and random draws conducted, this exercise increased participants' payoffs by $\$ 0.00, \$ 2.00$, or $\$ 4.00$. This amount is included in the disclosed average payoff and range information.

\section{Measuring the Dark Triad}

In order to assess the extent to which participants associate with the Dark Triad, I administer the Short Dark Triad (SD3) questionnaire (Jones and Paulhus, in press) after the final round of the experiment. The SD3 is intended to provide a concise but reliable instrument to measure the three personalities in the Dark Triad: psychopathy, narcissism, and Machiavellianism. Through testing the full instruments for each personality against the SD3 with a large sample of participants, Jones and Paulhus (in press) conclude that the SD3 scales are strongly correlated with the full instruments, have an acceptable factor structure, and exhibit acceptable internal consistencies for each personality. Figure 1 shows the SD3 questionnaire. ${ }^{6}$

\section{Manipulations}

Figure 2 illustrates the experimental manipulations. As the primary manipulation, I manipulate between-participants whether or not the reasonable range disclosed to managers is also disclosed to investors. In other words, when the reasonable range is disclosed to investors, investors view the reported value within the context of the

\footnotetext{
${ }^{6}$ The authors of the SD3 questionnaire later made small refinements to the instrument, such that there are several minor differences between the SD3 questionnaire shown in Figure 1 and the final version (Jones and Paulhus, in press). I have no reason to expect that these refinements would interact with the results of my study.
} 
reasonable range. Absent disclosure of the reasonable range, investors only see the report within the possible asset values from 1 to 100 .

To make the primary range disclosure manipulation meaningful, I manipulate three additional factors within-participants. First, I manipulate whether the reasonable range is at the low, medium, or high end of the possible asset values from 1 to 100 . I operationalize this factor by structuring reasonable ranges with possible midpoints of 20 , 50 , or 80 . Without this manipulation, the reasonable range disclosure would lack information content. Second, I manipulate whether the reasonable range narrows down the possible outcomes within 10 points or within 30 points, representing the precision of the asset value. Although I vary the width of the reasonable range, I hold constant the midpoint within each range location. Thus, reasonable ranges of 10 points span 5 points below and 5 points above the possible midpoints of 20,50 , and 80 , while reasonable ranges of 30 points span 15 points below and 15 points above the possible midpoints of 20, 50, and 80. Third, I manipulate whether the manager's private information indicates that the asset's value is likely to be at the low, medium, or high end of the reasonable range. These within-participant manipulations result in a total of 18 possible reasonable ranges, which I administer to each of the six managers in a different random order during the 18 periods of the experimental session to guard against order effects. 


\section{Chapter 5: Results and Analysis}

\section{Manipulation Checks}

To validate that managers attend to the range disclosure manipulation, I ask managers if investors view (1) the range that they view in the experiment and (2) their private information. Overall, 23 of the 24 (21 of the 24) managers in the no range disclosed (range disclosed) condition respond accurately to this question. The manager results are statistically significant at the same critical levels when excluding managers who fail the manipulation check. To validate that managers attend to the provision of feedback on investor actions each period, I ask managers if they view the amount the investor reduced their payoff each period. All managers accurately respond to this question.

To validate that investors attend to the range disclosure manipulation, I ask investors if they view (1) the range that managers saw in the experiment and (2) the manager's private information. Overall, 24 of 24 (23 of 24) investors in the no range disclosed (range disclosed) condition respond accurately to this question. To validate that investors attend to the feedback provided to managers, I ask them if managers viewed how much they reduced their payoff each period. Overall, 45 of the 48 investors respond accurately to this question. The investor results are statistically significant at the same critical levels when excluding investors who fail either of the manipulation check questions. 


\section{Distribution of Dark Triad Personality Scores}

Figure 3 displays the distributions of managers' average scores on each of the Dark Triad personalities. Each of the distributions appears roughly consistent with a normal distribution. The distribution of scores for psychopathy is shifted further toward lower values than the distributions for Machiavellianism or narcissism. Jones and Paulhus (in press) provide mean statistics of their population of 3.1 for Machiavellianism, 2.8 for narcissism, and 2.4 for psychopathy. In this study, experimental participants average 3.0 for Machiavellianism, 3.2 for narcissism, and 2.2 for psychopathy. The current participants appear somewhat more narcissistic than the participants in Jones and Paulhus (in press), but exhibit slightly lower association with Machiavellian and psychopathy. Nevertheless, participants in this study appear to reasonably approximate those in Jones and Paulhus's (in press) sample. For example, the average score for psychopathy is the lowest of the three personalities for both groups.

\section{Primary Results for Managers}

To develop a dependent variable for manager reporting, I first calculate the raw amount that each reported estimate is above the lower bound of the reasonable range. I then standardize this amount by dividing by the range width ( 30 for wide ranges and 10 for narrow ranges). Each manager provides 18 repeated-measures observations for the analysis. 


\section{The Influence of Range Disclosure on Managers}

Figure 4, Panel A, plots managers' reported estimates in regimes of no range disclosure and range disclosure by whether the manager associates with (1) none of the Dark Triad personalities, (2) Machiavellianism, (3) narcissism, and (4) psychopathy. To determine whether a manager associates with a personality, I classify each manager above (at or below) the median as exhibiting (not exhibiting) association with the personality. Consistent with the characterization of the Dark Triad personalities as empirically overlapping and findings in prior research, I observe statistically significant correlations between the continuous scores for narcissism and Machiavellianism $(\mathrm{r}=$ 0.53 ; one-tailed $\mathrm{p}<0.01)$, narcissism and psychopathy $(\mathrm{r}=0.45$; one-tailed $\mathrm{p}<0.01)$ and psychopathy and Machiavellianism $(r=0.76$; one-tailed $\mathrm{p}<0.01){ }^{7}$

As evidenced in Figure 4, Panel A, the primary distinction in reporting behavior is observed between managers associated with none of the Dark Triad personalities (hereafter, "non-Dark Triad" managers) and managers associated with any of the Dark Triad personalities (hereafter, "Dark Triad" managers). Put differently, managers associated with Machiavellianism, narcissism, or psychopathy all report relatively aggressive estimates in a regime of no range disclosure and reduce aggressive reporting in a regime of range disclosure. Conversely, non-Dark Triad managers report less aggressive estimates than Dark Triad managers in a regime of no range disclosure, and do not modify reporting behavior in a regime of range disclosure. As further evidence, Panel

\footnotetext{
7 The correlations between the dichotomous measures of the Dark Triad are as follows: narcissism and Machiavellianism $(r=0.23$; one-tailed $\mathrm{p}=0.01)$, narcissism and psychopathy $(\mathrm{r}=.16$; one-tailed $\mathrm{p}=.14)$; psychopathy and Machiavellianism $(r=.56$; one-tailed $\mathrm{p}<0.01)$.
} 
A of Figure 5 plots managers' reported estimates in regimes of no range disclosure and range disclosure by whether they are associated with none, one, two, or all three of the Dark Triad personalities. The pattern of results in Figure 5, Panel A is similar to that in Figure 4, Panel A. Taken together, these figures suggest that the driver of different manager reporting is association with one or more of the Dark Triad personalities, as opposed to a particular Dark Triad personality. Therefore, I analyze the data by classifying managers as either non-Dark Triad (associated with none of the Dark Triad personalities) or Dark Triad (associated with one or more of the Dark Triad personalities). This method of analysis also reflects the fact that there is substantial overlap among the Dark Triad personalities.

Specifically, I conduct a repeated-measures ANOVA, with range disclosure as a between-participants variable, asset value precision, range location, and private information as within-participant variables, and standardized manager reports as the dependent variable. I also include an independent variable in the ANOVA to classify each manager as non-Dark Triad or Dark Triad by assigning a dichotomous variable a value of $1(0)$ for Dark Triad (non-Dark Triad) managers. Table 1, Panel A reports the results.

Range disclosure has a significant main effect on manager reporting $(\mathrm{F}=5.32$; one-tailed $\mathrm{p}<0.01$ ), supporting the prediction in $\mathrm{H} 1$ that managers will reduce reporting aggressiveness in response to disclosure of ranges to investors. The Dark Triad also has a significant effect on manager reporting $(F=7.72$; one-tailed $\mathrm{p}<0.01)$. However, these 
two main effects are qualified by a significant interaction between range disclosure and the Dark Triad $(F=10.39$; one-tailed $\mathrm{p}<0.01)$, supporting the interactive prediction of H3 that managers' reduction in reporting aggressiveness in response to range disclosure will be more pronounced for Dark Triad managers than non-Dark Triad managers.

As shown in Panel A of Figure 6, there is a clear distinction between Dark Triad managers and non-Dark Triad managers. Dark Triad managers exhibit substantially less reporting aggressiveness in a regime of range disclosure than when there is no range disclosure, while non-Dark Triad managers exhibit no discernible reporting sensitivity to range disclosure. Table 1 , Panel $\mathrm{B}$, sheds insight on the nature of this interaction, indicating a significant disciplining effect of range disclosure for Dark Triad managers ( $\mathrm{F}$ $=26.38$; one-tailed $\mathrm{p}<0.01)$, but not for non-Dark Triad managers $(\mathrm{F}=0.30$; one-tailed $\mathrm{p}=0.29)$. These results suggest that Dark Triad managers engage in first-order reasoning, anticipating that investors would take harmful actions if viewing reports near the upper bound of a disclosed range, leading such managers to reduce reported estimates in order to circumvent such actions. Conversely, non-Dark Triad managers have no need to exercise first-order reasoning because, even absent range disclosure, they do not report aggressively. More precisely, non-Dark Triad managers appear to make reporting decisions based largely on their beliefs about the asset's value, which I corroborate in later analyses, rather than strategic considerations. Next, I explore whether imposing a regime of range disclosure mutes the advantage that Dark Triad managers gain by 
reporting more aggressively than their non-Dark Triad counterparts in a regime of no range disclosure.

As illustrated in Table 1, Panel C, there is a significant effect of the Dark Triad on manager reporting in a regime of no range disclosure $(F=21.62$; one-tailed $p<0.01)$, showing that Dark Triad managers report more aggressively than non-Dark Triad managers in such a regime. Conversely, there is no effect of the Dark Triad in a regime of range disclosure $(\mathrm{F}=0.09$; one-tailed $\mathrm{p}=.39)$. This pattern of results suggests that range disclosure prompts Dark Triad managers to reduce reporting aggressiveness, such that the reporting aggressiveness of non-Dark Triad and Dark Triad managers converge in a regime of range disclosure.

The different motivations of Dark Triad and non-Dark Triad managers in a regime of no range disclosure can be observed from comments by managers falling in each of these categories. As phrased by one non-Dark Triad manager in the post experimental questionnaire:

I never attempted to take advantage of the fact that Player B did not know the range of numbers and place my number higher than what was likely. I place a high value on integrity and honesty so I always chose a number within the likely range [i.e., private information].

This comment is in stark contrast to the essence of comments made by Dark Triad managers, as stated succinctly by one Dark Triad manager below:

I knew that Player B had no idea what the range was, so I went high every time to maximize points. 
Note that the questions administered to assess managers' association with each of the Dark Triad personalities (displayed in Figure 1) do not explicitly refer to constructs that emerge in the above comments, such as integrity and honesty (for non-Dark Triad managers) and reporting particularly aggressively to maximize personal welfare (for Dark Triad managers). Rather, the questions assess whether managers associate with any of the Dark Triad personalities, with this association (or lack of association) influencing the motivations behind their reporting decisions.

To further investigate the pattern of results behind the interaction between range disclosure and the Dark Triad, I next examine how reported estimates vary with the manager's private information. Observing the data in this manner is informative because it sheds insight on how managers' reports compare to their private information about where the asset value lies within the reasonable range.

\section{Supplemental Analyses for Managers}

\section{The Influence of Private Information on Managers}

To examine the influence of private information on manager reporting, I refer back to the ANOVA results in Panel A of Table 1. Overall, private information has a significant effect on manager decisions $(F=88.01$; two-tailed $\mathrm{p}<0.01)$, demonstrating that, as private information indicates the asset value is likely to be higher within the reasonable range, managers report higher estimates to investors. There is a significant interaction between private information and the Dark Triad $(\mathrm{F}=11.38$; two-tailed $\mathrm{p}<$ 0.01), indicating that Dark Triad managers impound less of their private information in 
their reported estimates than do non-Dark Triad managers. Simple effects (untabulated) show that this difference is significant at low and medium levels of private information ( $\mathrm{F}$ $=12.28$; two-tailed $\mathrm{p}<0.01$ and $\mathrm{F}=5.71$; two-tailed $\mathrm{p}=0.02$, respectively) but not at high levels of private information $(F=0.00$; two-tailed $p>0.50)$. As discussed next, the result for high private information is driven by less scope for variation in reporting above private information when private information is high.

Figure 7, Panel A, plots how non-Dark Triad and Dark Triad managers' reported estimates vary with their private information. Note that the minimum possible standardized report is 0.00 , representing the lower bound of the reasonable range, while the maximum possible standardized report is 1.00 , representing the upper bound of the reasonable range. The boxed areas in Panel A of Figure 7 show the private information the manager learns about the area in the reasonable range within which the asset's true value likely lies. Recall that managers can report estimates outside of their private information, but are restricted to report an estimate within the reasonable range. The benchmark of an unbiased estimate, which I consider to be the midpoint of the manager's private information, is represented by the $\times$ symbol.

As Panel A of Figure 7 indicates, non-Dark Triad managers report similar estimates in regimes of no range disclosure and range disclosure. When private information is low and medium, non-Dark Triad managers report estimates that are above the unbiased estimate, but these reported estimates are still fairly close to the highest asset value indicated by their private information. This pattern of results is consistent 
with research finding that people generally act opportunistically enough to profit from such actions, but not so opportunistically as to harm self-perceptions of integrity (e.g., Mazar et al. 2008). When private information is high, non-Dark Triad managers report estimates that are closer to the unbiased estimate, which can be attributed to the fact that when private information is high, the upper bound of the reasonable range and the highest asset value indicated by the manager's private information coincide. As such, there is less scope for variation in manager reporting above the unbiased estimate when private information is high.

In contrast to non-Dark Triad managers, Dark Triad managers report more aggressive estimates in a regime of no range disclosure than in a regime of range disclosure. As shown in Panel A of Figure 7, when private information is low and medium, estimates reported by these managers in a regime of no range disclosure are far above the highest asset value indicated by their private information, suggesting that Dark Triad managers are taking advantage of investors' lack of knowledge for their personal gain. But in a regime of range disclosure, Dark Triad managers report less aggressive estimates that more accurately reflect their private information regarding where the true asset value lies. Similar to non-Dark Triad managers, Dark Triad managers report estimates near the unbiased benchmark when private information is high, which can also be attributed to less scope for variation when private information is high. 


\section{Manager Reporting Over Time}

The question arises if managers' reporting aggressiveness, as a function of their association with the Dark Triad and whether they are in a regime of no range disclosure or range disclosure, changes throughout the 18 periods of the experiment. One reason that managers' behavior might be changing over the course of the experiment is that they could be responding to the feedback provided each period about investor actions taken against them.

To test for significant time trends, I conduct a repeated-measures ANOVA individually for each of the four sets of conditions (i.e., Dark Triad and range disclosure, Non-Dark Triad and range disclosure, Dark Triad and no range disclosure, Non-Dark Triad and no range disclosure), testing for the significance of a within-subjects contrast examining the linear effect of time period. One significant trend emerges from this analysis. Results show a significant effect of period on the aggressiveness of Dark Triad managers in a regime of no range disclosure $(F=5.60$; two-tailed $\mathrm{p}=0.03)$. The nature of this trend is that Dark Triad managers become increasingly aggressive over the course of the experiment in a regime of no range disclosure. This pattern of results suggests that Dark Triad managers observe that they are not incurring substantial investor actions for their reporting aggressiveness, and therefore, increase their reporting aggressiveness even further. 


\section{Do Dark Triad Managers Receive More Investor Actions?}

As shown in the previous analyses, Dark Triad managers report relatively aggressively in a regime of no range disclosure, taking advantage of investors' lack of knowledge about the reasonable range of estimates for their personal gain. This result prompts the question of whether investors react to the particularly aggressive reporting of Dark Triad managers by taking more actions against these managers in a regime of no range disclosure. Investors' ability to identify aggressive reporting is relatively limited in such a regime, suggesting that Dark Triad managers likely do not receive more investor actions than non-Dark Triad managers, despite their greater aggressiveness. In support of this premise, there is no significant difference between actions taken against non-Dark Triad and Dark Triad managers in a regime of no range disclosure $(F=0.43$; one-tailed $p$ $=0.26)$. Interestingly, results of this analysis are consistent with the familiar intuition that selfish individuals often escape the consequences for taking actions that harm others' welfare.

\section{Primary Results for Investors}

In this section, I discuss the results for tests of $\mathrm{H} 2$ for investor actions. To analyze investor behavior, I utilize the cost that investors spend to reduce managers' payoffs in each period. Each investor provides 18 repeated-measures observations for the analysis.

\section{The Influence of Range Disclosure on Investors}

To test investor actions taken against managers, I run a mixed-effects model, with range disclosure as a between-participants variable, asset value precision, range location, 
and the manager's private information as within-participant variables, and the amount investors spend to reduce manager payoffs as the dependent variable. ${ }^{8} \mathrm{~A}$ mixed-effects model is needed to analyze investor actions to accommodate the fact that the manipulations occur at the manager level, with investors randomly interacting with managers for the 18 periods. Specifically, because there are six managers and six investors, each investor interacts with each manager three times (with pairings randomly determined). The random determination of manager-investor pairings for the 18 periods causes investors to receive a randomized combination of the 18 possible ranges. The mixed-effects model accommodates this feature of the experimental design, while also providing the benefit of clustering standard errors by participant to account for the repeated-measures nature of the manipulations. Table 2 displays the results.

The results yield an insignificant effect of range disclosure on investor actions against managers $(\beta=0.44 ; \mathrm{t}=0.29$; two-tailed $\mathrm{p}>.50)$, indicating that investor actions do not change when ranges are disclosed. This result underscores the importance of examining range disclosure in an interactive environment, as managers' revised reports in anticipation of investors' potential actions in response to range disclosure appear to preempt changes in investor behavior.

\footnotetext{
8 To maintain symmetry in the experimental design, I also administer the Dark Triad questionnaire to investors. I do not hypothesize, nor do I detect, any influence of the Dark Triad on investor actions taken against managers. I do not hypothesize such an effect because taking actions against managers is costly, which causes the effect of the Dark Triad to be unclear. For example, Gunnthorsdottir et al. (2002) find that high Machiavellians are more prone to betray their counterpart in a trust game than low Machiavellians, but Jones and Paulhus (2009) conjecture that this tendency is due to the fact that the wronged party has no chance for retribution. As such, betrayal is clearly the most profitable action, which is not the case with taking actions against managers in this study.
} 
It is important to note that inherent differences between a regime of no range disclosure and a regime of range disclosure could yield differences in the nature of the cue provoking investor actions, which is distinct from the above conclusion that the extent of investor actions does not differ between the regimes. Specifically, investors view the manager's estimate in the context of the disclosed range in a regime of range disclosure, but in the context of all possible asset values in a regime of no range disclosure. Notwithstanding the insignificant main effect of range disclosure on investor actions, this inherent difference between the two regimes could give rise to both range disclosure $\times$ private information and range disclosure $\times$ range location interactions. To see this point, recall that, in a regime of range disclosure, the manager's private information is a key determinant of where their reported estimate lies within the disclosed range. As such, the manager's private information, indirectly via its effect on manager reporting, is a stronger cue of aggressiveness for investors in a regime of range disclosure than in a regime of no range disclosure, which could give rise to a range disclosure $\times$ private information interaction. But in a regime of no range disclosure, the range location is a key determinant of where the manager's reported estimate lies within all possible asset values. As such, the range location is a stronger cue of aggressiveness for investors in a regime of no range disclosure than in a regime of range disclosure, which could give rise to a range disclosure $\times$ range location interaction. Next, I report results for each of these interactions. 
Although there is no main effect of range disclosure on investor actions, I do observe a marginally significant interaction between range disclosure and the manager's private information $(\beta=0.26 ; \mathrm{t}=1.88$; two-tailed $\mathrm{p}=0.06)$, suggesting that private information has a greater impact on investor actions in a regime of range disclosure. Recall that, in a regime of range disclosure, managers report estimates that increase as their private information increases. The apparent interaction suggests that, in a regime of range disclosure, investors view the location of the report within the disclosed range as a cue to assess aggressiveness, which is consistent with investors engaging in zero-order and first-order reasoning.

This result occurs even though investors are incentivized to prefer high estimates when the true asset value is high, as they have a vested interest in the true asset value. Put differently, because managers report estimates that increase as their private information increases in a regime of range disclosure, this tactic is relatively ineffective in identifying aggressiveness, as investors are incentivized to prefer managers to report in accordance with their private information. However, this result likely occurs because managers cannot credibly signal to investors that higher estimates reflect high private information. Recall that in a regime of no range disclosure, the reported estimate's location within all possible asset values, which is primarily determined by the location of the reasonable range itself rather than the location of the estimate within the reasonable range, is likely to serve as the investor's cue of aggressiveness. As such, I turn next to testing the interactive effect of range disclosure and range location. 
In addition to the range disclosure $\times$ private information interaction, Table 2 also reports a significant interaction between range disclosure and range location $(\beta=-0.29 ; \mathrm{t}$ $=-2.10$; two-tailed $\mathrm{p}=0.04)$, indicating that range location has a greater impact on investor actions in a regime of no range disclosure. This interaction is consistent with investors using the location of the reported estimate within all possible asset values as a cue to assess aggressiveness in a regime of no range disclosure. This finding is also consistent with Bloomfield (1996), who finds that investors rely on report magnitude as a signal of managerial aggressiveness. Importantly, managers do not exhibit a change in reporting aggressiveness as the range location becomes higher, as shown by the insignificant main effect of range location in Table $1(\mathrm{~F}=0.50$; two-tailed $\mathrm{p}>.50)$ and by the insignificant interaction (untabulated) between range disclosure and range location on reporting aggressiveness $(\mathrm{F}=0.62$; two-tailed $\mathrm{p}>.50)$. Accordingly, investors' inferences do not appear to successfully identify the actual degree of reporting aggressiveness. ${ }^{9}$

Notably, these interactions also corroborate that the insignificant main effect of range disclosure is not driven by the absence of feedback to investors on actual manager aggressiveness. That is, one could conjecture that investors generally believe taking actions against managers is not worthwhile because investors do not receive feedback, causing them to be uncertain about the success of their strategy. Such uncertainty could

\footnotetext{
${ }^{9} \mathrm{I}$ also discern a three-way interaction between range disclosure, range location, and the precision of the asset value being estimated $(\beta=0.01 ; \mathrm{t}=1.98$; two-tailed $\mathrm{p}=0.05)$. Recall that the two-way interaction between range disclosure and range location demonstrates that range location has a greater impact on investor actions when ranges are not disclosed. The three-way interaction implies that this relationship is slightly less pronounced for asset values of less precision.
} 
manifest itself as no difference in investor actions in a regime of no range disclosure and a regime of range disclosure. The nature of the interactions demonstrates that, although there is no overall difference in investor actions between the two regimes (consistent with $\mathrm{H} 2$ ), investors are taking actions against managers in a meaningful fashion.

\section{Supplemental Analyses for Investors}

\section{Investor Actions Conditional on Aggressive Reporting}

For the primary analysis of investor actions taken against managers, I utilize a mixed-model regression with the experimental manipulations as independent variables. Such a design enables a direct test of how investor actions differ in a regime of no range disclosure vs. range disclosure. However, a test of how investor actions respond to manager reporting aggressiveness is also informative, as I explore in this supplemental analysis. That is, I utilize manager reporting aggressiveness, measured as the location of the reported estimate within the range, and the presence or absence of range disclosure as independent variables in an analysis of investor actions taken against managers.

This supplemental analysis (untabulated) yields a significant main effect of range disclosure condition $(\beta=1.59 ; \mathrm{t}=2.49$; two-tailed $\mathrm{p}=0.01)$. There is also a significant effect of manager reporting aggressiveness on investor actions taken against managers, indicating that, as managers report more aggressively, investors take more actions against them $(\beta=2.76 ; \mathrm{t}=7.03$; two-tailed $\mathrm{p}<0.01)$. However, these main effects are qualified by a significant interaction between range disclosure condition and manager reporting aggressiveness $(\beta=-2.01 ; \mathrm{t}=-3.74$; two-tailed $\mathrm{p}<0.01)$, indicating that the relationship 
between manager reporting aggressiveness and investor actions is less pronounced in the absence of range disclosure. The significant interaction provides additional evidence that investors are better able to detect aggressive reporting when range disclosure is available. This result also suggests that any managers who are not disciplined by range disclosure receive investor actions as a result. For simple effects, running the mixed model in each range disclosure condition yields a significant effect of manager aggressiveness on investor actions taken against managers in a regime of range disclosure $(\beta=2.75 ; \mathrm{t}=$ 7.78; two-tailed $\mathrm{p}<0.01$ ), with a slope over three times the magnitude of the slope in a regime of no range disclosure $(\beta=0.74 ; \mathrm{t}=1.86$; two-tailed $\mathrm{p}=0.06)$.

The above analysis defines aggressiveness in terms of the location of the manager's report within the reasonable range. However, the question arises if investors can detect aggressive reporting when it is defined relative to the manager's private information. By definition, investors do not know managers' private information and cannot credibly infer this information from managers' reporting decisions. When utilizing manager's reporting relative to their private information as the definition of reporting aggressiveness, I observe an insignificant effect of range disclosure condition $(\beta=-0.47$; $\mathrm{t}=-0.38$; two-tailed $\mathrm{p}=0.38$ ). There is a significant effect of manager reporting aggressiveness on investor actions taken against managers, indicating, that as managers report more aggressively relative to their private information, investors take more actions against them $(\beta=1.31 ; \mathrm{t}=3.30$; two-tailed $\mathrm{p}<0.01)$. However, there is a significant interaction between range disclosure condition and manager reporting aggressiveness ( $\beta$ 
$=-0.97 ; \mathrm{t}=-1.86$; two-tailed $\mathrm{p}=0.06$ ), indicating that the relationship between manager reporting aggressiveness relative to their private information and investor actions is less pronounced in a regime of no range disclosure. For simple effects, running the mixed model in each range disclosure condition yields a significant effect of manager aggressiveness on investor actions taken against managers in a regime of range disclosure $(\beta=1.31 ; \mathrm{t}=3.55 ;$ two-tailed $\mathrm{p}<0.01)$, but an insignificant effect in a regime of no range disclosure $(\beta=0.34 ; \mathrm{t}=0.95$; two-tailed $\mathrm{p}=0.34)$. Taken together, results of these analyses suggest that range disclosures enable investors to more effectively identify aggressive reporting. 


\section{Chapter 6: Conclusions and Opportunities for Future Research}

\section{Concluding Remarks}

Communication of measurement uncertainty to investors is a topic receiving prominent attention in discussions of potential enhancements to the auditor's report (e.g., PCAOB 2012) and related proposed standards (IAASB 2013; PCAOB 2013). In conversations about measurement uncertainty, the SEC and roundtable participants have also discussed the possibility of communicating this information to investors, either by a firm's auditor or by management (SEC 2011). I conduct a laboratory experiment to shed insight on how disclosing this information to investors, in the form of a reasonable range of estimates for an asset value, could modify manager reporting of estimates and investor actions in response to these estimates, as compared to regime in which this information is not communicated to investors.

Ceteris paribus, as range disclosures give investors greater ability to identify aggressive reporting, one could conjecture that investor actions against managers should increase if ranges are disclosed (as compared to a regime in which ranges are not disclosed). However, this conjecture does not account for the endogenous nature of managers' reporting decisions. That is, if managers strategically anticipate that range disclosures aid investors in identifying aggressive reporting, their reporting decisions are unlikely to be consistent between regimes of range disclosure and no range disclosure, implying that range disclosure should have a disciplining effect on manager reporting. The study's results support this premise, but the effect is more subtle than a uniform disciplining response for all managers. 
Specifically, the disciplining effect of range disclosures is concentrated in managers exhibiting association with one or more of the personalities collectively referred to in psychology as the Dark Triad, specifically psychopathy, narcissism, and Machiavellianism (Paulhus and Williams 2002). This result occurs because managers not associated with the Dark Triad report less aggressively than their Dark Triad counterparts in a regime of no range disclosure, such that there is less aggressiveness in these managers to be disciplined.

Further investigation reveals that managers associated with the Dark Triad report relatively aggressive estimates in a regime of no range disclosure, suggesting that these managers take advantage of investors' lack of knowledge in such a regime. In contrast, managers not associated with the Dark Triad report estimates that more accurately reflect their private information, suggesting that these managers do not take advantage of the information gap in a regime of no range disclosure. Importantly, the imposition of range disclosure appears to prompt Dark Triad managers to engage in first-order strategic reasoning (e.g., Zimbelman and Waller 1999; Bowlin 2011), reducing reporting aggressiveness to the point that Dark Triad and non-Dark Triad managers report similar estimates in a regime with range disclosure. Results also indicate that the disciplining effect is sufficient to avoid provoking increased investor actions in a regime of range disclosure, as there is little difference in investor actions taken against managers in a regime of no range disclosure vs. a regime of range disclosure.

This study contributes regulatory insights regarding the potential effects of range disclosures on manager reporting and investor actions taken against managers. In 
particular, the results suggest that range disclosures should discipline the managers most prone to take advantage of their information advantage in a regime of no range disclosure, while not changing the reporting behavior of managers who do not capitalize on information asymmetry.

Another key differentiating point of this study is the use of strategic managers, endowed with economic incentives to report aggressively biased estimates while avoiding costly investor actions. Determining reports endogenously enables this study to speak to how the provision of range disclosures could influence the strategic interaction between managers and investors, thereby adding to prior studies with endogenous reporting designs (e.g., Bloomfield 1996; Hobson and Kachelmeier 2005) and examining strategic reasoning (e.g., Zimbelman and Waller 1999; Bowlin 2011). Finally, this study adds to the emerging literature on how individual attributes of managers influence their reporting decisions (e.g., Bamber et al. 2010; Murphy 2012; Hales et al. 2012). By identifying the different reporting behavior of managers as a function of their association with the Dark Triad, this study highlights the importance of individual differences among managers.

\section{Limitations and Future Research Opportunities}

Elements of this dissertation are subject to key assumptions that merit further discussion, as I discuss in this closing section. These assumptions suggest interesting opportunities for future research, which I also explore.

This study is conducted in the tradition of experimental economics, such that student participants receive meaningful monetary incentives and interact in roles analogous to managers and investors. Such a design proffers important advantages, such 
as enabling the observance of strategic interactions between managers and investors, but also necessarily abstracts from characteristics of real-world professionals, such as manager expertise or investor sophistication that could be a captured in a more contextrich experimental design (e.g., Kachelmeier and King 2002). Although the abstract experimental task is designed to capture key elements of reporting estimates in practice, it does not capture the context that a more realistic case study, for example, could capture.

Moreover, the experimental design also abstracts from other complexities of realworld financial reporting environments, such as managers' communication with investors and ability to form reputations for reliable reporting. To this end, an interesting topic for future research would be investigating the extent to which giving managers opportunities to communicate with investors could influence the findings of this study. If Dark Triad managers can successfully convince investors that aggressive reported estimates actually represent legitimate private beliefs, range disclosure's effectiveness as a disciplining mechanism might be compromised when communication vehicles such as conference calls or investor relations programs are utilized. Future research could also extend prior studies exploring the role of reputation building in disclosure environments (e.g., King 1996; Mayhew 2001) to investigate if reporting reputations interact with the disciplining effect of range disclosure and if there are differences between the reputation building tactics of managers as a function of their association with the Dark Triad.

An additional key assumption of this study is that, although managers receive feedback about investor actions, investors do not receive feedback revealing the actual aggressiveness of manager's estimates. I make this design choice to capture the 
institutional reality that there is often a considerable lag between the reporting of fairvalued financial statement items and other estimates and the determination of the associated realized values (e.g., Bratten et al. 2013). Future research could examine if learning the differences between managers' reported estimates and realized asset values changes the amount of actions investors take against managers and circumstances under which they take these actions.

The disclosed range in this study is not subject to manipulation by managers. However, in practice, managers might be able to manipulate range disclosure itself due to factors such as lack of auditor expertise with particularly challenging estimates (e.g., Griffith et al. 2012), auditors anchoring on management's selected range and adjusting insufficiently (cf., Tversky and Kahneman 1974), or management pressure on auditors. Abstracting from such factors enables this study to provide a clear ceteris paribus picture of the potential effects of range disclosure. Future research could explore providing managers with discretion over the disclosed range, examine if managers react to this discretion differently depending on their attributes (such as association with the Dark Triad), and test if investors have the ability to anticipate management's actions and adjust the disclosed range for any exercised discretion. If managers exploit this discretion and investors are unable to adjust disclosed ranges to account for this discretion, the importance of the auditor's (objective) role in range disclosure is underscored further.

Broad themes in this dissertation also motivate interesting questions for future research. For example, as discussed in Chapter 3, this dissertation explores manager behavior that is similarly manifested by all three personalities in the Dark Triad, 
presumably because overlapping elements of the Dark Triad are also predictors of aggressive reporting. To this end, it would be intriguing to explore conditions under which distinctions between the three Dark Triad personalities could emerge in a reporting environment.

Moreover, this study's focus on proposed changes to the auditor's reporting model places it in the realm of mandatory disclosure (from the perspective of managers), but examining managers' behavior when range disclosures are voluntary could also shed interesting insights. At first glance, it seems that managers would have little incentive to voluntarily disclose ranges, as results from this dissertation suggest that range disclosure inhibits their ability to report aggressively. However, this baseline prediction does not account for the fact that non-Dark Triad managers did not report particularly aggressively, even absent range disclosure, meaning that non-Dark Triad managers have little incentive to withhold range disclosures from investors. Moreover, such a prediction does not account for the fact that investors in an environment of voluntary disclosure might react to manager lack of disclosure with suspicion - especially if they observe managers from peer firms disclosing ranges voluntarily. As such, Dark Triad managers face an intriguing dilemma of managing investor perceptions while maximizing their ability to report aggressively. In such an environment, the auditor's role in verifying or independently disclosing ranges would become especially critical if managers attempt to control investor perceptions by disclosing ranges voluntarily. 


\section{FIGURE 1 \\ Short Dark Triad (SD3) Questionnaire \\ (Jones and Paulhus, in press) $^{\mathrm{a}}$}

Each participant was asked to indicate the extent to which they agreed or disagreed with each of the following statements on a scale of 1 (Strongly Disagree) to 5 (Strongly Agree).

\section{Machiavellianism Subscale}

1. It's not wise to tell your secrets.

2. Generally speaking, people won't work hard unless they have to.

3. Whatever it takes, you must get the important people on your side.

4. Avoid direct conflict with others because they may be useful in the future.

5. It's wise to keep track of information that you can use against people later.

6. You should wait for the right time to get back at people.

7. There are things you should hide from other people because they don't need to know.

8. Make sure your plans benefit you, not others.

9. Most people are suckers.

10. Most people deserve respect. (R)

\section{Narcissism Subscale}

1. People see me as a natural leader.

2. I hate being the center of attention. (R)

3. Many group activities tend to be dull without me.

4. I know that I am special because everyone keeps telling me so.

5. I like to get acquainted with important people.

6. I feel embarrassed if someone compliments me. (R)

7. I have been compared to famous people.

8. I am an average person. (R)

9. I insist on getting the respect I deserve.

\section{Psychopathy Subscale}

1. I like to get revenge on authorities.

2. I avoid dangerous situations. (R)

3. Payback needs to be quick and nasty.

4. People often say I'm out of control.

5. It's true that I can be cruel.

6. People who mess with me always regret it.

7. I have never gotten into trouble with the law. ${ }^{b}(\mathrm{R})$

8. I like to pick on losers.

9. I'll say anything to get what I want.

\footnotetext{
${ }^{a}$ Items labeled (R) are reverse-scored.

$\mathrm{b}$ I exclude this question due to the sensitive nature of the question.
} 
FIGURE 2: Experimental Conditions

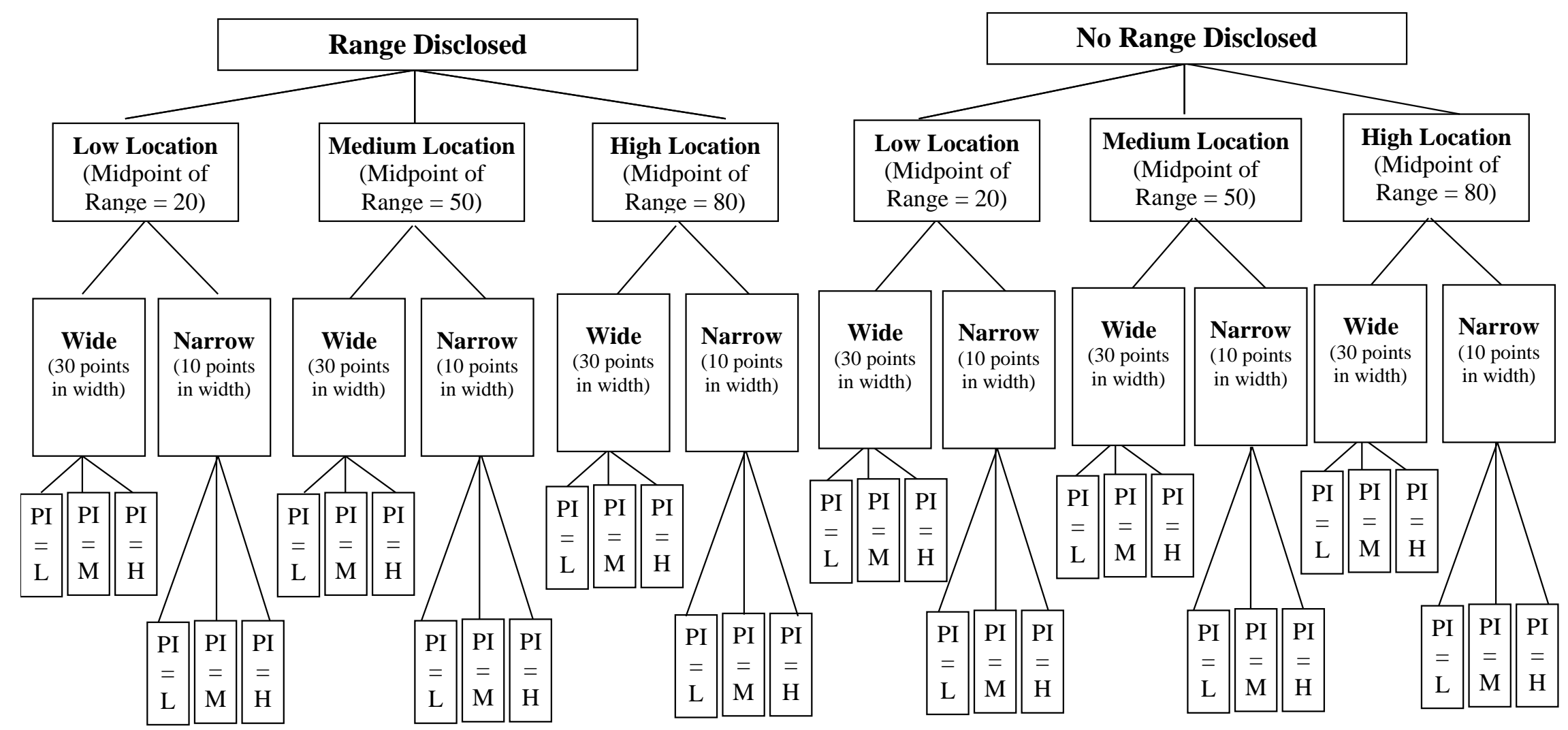

Figure 2 illustrates the 36 total experimental conditions. The diagram first specifies the between-participants manipulation of whether or not the reasonable range of estimates is disclosed to investors. Range location is then manipulated within-participants, by varying whether the midpoint of the reasonable range is Low (20 points), Medium (50 points), or High (80 points) within the possible asset values of 1 to 100 points. Asset value precision is then manipulated within-participants, by varying whether the reasonable range is 30 points in width or 10 points in width. Private Information (PI) is then manipulated within-participants, indicating that the asset value is likely to lie in the low part of the range $(\mathrm{L})$, medium part of the range $(\mathrm{M})$, or high part of the range $(\mathrm{H})$. 


\section{FIGURE 3}

Frequency Distributions of Dark Triad Mean Scores
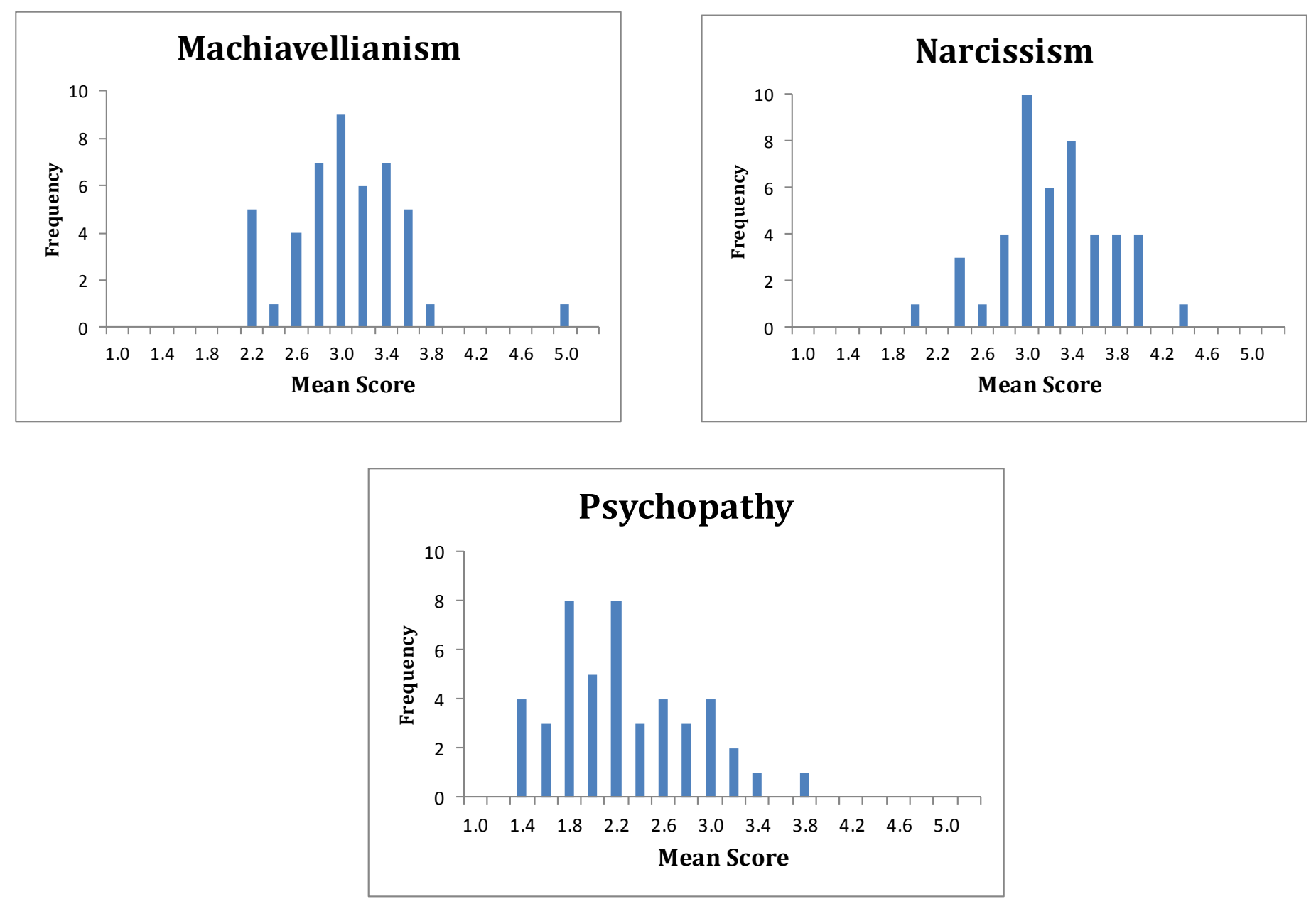
FIGURE 4

Range Disclosure and the Dark Triad by Personality Type

Panel A: Plot of Aggressiveness of Managers by Range Disclosure and Dark Triad

Dependent Variable: Average Reporting Aggressiveness

Reported Estimate - Lower Bound of Reasonable Range

Maximum Report

Width of Reasonable Range

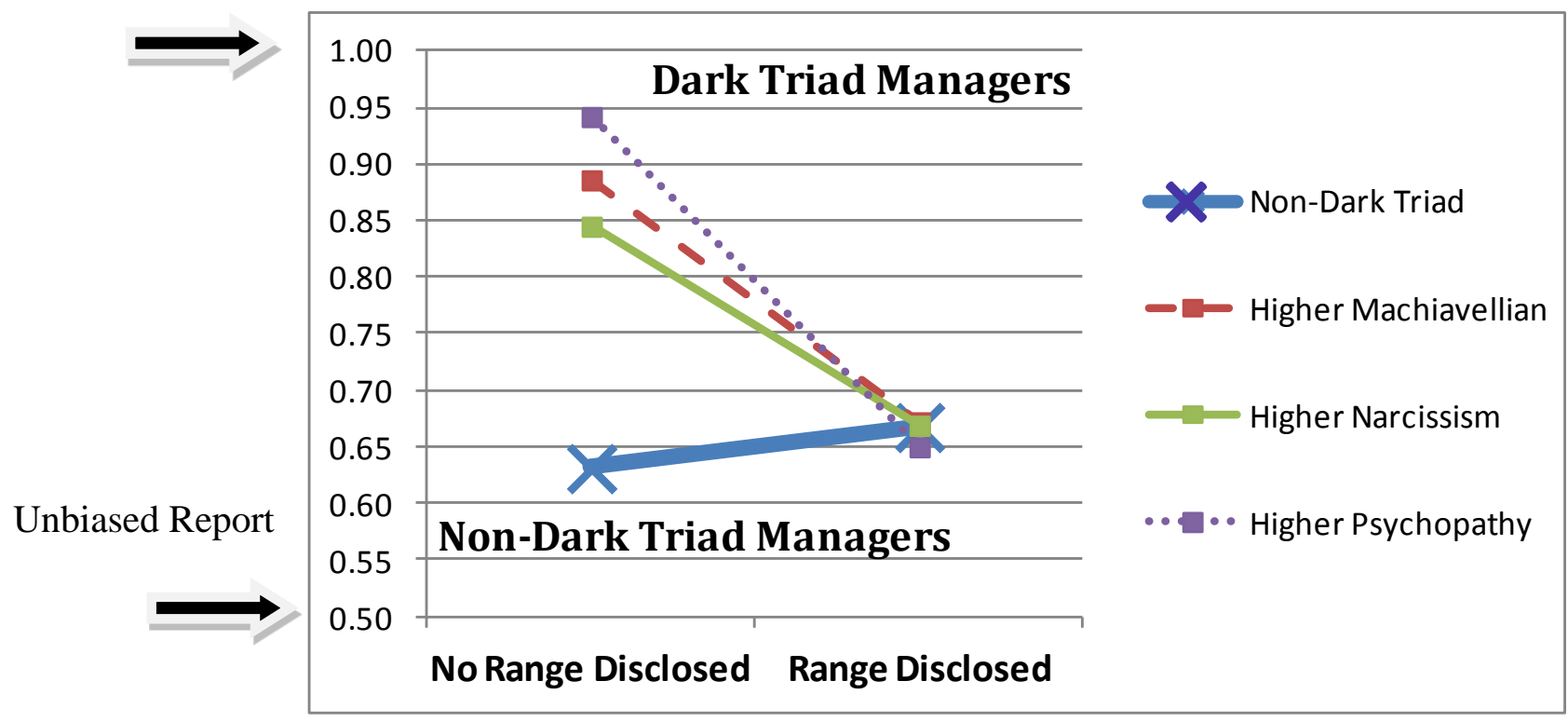

Panel B: Descriptive Statistics

\section{Dark Triad Classification}

Non-Dark Triad

$(\mathrm{n}=14)$

Higher Machiavellian

$(\mathrm{n}=20)$

Higher Narcissism

$(\mathrm{n}=21)$

Higher Psychopathy

$(\mathrm{n}=18)$
Mean

(Standard Error)

Mean

(Standard Error)

Mean

(Standard Error)

Mean

(Standard Error)
No Range Disclosure Range Disclosure
0.63
0.67
$(0.04)$
(0.05)

0.89

0.67

(0.04)

0.85

0.67

$(0.04)$

(0.03)

0.94

0.65

(0.05) 
FIGURE 5

Range Disclosure and the Dark Triad by Number of Personalities

Panel A: Plot of Aggressiveness of Managers by Range Disclosure and Dark Triad

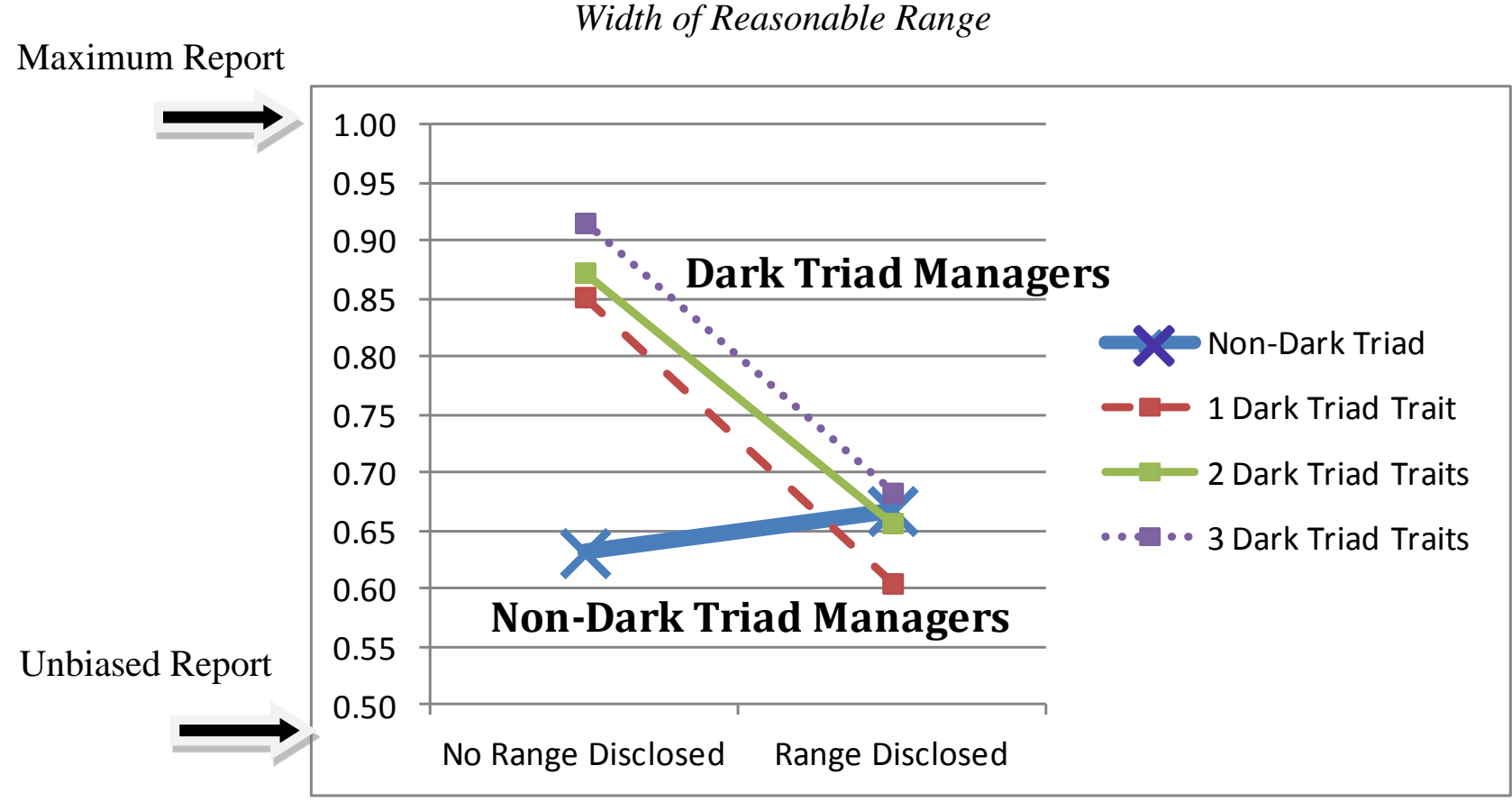

Dependent Variable: Average Reporting Aggressiveness

Reported Estimate - Lower Bound of Reasonable Range

Width of Reasonable Range

Panel B: Descriptive Statisticsa

\section{$\underline{\text { Dark Triad Classification }}$}

Non-Dark Triad

$(\mathrm{n}=14)$

1 Dark Triad Trait

$(\mathrm{n}=15)$

2 Dark Triad Traits

$(\mathrm{n}=7)$

3 Dark Triad Traits

$(\mathrm{n}=10)$
Mean

(Standard Error)

Mean

(Standard Error)

Mean

(Standard Error)

Mean

(Standard Error) $\underline{\text { No Range Disclosure Range Disclosure }}$

0.63

0.67

(0.04)

(0.05)

0.85

0.60

(0.04)

$(0.05)$

0.87

0.66

(0.09)

(0.05)

0.92

0.68

(0.07)

$(0.05)$

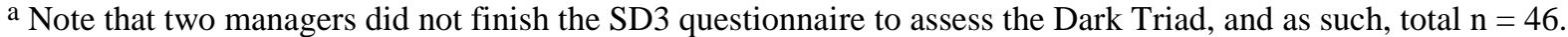


FIGURE 6

Range Disclosure and the Dark Triad

Panel A: Plot of Aggressiveness of Managers by Range Disclosure and Dark Triad

\section{Dependent Variable: Average Reporting Aggressiveness \\ Reported Estimate - Lower Bound of Reasonable Range \\ Width of Reasonable Range}

Maximum Report

Unbiased Report

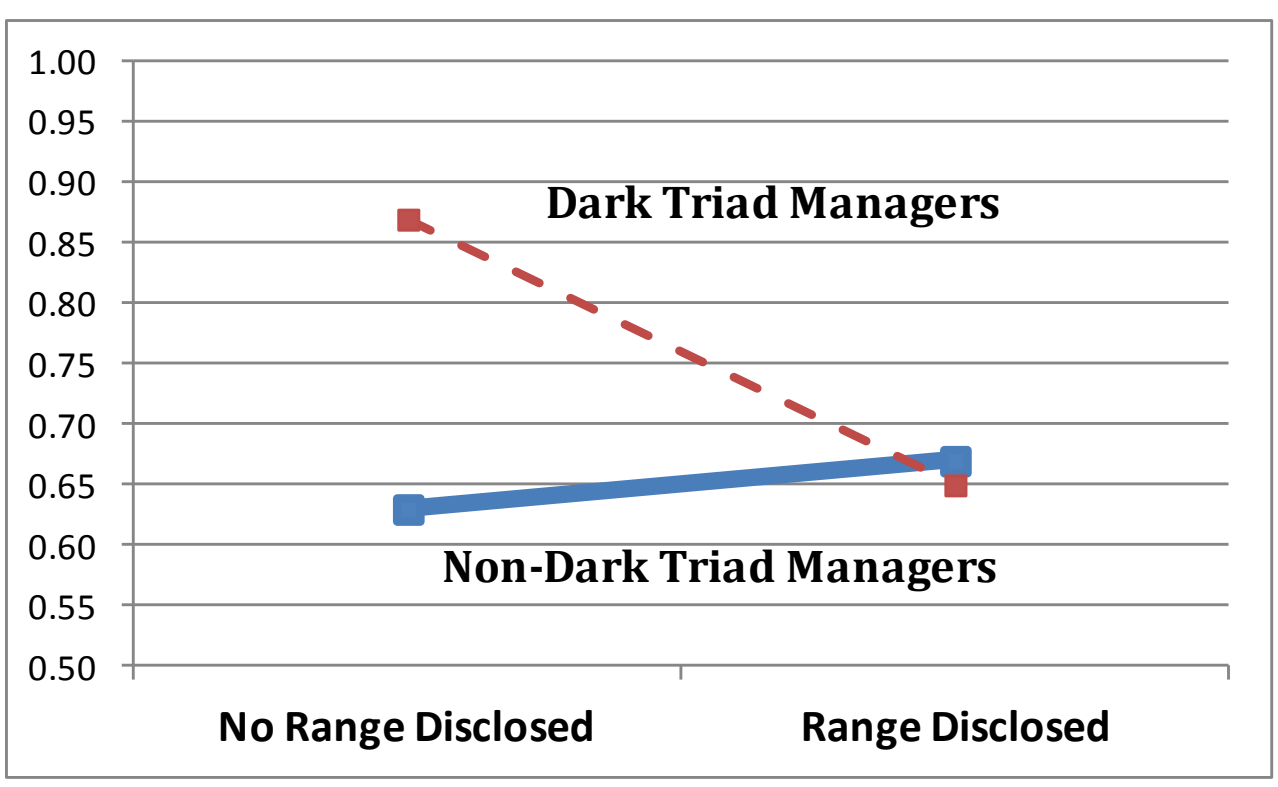

Panel B: Descriptive Statistics

$\underline{\text { Dark Triad Classification }}$

Non-Dark Triad

$(\mathrm{n}=14)$

Dark Triad

$(n=32)$
No Range Disclosure

0.63

(0.04)

0.87

(0.03) $\underline{\text { Range Disclosure }}$

0.67

(0.05)

0.65

(0.03) 
FIGURE 7

Range Disclosure and the Dark Triad by Private Information

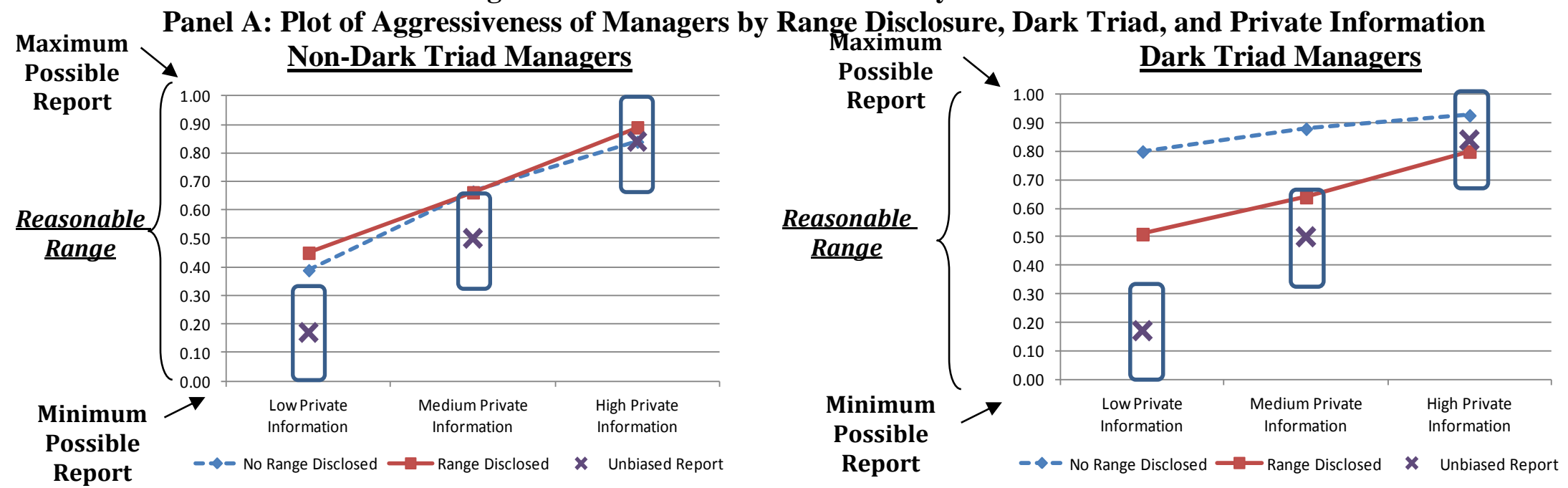

Panel A displays how non-Dark Triad and Dark Triad managers' reported estimates vary with their private information in regimes of no range disclosure and range disclosure. The vertical axis represents the reasonable range within which the manager can report an estimate. The boxes represent the manager's private information about the area in the reasonable range within which the asset's true value likely lies. The $\times$ represents an unbiased report (the midpoint of the manager's private information). Recall that managers are restricted to report within the reasonable range, but are permitted to report outside of their private information.

\section{Panel B: Descriptive Statistics}

No Range Disclosure

Private Information

\section{Dark Triad Classification}

Non-Dark Triad

$$
(\mathrm{n}=14)
$$

Dark Triad

$(\mathrm{n}=32)$
Mean

(Standard Error)

Mean

(Standard Error)

\section{Low}

0.39

(0.07)

0.80

(0.05)

$\begin{array}{ccc}\text { Medium } & & \text { High } \\ 0.66 & & 0.84 \\ (0.04) & & (0.03) \\ 0.88 & 0.93 \\ (0.03) & (0.03)\end{array}$

Range Disclosure

\section{Private Information}

\begin{tabular}{|c|c|c|}
\hline Low & Medium & $\underline{\text { High }}$ \\
\hline $\begin{array}{c}0.45 \\
(0.09)\end{array}$ & $\begin{array}{c}0.66 \\
(0.05)\end{array}$ & $\begin{array}{c}0.89 \\
(0.04)\end{array}$ \\
\hline $\begin{array}{c}0.51 \\
(0.05)\end{array}$ & $\begin{array}{c}0.64 \\
(0.03)\end{array}$ & $\begin{array}{c}0.80 \\
(0.02)\end{array}$ \\
\hline
\end{tabular}


FIGURE 8

Investor Actions Taken Against Managers

Panel A: Descriptive Statistics by the Manager's Private Information

\begin{tabular}{|c|c|c|c|c|c|}
\hline \multirow[b]{2}{*}{ Range Disclosure Condition } & & \multicolumn{3}{|c|}{ Manager's Private Information } & \multirow[b]{2}{*}{ Overall } \\
\hline & & Low & Medium & High & \\
\hline $\begin{array}{l}\text { No Range Disclosed } \\
(\mathrm{n}=432)\end{array}$ & $\begin{array}{l}\text { Mean } \\
\text { (Standard Error) }\end{array}$ & $\begin{array}{l}2.14 \\
(2.36)\end{array}$ & $\begin{array}{l}2.71 \\
(3.00)\end{array}$ & $\begin{array}{l}2.56 \\
(3.00)\end{array}$ & $\begin{array}{l}2.47 \\
(2.81)\end{array}$ \\
\hline $\begin{array}{l}\text { Range Disclosed } \\
(\mathrm{n}=432)\end{array}$ & $\begin{array}{l}\text { Mean } \\
\text { (Standard Error) }\end{array}$ & $\begin{array}{l}1.76 \\
(2.21)\end{array}$ & $\begin{array}{l}1.97 \\
(2.34)\end{array}$ & $\begin{array}{l}2.59 \\
(2.88)\end{array}$ & $\begin{array}{l}2.11 \\
(2.51)\end{array}$ \\
\hline Overall & $\begin{array}{l}\text { Mean } \\
\text { (Standard Error) }\end{array}$ & $\begin{array}{l}1.95 \\
(2.29)\end{array}$ & $\begin{array}{l}2.34 \\
(2.71)\end{array}$ & $\begin{array}{l}2.58 \\
(2.93)\end{array}$ & \\
\hline
\end{tabular}

Panel B: Descriptive Statistics by the Range Location

\begin{tabular}{|c|c|c|c|c|c|}
\hline \multirow[b]{2}{*}{ Range Disclosure Condition } & & \multicolumn{3}{|c|}{ Range Location } & \multirow[b]{2}{*}{ Overall } \\
\hline & & Low & Medium & High & \\
\hline $\begin{array}{l}\text { No Range Disclosed } \\
(\mathrm{n}=432)\end{array}$ & $\begin{array}{l}\text { Mean } \\
\text { (Standard Error) }\end{array}$ & $\begin{array}{l}1.36 \\
(1.79)\end{array}$ & $\begin{array}{l}2.31 \\
(2.40)\end{array}$ & $\begin{array}{l}3.74 \\
(3.45)\end{array}$ & $\begin{array}{l}2.47 \\
(2.81)\end{array}$ \\
\hline $\begin{array}{l}\text { Range Disclosed } \\
(\mathrm{n}=432)\end{array}$ & $\begin{array}{l}\text { Mean } \\
\text { (Standard Error) }\end{array}$ & $\begin{array}{l}2.17 \\
(2.61)\end{array}$ & $\begin{array}{l}2.03 \\
(2.36)\end{array}$ & $\begin{array}{l}2.12 \\
(2.58)\end{array}$ & $\begin{array}{l}2.11 \\
(2.51)\end{array}$ \\
\hline Overall & $\begin{array}{l}\text { Mean } \\
\text { (Standard Error) }\end{array}$ & $\begin{array}{l}1.76 \\
(2.27)\end{array}$ & $\begin{array}{l}2.17 \\
(2.38)\end{array}$ & $\begin{array}{l}2.93 \\
(3.15)\end{array}$ & \\
\hline
\end{tabular}


TABLE 1

Repeated-Measures Analysis of Variance for Managers

Panel A: Primary Analysis

\begin{tabular}{lccc} 
Dependent variable $=$ Standardized Report & df & F-statistic & p-value \\
\hline Between-participants factor: & & & \\
Range Disclosure & 1 & 5.32 & $<0.01^{*}$ \\
Dark Triad & 1 & 7.72 & $<0.01^{*}$ \\
& & & \\
Within-participants factors: & 1 & 2.62 & 0.11 \\
Precision & 2 & 0.50 & $>0.50$ \\
Range Location & 2 & 88.01 & $<0.01$ \\
Private Information & & & \\
& & & \\
Interactions Significant at p $<\mathbf{0 . 1 0}$ or lower:b & & & \\
Range Disclosure $\times$ Dark Triad & 1 & 10.39 & $<0.01^{*}$ \\
Private Information $\times$ Dark Triad & 2 & 11.38 & $<0.01$ \\
Precision $\times$ Dark Triad & 1 & 2.90 & 0.10 \\
Range Disclosure $\times$ Precision $\times$ Private Information & 2 & 2.46 & 0.09
\end{tabular}

\section{Panel B: Effect of Range Disclosure on Dark Triad Managers}

\begin{tabular}{lrrr} 
& df & F-statistic & p-value \\
\hline The Effect of Range Disclosure on Non-Dark Triad Managers & 1 & 0.30 & $0.29^{*}$ \\
The Effect of Range Disclosure on Dark Triad Managers & 1 & 26.38 & $<0.01^{*}$
\end{tabular}

\section{Panel C: Effect of the Dark Triad in Each Regime}

The Effect of the Dark Triad in a Regime of No Range Disclosure $1 \quad 21.62<0.01^{*}$

The Effect of the Dark Triad in a Regime of Range Disclosure $110.09 \quad 0.39 *$

\footnotetext{
a Reported p-values are one-tailed if asterisked (*) and two-tailed otherwise.

b Other two-, three-, four-, and five-way interactions (not statistically significant) are included in the ANOVA, but are not reported here to reduce clutter.
} 
TABLE 2

Mixed-Effects Model for Treatment Effects on Investors

\begin{tabular}{lccr} 
Dependent variable = Cost of Reduction in Payoff & Slope Estimate & t-statistic & p-valuea \\
\hline Between-participants factor: & & & \\
Range Disclosure & 0.44 & 0.29 & $>0.50$ \\
& & & \\
Within-participants factors: & 0.04 & 0.91 & 0.36 \\
Precision & 0.17 & 0.17 & $>0.50$ \\
Range Location & 0.00 & 0.10 & $>0.50$ \\
Private Information & & & \\
& & & \\
Interactions Significant at p $<\mathbf{0 . 1 0}$ or lower:b & -0.29 & -2.10 & 0.04 \\
Range Disclosure $\times$ Range Location & 0.26 & 1.88 & 0.06 \\
Range Disclosure $\times$ Private Information & 0.01 & 1.98 & 0.05 \\
Range Disclosure $\times$ Precision $\times$ Range Location & &
\end{tabular}

\footnotetext{
${ }^{a}$ All p-values are two-tailed.

${ }^{b}$ Other two-, three-, four-way interactions (not statistically significant) are included in the mixed model, but are not reported here to reduce clutter.
} 


\title{
APPENDIX A: Experimental Instructions for Managers
}

\author{
Instructions
}

\section{Ground Rules}

Before describing the experiment, it is important to establish three ground rules:

1. No talking. Please help maintain control over the experiment by refraining from comments or other communication with your fellow participants in this session or with other students who might be participating in future sessions. If you have any questions, just raise your hand and the experimenter will assist you.

2. No Deception. The experimenter promises to carry out the experiment in the manner described in these instructions, with no deception of any form.

3. Privacy. This experiment is structured so that no one, including the experimenters and other participants, will ever know the personal decisions of anyone in the experiment. Neither your name nor your UTEID will appear on any form that records your decisions in the experiment. The only identifying mark associated with your decisions will be an anonymous participant number handed to you when you arrived at today's session.

\section{Notes specific to these instructions:}

- These instructions are for manager participants

- Italicized text is only included in the "range disclosed" condition instructions.

- CAPITALIZED TEXT is only included in the "no range disclosed" condition instructions. 


\section{Overview of Experiment}

\section{Basic Structure of the Experiment}

You will be in the role of the "A Player" during the experiment. You will be randomly matched with a person in this room, henceforth referred to as the "B Player". There is an asset in the experiment that has a value between 1 and 100 points (with only integer values possible). You will learn a more precise range within the overall range of 1 to 100 points, in which the asset's true value lies. The more precise range communicated to you will, with equal likelihood, either narrow down the possible outcomes within 10 points or within 30 points. The $\boldsymbol{B}$ Player is also aware that the asset in the experiment has a value between 1 and 100 points. The $\boldsymbol{B}$ Player is aware that the more precise range is either 10 or 30 points wide, and s/he will also (BUT S/HE WILL NOT) learn this more precise range.

You will also receive private information about where, within the more precise range, the asset's value is most likely to lie. Specifically, you will learn whether the asset value is most likely to lie near the lower end, the middle, or the upper end of the more precise range. This additional information is private to you, and will not be communicated to the other person.

\section{Decision Made By You}

After learning the information described above, you will be asked to send a report to the $\boldsymbol{B}$ Player about the value of the asset. It is entirely up to you which value you report to the $\boldsymbol{B}$ Player, but you must report a value that falls within the more precise range provided to you.

\section{Decision Made By the B Player}

After seeing the report from you, the $\boldsymbol{B}$ Player will decide if s/he would like to pay a cost to reduce your payoff in the experiment.

\section{Payoffs for You and the B Player:}

YOUR PAYOFF:

20 points (base compensation)

PLUS + Reported value of the asset (which could differ from the asset's true value)

LESS - Reduction to your payoff imposed by the $\boldsymbol{B}$ Player, if any

= Your total payoff
THE B PLAYER'S PAYOFF:

20 points (base compensation)

PLUS + Either the true value of the asset, if the asset's reported value is greater than or equal to the true value, or the reported value of the asset, if the asset's reported value is less than the true value LESS - Excess, if any, of the reported asset value over the true asset value

LESS - Cost to reduce your payoff, if the B Player imposes any such reduction

= The $B$ Player's total payoff 
Note from this structure that all participants start with 20 points. You will then always receive the reported value, whether or not it differs from the true value. The $\boldsymbol{B}$ Player will receive either the true value of the asset, if the reported value is greater than or equal to the true value, or the reported value otherwise. However, if the reported value is greater than the true value, the $\boldsymbol{B}$ Player will also incur a loss equal to the difference. S/he will then have the option to pay a cost that reduces your profits.

Example 1: Assume that the true value of the asset is 50 and the reported value is 53 . Your profit: 20 points base compensation

Plus 53 points (reported value)

Equals 73 points before deducting any reduction in profit imposed by the other person.

The B Player's profit: 20 points base compensation

Plus 50 points (true value)

Minus 3 points (excess of reported value over true value)

Equals 67 points before deducting any additional cost s/he wishes to pay to reduce your profit.

Example 2: Assume that the true value of the asset is 50 and the reported value is 47.

Your profit: 20 points base compensation

Plus 47 points (reported value)

Equals 67 points before deducting any reduction in profit imposed by the other person.

The B Player's profit: 20 points base compensation

Plus 47 points (reported value)

Equals 67 points before deducting any additional cost s/he wishes to pay to reduce your profit.

\section{- Multiple Periods}

You will repeat the process described above for 18 periods, each time randomly and anonymously matched with one of the $\boldsymbol{B}$ players in this room. At the end of the experiment, you will receive compensation based on the cash equivalent of your profit for 6 of the 18 periods, to be determined randomly. 


\section{$\underline{\text { Next Steps }}$}

- The instructions that follow explain today's session in greater detail.

- To ensure that you fully understand these instructions, you will be asked several questions about the instructions after reading through them. 


\section{The Range and Asset Value}

There is an asset in the experiment that has a value between 1 and 100 points (with only integer values possible). The $\boldsymbol{B}$ Player with whom you are matched also knows that the asset value is between 1 and 100 points.

The computer program will also inform you of a more precise range, within the range of 1 to 100 points, in which the asset's true value lies. The B Player will also (WILL NOT) learn this more precise range. This more precise range will be either 10 or 30 points wide, and can lie anywhere within the overall range of 1 to 100 points.

The computer program will also inform you of where, within this more precise range, the asset value is most likely to lie. Specifically, you will learn whether the asset value is most likely to lie near the lower end, the middle, or the upper end of the more precise range. This additional information is private to you, and will not be communicated to the other person.

\section{Summary:}

- The computer program will inform you of a more precise range in which the asset's true value lies.

- This more precise range will also (WILL NOT) be disclosed to the B Player.

- The computer program will also inform you of where, within this more precise range, the asset value is most likely to lie (i.e., lower end, middle, or upper end of the more precise range). This information will not be revealed to the B Player. 


\section{$\underline{\text { Your Decision }}$}

You will decide which asset value you wish to report to the B Player.

The only requirement for the reported value is that it must fall within the more precise range that is either 10 or 30 points wide. Thus, you are free to report a value that is consistent with or different from your private information about where the asset's value is most likely to lie within the more precise range (i.e., lower end, middle, or upper end of the more precise range), so long as the reported value does not fall outside the more precise range. The B Player will (WILL NOT) be aware of the more precise range that has been provided to you.

As detailed later in these instructions, your payoff will be based on the asset value that you report to the $\boldsymbol{B}$ Player, such that higher reports yield higher payoffs for you. However, if you report a value that is higher than the true asset value, the $\boldsymbol{B}$ Player will incur a loss equal to the excess of the reported value over the true asset value that will reduce his/her payoff. 


\section{Decision Made By The B Player}

The decision made by the $\boldsymbol{B}$ Player is whether or not to reduce your payoff in the experiment.

When making this decision, the $\boldsymbol{B}$ Player will know the following information:

- The value you report to him/her.

- THAT THE ASSET'S VALUE IS BETWEEN 1 AND 100 POINTS.

- The more precise range within which the asset's value lies.

However, when making his/her decision, the B Player will not know:

- Your private information about where the asset's value is most likely to lie within the precise range (i.e., lower end, middle, or upper end of the more precise range).

- The true asset value.

- THE MORE PRECISE RANGE WITHIN WHICH THE ASSET'S VALUE LIES.

If the $\boldsymbol{B}$ Player decides to reduce your payoff, for every point s/he pays to reduce your payoff, your payoff will be reduced by $\mathbf{4}$ points. For example, if the $\boldsymbol{B}$ Player pays 1 point to reduce your payoff, your payoff will be reduced by 4 points. The $\boldsymbol{B}$ Player can pay a maximum of 10 points to reduce your payoff. Thus, $\mathrm{s} /$ he can reduce your payoff by a minimum of 0 points or a maximum of 40 points.

This decision is entirely up to the $\boldsymbol{B}$ Player, but s/he cannot change his/her mind after s/he inputs his/her decision into the computer (which occurs before the true asset value is revealed for compensation purposes). 


\section{True Asset Value}

For each of the 18 periods, a computer program will select a true asset value from a distribution of possible asset values that is within the more precise range disclosed to you and the B Player, and that is consistent with the information given to you about where the asset's value likely lies within the more precise range. 


\section{Compensation For You and The B Player}

\begin{tabular}{|c|c|c|}
\hline & If Reported Value $\geq$ True Asset Value & If Reported Value < True Asset Value \\
\hline Your Payoff & \multicolumn{2}{|c|}{$\begin{array}{l}\text { 20 points (base compensation) } \\
\text { PLUS + Reported Asset Value } \\
\text { LESS - Reduction in payoff imposed by the } \\
\text { B Player, if any } \\
\text { Your total payoff }\end{array}$} \\
\hline $\begin{array}{l}\text { Payoff for the } \\
\text { B Player }\end{array}$ & $\begin{array}{l}20 \text { points (base compensation) } \\
\text { PLUS + True Asset Value } \\
\text { LESS - Excess of the reported asset value } \\
\text { over the true asset value } \\
\text { LESS - Cost to reduce your payoff, if the } \\
\text { B Player imposes any such reduction } \\
\text { The B Player's total payoff }\end{array}$ & $\begin{array}{l}20 \text { points (base compensation) } \\
\text { PLUS + Reported Asset Value } \\
\text { LESS - Cost to reduce your payoff, if the } \\
\text { B Player imposes any such reduction } \\
\text { The B Player's total payoff }\end{array}$ \\
\hline
\end{tabular}

\section{Examples:}

Example 1: Assume that the true asset value and the reported asset value are both 50 points, a value that is equidistant between the lowest possible and highest possible asset values of 1 and 100 , respectively.

Your payoff:

\begin{tabular}{|l|l|}
\hline Base compensation & 20 points \\
\hline Plus Reported Value & +50 points \\
\hline Minus payoff reduction imposed by the & $\begin{array}{l}-4 \text { points for every 1 point the } \boldsymbol{B} \text { Player pays } \\
\text { to reduce your payoff }\end{array}$ \\
\hline Net payoff & $\begin{array}{l}=70 \text { points minus } 4 \text { points for every 1 point } \\
\text { the } \text { B Player pays to reduce your payoff }\end{array}$ \\
\hline
\end{tabular}

The B Player's payoff:

\begin{tabular}{|l|l|}
\hline Base compensation & 20 points \\
\hline Plus True Asset Value = Reported Value & +50 points \\
\hline Minus cost to reduce your payoff, if any & $\begin{array}{l}-1 \text { point for every 4 points of payoff } \\
\text { reduction the } \boldsymbol{B} \text { Player imposes on you }\end{array}$ \\
\hline Net payoff & $\begin{array}{l}=70 \text { points minus 1 point for every 4 points } \\
\text { of payoff reduction the } \boldsymbol{B} \text { Player imposes on } \\
\text { you }\end{array}$ \\
\hline
\end{tabular}




\section{Examples:}

Example 2: Assume that the true asset value is 50 and the reported asset value is 53 .

Your payoff:

\begin{tabular}{|l|l|}
\hline Base compensation & 20 points \\
\hline Plus Reported Value & +53 points \\
\hline Minus payoff reduction imposed by the & $\begin{array}{l}\text { - 4 points for every 1 point the } \boldsymbol{B} \text { Player pays } \\
\text { to reduce your payoff }\end{array}$ \\
\hline Net payoff & $\begin{array}{l}=73 \text { points minus } 4 \text { points for every 1 point } \\
\text { the } \boldsymbol{B} \text { Player pays to reduce your payoff }\end{array}$ \\
\hline
\end{tabular}

The B Player's payoff:

\begin{tabular}{|l|l|}
\hline Base compensation & \multicolumn{1}{|c|}{20 points } \\
\hline Plus True Asset Value & +50 points \\
\hline $\begin{array}{l}\text { Minus excess of reported value over the true } \\
\text { asset value }(53-50)\end{array}$ & -3 points \\
\hline Minus cost to reduce your payoff, if any & $\begin{array}{l}-1 \text { point for every 4 points of payoff } \\
\text { reduction the } \boldsymbol{B} \text { Player imposes on you }\end{array}$ \\
\hline Net payoff & $\begin{array}{l}=67 \text { points minus 1 point for every 4 points } \\
\text { of payoff reduction the } \boldsymbol{B} \text { Player imposes on } \\
\text { you }\end{array}$ \\
\hline
\end{tabular}

Example 3: Assume that the true asset value is 50 and the reported asset value is 47.

Your payoff:

\begin{tabular}{|l|l|}
\hline Base compensation & 20 points \\
\hline Plus Reported Value & +47 points \\
\hline Minus payoff reduction imposed by the & $\begin{array}{l}-4 \text { points for every 1 point the } \boldsymbol{B} \text { Player pays } \\
\text { B Player, if any }\end{array}$ \\
\hline Net payoff & $\begin{array}{l}=67 \text { points minus 4 points for every 1 point } \\
\text { the } \boldsymbol{B} \text { Player pays to reduce your payoff }\end{array}$ \\
\hline
\end{tabular}

The B Player's payoff:

\begin{tabular}{|l|l|}
\hline Base compensation & 20 points \\
\hline Plus Reported Asset Value & +47 points \\
\hline Minus cost to reduce your payoff, if any & $\begin{array}{l}-1 \text { point for every 4 points of payoff } \\
\text { reduction the } \boldsymbol{B} \text { Player imposes on you }\end{array}$ \\
\hline Net payoff & $\begin{array}{l}=67 \text { points minus 1 point for every 4 points } \\
\text { of payoff reduction the } \boldsymbol{B} \text { Player imposes on } \\
\text { you }\end{array}$ \\
\hline
\end{tabular}


Example 4: Assume that the true asset value is 50 and the reported asset value is 77.

Your payoff:

\begin{tabular}{|l|l|}
\hline Base compensation & 20 points \\
\hline Plus Reported Value & +77 points \\
\hline Minus payoff reduction imposed by the $\boldsymbol{B}$ & $\begin{array}{l}\text { - 4 points for every 1 point the } \boldsymbol{B} \text { Player pays } \\
\text { to reduce your payoff }\end{array}$ \\
\hline Net payoff & $\begin{array}{l}=97 \text { points minus } 4 \text { points for every 1 point } \\
\text { the } \boldsymbol{B} \text { Player pays to reduce your payoff }\end{array}$ \\
\hline
\end{tabular}

The B Player's payoff:

\begin{tabular}{|l|l|}
\hline Base compensation & \multicolumn{1}{|c|}{20 points } \\
\hline Plus True Asset Value & +50 points \\
\hline $\begin{array}{l}\text { Minus excess of reported value over the true } \\
\text { asset value }(77-50)\end{array}$ & -27 points \\
\hline Minus cost to reduce your payoff, if any & $\begin{array}{l}-1 \text { point for every } 4 \text { points of payoff } \\
\text { reduction the } \boldsymbol{B} \text { Player imposes on you }\end{array}$ \\
\hline Net payoff & $\begin{array}{l}=43 \text { points minus 1 point for every } 4 \text { points } \\
\text { of payoff reduction the } \boldsymbol{B} \text { Player imposes on } \\
\text { you }\end{array}$ \\
\hline
\end{tabular}

Example 5: Assume that the true asset value is 50 and the reported asset value is 23 .

Your payoff:

\begin{tabular}{|l|l|}
\hline Base compensation & 20 points \\
\hline Plus Reported Value & +23 points \\
\hline Minus payoff reduction imposed by the $\boldsymbol{B}$ & $\begin{array}{l}-4 \text { points for every 1 point the } \boldsymbol{B} \text { Player pays } \\
\text { to reduce your payoff }\end{array}$ \\
\hline Net payoff & $\begin{array}{l}=43 \text { points minus } 4 \text { points for every 1 point } \\
\text { the } \boldsymbol{B} \text { Player pays to reduce your payoff }\end{array}$ \\
\hline
\end{tabular}

The B Player's payoff:

\begin{tabular}{|l|l|}
\hline Base compensation & 20 points \\
\hline Plus Reported Asset Value & +23 points \\
\hline Minus cost to reduce your payoff, if any & $\begin{array}{l}-1 \text { point for every 4 points of payoff } \\
\text { reduction the } \boldsymbol{B} \text { Player imposes on you }\end{array}$ \\
\hline Net payoff & $\begin{array}{l}=43 \text { points minus 1 point for every 4 points } \\
\text { of payoff reduction the } \boldsymbol{B} \text { Player imposes on } \\
\text { you }\end{array}$ \\
\hline
\end{tabular}




\section{Your total compensation in the experiment:}

- At the end of the experiment, you and the other experimental participants will be compensated for a random selection of $\mathbf{6}$ of the 18 periods.

○ Thus, the computer will sum the points you earned during the six periods selected for compensation.

- The point total from these six periods will then be multiplied by $\$ .06$, which is the amount of total compensation you will receive for the experiment.

Examples:

A participant who earns an average of 40 points per period would get $40 \times 6 \times \$ .06=$ $\$ 14.40$ total compensation.

A participant who earns an average of 70 points per period would get $70 \times 6 \times \$ .06=$ $\$ 25.20$ total compensation.

A participant who earns an average of 100 points per period would get $100 \times 6 \times \$ .06=$ $\$ 36.00$ total compensation.

Note that these are considered illustrative examples only.

At the conclusion of today's session, you will be paid your compensation in cash and dismissed after completing a post-experimental questionnaire and cash receipt form. 


\title{
APPENDIX B: Experimental Instructions for Investors
}

\author{
Instructions
}

\section{Ground Rules}

Before describing the experiment, it is important to establish three ground rules:

1. No talking. Please help maintain control over the experiment by refraining from comments or other communication with your fellow participants in this session or with other students who might be participating in future sessions. If you have any questions, just raise your hand and the experimenter will assist you.

4. No Deception. The experimenter promises to carry out the experiment in the manner described in these instructions, with no deception of any form.

5. Privacy. This experiment is structured so that no one, including the experimenters and other participants, will ever know the personal decisions of anyone in the experiment. Neither your name nor your UTEID will appear on any form that records your decisions in the experiment. The only identifying mark associated with your decisions will be an anonymous participant number handed to you when you arrived at today's session.

\section{Notes specific to these instructions:}

- These instructions are for investor participants

- Italicized textonly is only included in the "range disclosed" condition instructions.

- CAPITALIZED TEXT is only included in the "no range disclosed" condition instructions. 


\section{Overview of Experiment}

\section{Basic Structure of the Experiment}

You will be in the role of the "B Player" during the experiment. You will be randomly matched with a person in this room, henceforth referred to as the "A Player". There is an asset in the experiment that has a value between 1 and 100 points (with only integer values possible). The $\boldsymbol{A}$ Player will learn a more precise range within the overall range of 1 to 100 points in which the asset's true value lies. The more precise range communicated to the $\boldsymbol{A}$ Player will, with equal likelihood, either narrow down the possible outcomes within 10 points or within 30 points. You will also (WILL NOT) learn this more precise range.

The $\boldsymbol{A}$ Player will also receive private information about where, within the more precise range, the asset's value is most likely to lie. Specifically, the $\boldsymbol{A}$ Player will learn whether the asset value is most likely to lie near the lower end, the middle, or the upper end of the more precise range. This additional information is private to the $\boldsymbol{A}$ Player, and will not be communicated to you.

\section{Decision Made By the A Player}

After learning the information described above, the $\boldsymbol{A}$ Player will be asked to send a report to you about the value of the asset. It is entirely up to the $\boldsymbol{A}$ Player which value s/he reports to you, but $\mathrm{s} / \mathrm{he}$ must report a value that falls within the more precise range provided to him/her.

\section{Decision Made By You}

After seeing the report from the $\boldsymbol{A}$ Player, you will decide if you would like to pay a cost to reduce his/her payoff in the experiment.

\section{Payoffs for You and the A Player:}

YOUR PAYOFF:

20 points (base compensation)

PLUS + Either the true value of the asset, if the asset's reported value is greater than or equal to the true value, or the reported value of the asset, if the asset's reported value is less than the true value

LESS - Excess, if any, of the reported asset value over the true asset value

LESS - Cost to reduce the $\boldsymbol{A}$ Player's payoff if you impose any such reduction

= Your total payoff
THE A PLAYER'S PAYOFF:

20 points (base compensation)

PLUS + Reported value of the asset (which could differ from the asset's true value)
LESS - Reduction in payoff

imposed by you, if any

= The A Player's total payoff 
Note from this structure that all participants start with 20 points. You will then receive either the true value of the asset, if the reported value is greater than or equal to the true value, or the reported value otherwise. However, if the reported value is greater than the true value, you will also incur a loss equal to the difference. The $\boldsymbol{A}$ Player will always receive the reported value, whether or not it differs from the true value. You will then have the option to pay a cost that reduces the $\boldsymbol{A}$ Player's profits.

Example 1: Assume that the true value of the asset is 50 and the reported value is 53 .

Your profit: 20 points base compensation

Plus 50 points (true value)

Minus 3 points (excess of reported value over true value)

Equals 67 points before deducting any additional cost you wish to pay to reduce the A Player's profit.

A Player's profit:

20 points base compensation

Plus 53 points (reported value)

Equals 73 points before deducting any reduction in profit imposed by you.

Example 2: Assume that the true value of the asset is 50 and the reported value is 47.

Your profit: 20 points base compensation

Plus 47 points (reported value)

Equals 67 points before deducting any additional cost you wish to pay to reduce the A Player's profit.

A Player's profit:

20 points base compensation

Plus 47 points (reported value)

Equals 67 points before deducting any reduction in profit imposed by you.

\section{- Multiple Periods}

You will repeat the process described above for 18 periods, each time randomly and anonymously matched with one of the $\boldsymbol{A}$ Players in this room. At the end of the experiment, you will receive compensation based on the cash equivalent of your profit for 6 of the 18 periods, to be determined randomly. 


\section{$\underline{\text { Next Steps }}$}

- The instructions that follow explain today's session in greater detail.

- To ensure that you fully understand these instructions, you will be asked several questions about the instructions after reading through them. 


\section{The Range and Asset Value}

There is an asset in the experiment that has a value between 1 and 100 points (with only integer values possible). The $\boldsymbol{A}$ Player with whom you are matched also knows that the asset value is between 1 and 100 points.

The computer program will also inform the $\boldsymbol{A}$ Player of a more precise range, within the range of 1 to 100 points, in which the asset's true value lies. You will also (WILL NOT) learn this more precise range. This more precise range will be either 10 or 30 points wide, and can lie anywhere within the overall range of 1 to 100 points.

The computer program will also inform the $\boldsymbol{A}$ Player of where, within this more precise range, the asset value is most likely to lie. Specifically, the $\boldsymbol{A}$ Player will learn whether the asset value is most likely to lie near the lower end, the middle, or the upper end of the more precise range. This additional information is private to the $\boldsymbol{A}$ Player, and will not be communicated to you.

\section{Summary:}

- The computer program will inform the $\boldsymbol{A}$ Player of a more precise range in which the asset's true value lies.

- This more precise range will also (WILL NOT) be disclosed to you.

- The computer program will also inform the $\boldsymbol{A}$ Player of where, within this more precise range, the asset value is most likely to lie (i.e., lower end, middle, or upper end of the more precise range). This information will not be revealed to you. 


\section{Decision Made By The A Player}

The $\boldsymbol{A}$ Player will decide which asset value s/he wishes to report to you.

The only requirement for the reported value is that it must fall within the more precise range that is either 10 or 30 points wide. Thus, the $\boldsymbol{A}$ Player is free to report a value that is consistent with or different from his/her private information about where the asset's value is most likely to lie within the more precise range (i.e., lower end, middle, or upper end of the more precise range), so long as the reported value does not fall outside the more precise range. You will (WILL NOT) be aware of the more precise range that has been provided to the

\section{A Player.}

As detailed later in these instructions, the payoff for the $\boldsymbol{A}$ Player will be based on the asset value that s/he reports to you, such that higher reports yield higher payoffs for the $\boldsymbol{A}$ Player). However, if the $\boldsymbol{A}$ Player reports a value that is higher than the true asset value, you will incur a loss equal to the excess of the reported value over the true asset value that will reduce your payoff. 


\section{$\underline{\text { Your Decision }}$}

Your decision is whether or not to reduce the payoff in the experiment of the A Player.

When making this decision, you will know the following information:

- The value the $\boldsymbol{A}$ Player reports to you.

- THAT THE ASSET'S VALUE IS BETWEEN 1 AND 100 POINTS.

- The more precise range within which the asset's value lies.

However, when making your decision, you will not know:

- The private information provided to the $\boldsymbol{A}$ Player about where the asset's value is most likely to lie within the precise range (i.e., lower end, middle, or upper end of the more precise range).

- The true asset value.

- THE MORE PRECISE RANGE WITHIN WHICH THE ASSET'S VALUE LIES.

If you decide to reduce the payoff of the $\boldsymbol{A}$ Player, for every point you pay to reduce the $\boldsymbol{A}$ Player's payoff, his/her payoff will be reduced by 4 points. For example, if you pay 1 point to reduce his/her payoff, his/her payoff will be reduced by 4 points. You can pay a maximum of 10 points to reduce $\boldsymbol{A}$ Player's payoff. Thus, you can reduce the $\boldsymbol{A}$ Player's payoff by a minimum of 0 points or a maximum of 40 points.

This decision is entirely up to you, but you cannot change your mind after you input your decision into the computer (which occurs before the true asset value is revealed for compensation purposes). 


\section{True Asset Value}

For each of the 18 periods, a computer program will select a true asset value from distribution of possible asset values that is within the more precise range disclosed to the $\boldsymbol{A}$ Player and you, and that is consistent with the information given to the $\boldsymbol{A}$ Player about where the asset's value likely lies within the more precise range. 


\section{Compensation For You and The A Player}

\begin{tabular}{|c|c|c|}
\hline & If Reported Value $\geq$ True Asset Value & If Reported Value < True Asset Value \\
\hline Your Payoff & $\begin{array}{l}20 \text { points (base compensation) } \\
\text { PLUS + True Asset Value } \\
\text { LESS - Excess of the reported asset value over } \\
\text { the true asset value } \\
\text { LESS - Cost to reduce the A Player's payoff, if } \\
\text { you impose any such reduction } \\
\text { Your total payoff }\end{array}$ & $\begin{array}{l}20 \text { points (base compensation) } \\
\text { PLUS + Reported Asset Value } \\
\text { LESS - Cost to reduce the A Player's payoff, if } \\
\text { you impose any such reduction } \\
\text { Your total payoff }\end{array}$ \\
\hline $\begin{array}{l}\text { Payoff for the } \\
\text { A Player }\end{array}$ & \multicolumn{2}{|c|}{$\begin{array}{l}30 \text { points (base compensation) } \\
\text { PLUS + Reported Asset Value } \\
\text { LESS - Reduction in payoff imposed } \\
\text { by you, if any } \\
\text { The } \text { A Player's total payoff }\end{array}$} \\
\hline
\end{tabular}

\section{Examples:}

Example 1: Assume that the true asset value and the reported asset value are both 50 points, a value that is equidistant between the lowest possible and highest possible asset values of 1 and 100 , respectively.

Your payoff:

\begin{tabular}{|l|l|}
\hline Base compensation & \multicolumn{1}{|c|}{20 points } \\
\hline Plus True Asset Value = Reported Value & +50 points \\
\hline $\begin{array}{l}\text { Minus cost to reduce the } \boldsymbol{A} \text { Player's payoff, if } \\
\text { any }\end{array}$ & $\begin{array}{l}\text { - 1 point for every 4 points of payoff } \\
\text { reduction you impose on the } \boldsymbol{A} \text { Player }\end{array}$ \\
\hline Net payoff & $\begin{array}{l}=70 \text { points minus 1 point for every 4 points } \\
\text { of payoff reduction you impose on the } \\
\text { A Player }\end{array}$ \\
\hline
\end{tabular}

The $\boldsymbol{A}$ Player's payoff:

\begin{tabular}{|l|l|}
\hline Base compensation & \multicolumn{1}{|c|}{20 points } \\
\hline Plus Reported Value & +50 points \\
\hline Minus payoff reduction imposed by you, if & -4 points for every 1 point you pay to reduce \\
any & the $\boldsymbol{A}$ Player's payoff \\
\hline Net payoff & $=70$ points minus 4 points for every 1 point \\
& you pay to reduce the $\boldsymbol{A}$ Player's payoff \\
\hline
\end{tabular}




\section{Examples:}

Example 2: Assume that the true asset value is 50 and the reported asset value is 53 .

Your payoff:

\begin{tabular}{|l|l|}
\hline Base compensation & \multicolumn{1}{|c|}{20 points } \\
\hline Plus True Asset Value & +50 points \\
\hline $\begin{array}{l}\text { Minus excess of reported value over the true } \\
\text { asset value (53 - 50) }\end{array}$ & - points \\
\hline $\begin{array}{l}\text { Minus cost to reduce the } \boldsymbol{A} \text { Player's payoff, if } \\
\text { any }\end{array}$ & $\begin{array}{l}-1 \text { point for every 4 points of payoff } \\
\text { reduction you impose on the } \boldsymbol{A} \text { Player }\end{array}$ \\
\hline Net payoff & $\begin{array}{l}\text { = 67 points minus 1 point for every 4 points } \\
\text { of payoff reduction you impose on the } \\
\text { A Player }\end{array}$ \\
\hline
\end{tabular}

The $A$ Player's payoff:

\begin{tabular}{|l|l|}
\hline Base compensation & 20 points \\
\hline Plus Reported Value & +53 points \\
\hline $\begin{array}{l}\text { Minus payoff reduction imposed by you, if } \\
\text { any }\end{array}$ & $\begin{array}{l}-4 \text { points for every 1 point you pay to reduce } \\
\text { the } \boldsymbol{A} \text { Player's payoff }\end{array}$ \\
\hline Net payoff & $\begin{array}{l}=73 \text { points minus 4 points for every 1 point } \\
\text { you pay to reduce the } \boldsymbol{A} \text { Player's payoff }\end{array}$ \\
\hline
\end{tabular}

Example 3: Assume that the true asset value is 50 and the reported asset value is 47 .

Your payoff:

\begin{tabular}{|l|l|}
\hline Base compensation & \multicolumn{1}{|c|}{30 points } \\
\hline Plus Reported Asset Value & +47 points \\
\hline $\begin{array}{l}\text { Minus cost to reduce the } \boldsymbol{A} \text { Player's payoff, if } \\
\text { any }\end{array}$ & $\begin{array}{l}\text { - 1 point for every 4 points of payoff } \\
\text { reduction you impose on the } \boldsymbol{A} \text { Player }\end{array}$ \\
\hline Net payoff & $\begin{array}{l}=77 \text { points minus 1 point for every 4 points } \\
\text { of payoff reduction you impose on the } \\
\text { A Player }\end{array}$ \\
\hline
\end{tabular}

The $\boldsymbol{A}$ Player's payoff:

\begin{tabular}{|l|l|}
\hline Base compensation & 30 points \\
\hline Plus Reported Value & +47 points \\
\hline $\begin{array}{l}\text { Minus payoff reduction imposed by you, if } \\
\text { any }\end{array}$ & $\begin{array}{l}-4 \text { points for every 1 point you pay to reduce } \\
\text { the } \boldsymbol{A} \text { Player's payoff }\end{array}$ \\
\hline Net payoff & $\begin{array}{l}=77 \text { points minus 4 points for every 1 point } \\
\text { you pay to reduce the } \boldsymbol{A} \text { Player's payoff }\end{array}$ \\
\hline
\end{tabular}


Example 4: Assume that the true asset value is 50 and the reported asset value is 77.

Your payoff:

\begin{tabular}{|l|l|}
\hline Base compensation & \multicolumn{1}{|c|}{20 points } \\
\hline Plus True Asset Value & +50 points \\
\hline $\begin{array}{l}\text { Minus excess of reported value over the true } \\
\text { asset value (77 - 50) }\end{array}$ & -27 points \\
\hline $\begin{array}{l}\text { Minus cost to reduce the } \boldsymbol{A} \text { Player's payoff, if } \\
\text { any }\end{array}$ & $\begin{array}{l}-1 \text { point for every 4 points of payoff } \\
\text { reduction you impose on the } \boldsymbol{A} \text { Player }\end{array}$ \\
\hline Net payoff & $\begin{array}{l}\text { = 43 points minus 1 point for every 4 points } \\
\text { of payoff reduction you impose on the } \\
\text { A Player }\end{array}$ \\
\hline
\end{tabular}

The $\boldsymbol{A}$ Player's payoff:

\begin{tabular}{|l|l|}
\hline Base compensation & 20 points \\
\hline Plus Reported Value & +77 points \\
\hline $\begin{array}{l}\text { Minus payoff reduction imposed by you, if } \\
\text { any }\end{array}$ & $\begin{array}{l}-4 \text { points for every 1 point you pay to reduce } \\
\text { the } \boldsymbol{A} \text { Player's payoff }\end{array}$ \\
\hline Net payoff & $\begin{array}{l}=97 \text { points minus 4 points for every 1 point } \\
\text { you pay to reduce the } \boldsymbol{A} \text { Player's payoff }\end{array}$ \\
\hline
\end{tabular}

Example 5: Assume that the true asset value is 50 and the reported asset value is 23 .

Your payoff:

\begin{tabular}{|c|c|}
\hline Base compensation & 20 points \\
\hline Plus Reported Asset Value & +23 points \\
\hline $\begin{array}{l}\text { Minus cost to reduce the } \boldsymbol{A} \text { Player's payoff, if } \\
\text { any }\end{array}$ & $\begin{array}{l}\text { - } 1 \text { point for every } 4 \text { points of payoff } \\
\text { reduction you impose on the } \boldsymbol{A} \text { Player }\end{array}$ \\
\hline Net payoff & $\begin{array}{l}=43 \text { points minus } 1 \text { point for every } 4 \text { points } \\
\text { of payoff reduction you impose on the } \\
\text { A Plaver }\end{array}$ \\
\hline
\end{tabular}

The $\boldsymbol{A}$ Player's payoff:

\begin{tabular}{|l|l|}
\hline Base compensation & 20 points \\
\hline Plus Reported Value & +23 points \\
\hline $\begin{array}{l}\text { Minus payoff reduction imposed by you, if } \\
\text { any }\end{array}$ & $\begin{array}{l}-4 \text { points for every 1 point you pay to reduce } \\
\text { the } \boldsymbol{A} \text { Player's payoff }\end{array}$ \\
\hline Net payoff & $\begin{array}{l}=43 \text { points minus 4 points for every 1 point } \\
\text { you pay to reduce the } \boldsymbol{A} \text { Player's payoff }\end{array}$ \\
\hline
\end{tabular}




\section{Your total compensation in the experiment:}

- At the end of the experiment, you and the other experimental participants will be compensated for a random selection of $\mathbf{6}$ of the 18 periods.

○ Thus, the computer will sum the points you earned during the six periods selected for compensation.

- The point total from these six periods will then be multiplied by $\$ .06$, which is the amount of total compensation you will receive for the experiment.

Examples:

A participant who earns an average of 40 points per period would get $40 \times 6 \times \$ .06=$ $\$ 14.40$ total compensation.

A participant who earns an average of 70 points per period would get $70 \times 6 \times \$ .06=$ $\$ 25.20$ total compensation.

A participant who earns an average of 100 points per period would get $100 \times 6 \times \$ .06=$ $\$ 36.00$ total compensation.

Note that these are examples for illustrative purposes only.

At the conclusion of today's session, you will be paid your compensation in cash and dismissed after completing a post-experimental questionnaire and cash receipt form. 


\section{APPENDIX C: Z-Tree Screens for Managers and Investors}

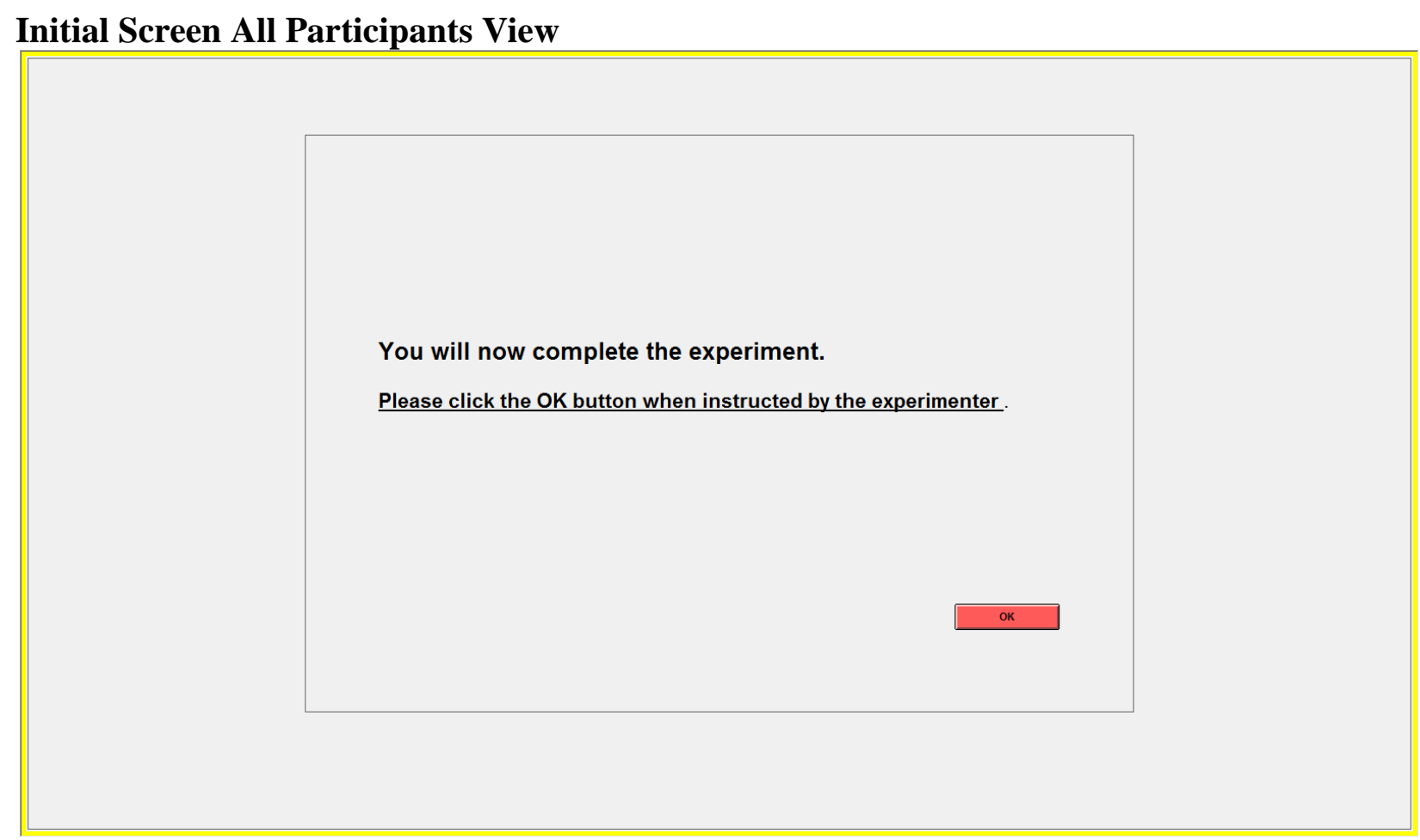

Initial Screen - Manager Reporting Decision (Range Disclosure Condition)

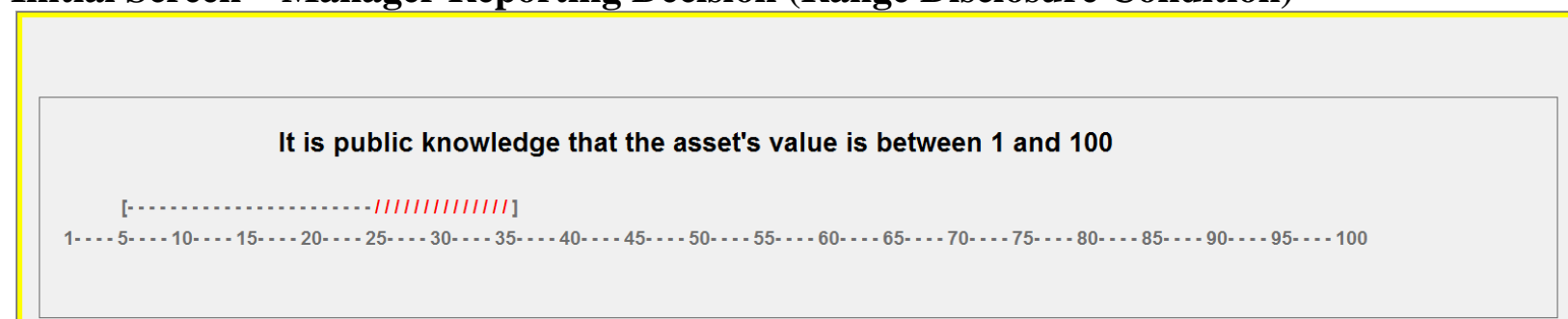

Here is some information pertaining to your decision.

(A) The more precise range for the asset value is between $\underline{\mathbf{5}}$ and $\underline{\mathbf{3 5}}$ (as shown above), and the B Player will know this range.

(B) Your private information indicates that the asset value is likely to be in the HIGH part of the more precise range, as indicated by the / / / area of the more precise range, and the B Player will not know this information.

You decide to report the following value to the B Player

Your reported value must be between $\underline{5}$ and $\underline{35}$

CLCK TO CALCULATE IMPACT OF THE REPORT ON YOUR PAYOFF

Period 


\section{Initial Screen - Manager Reporting Decision (No Range Disclosure Condition)}

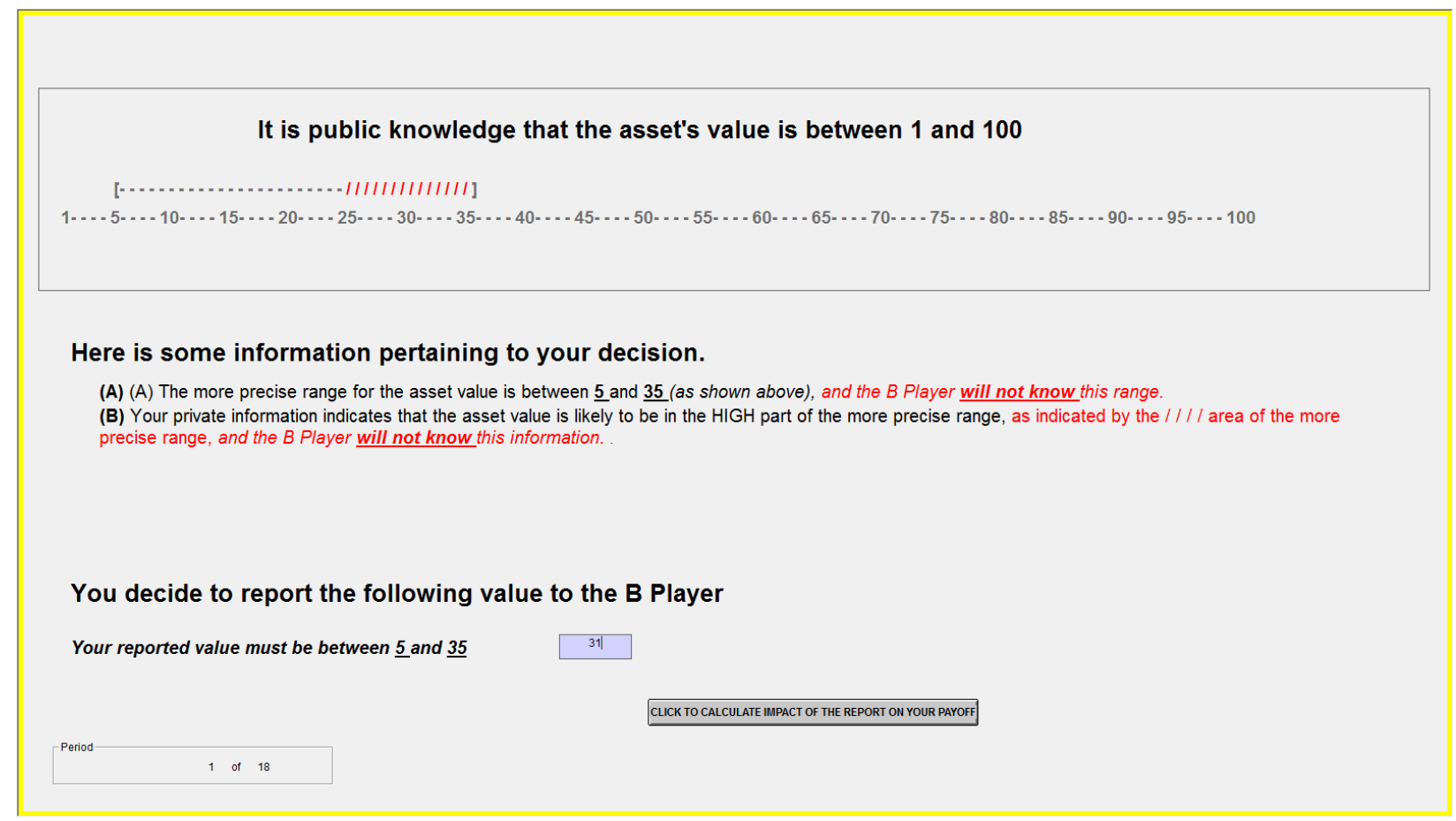

Manager Reporting Decision Screen - After Calculation (Range Disclosure Condition)

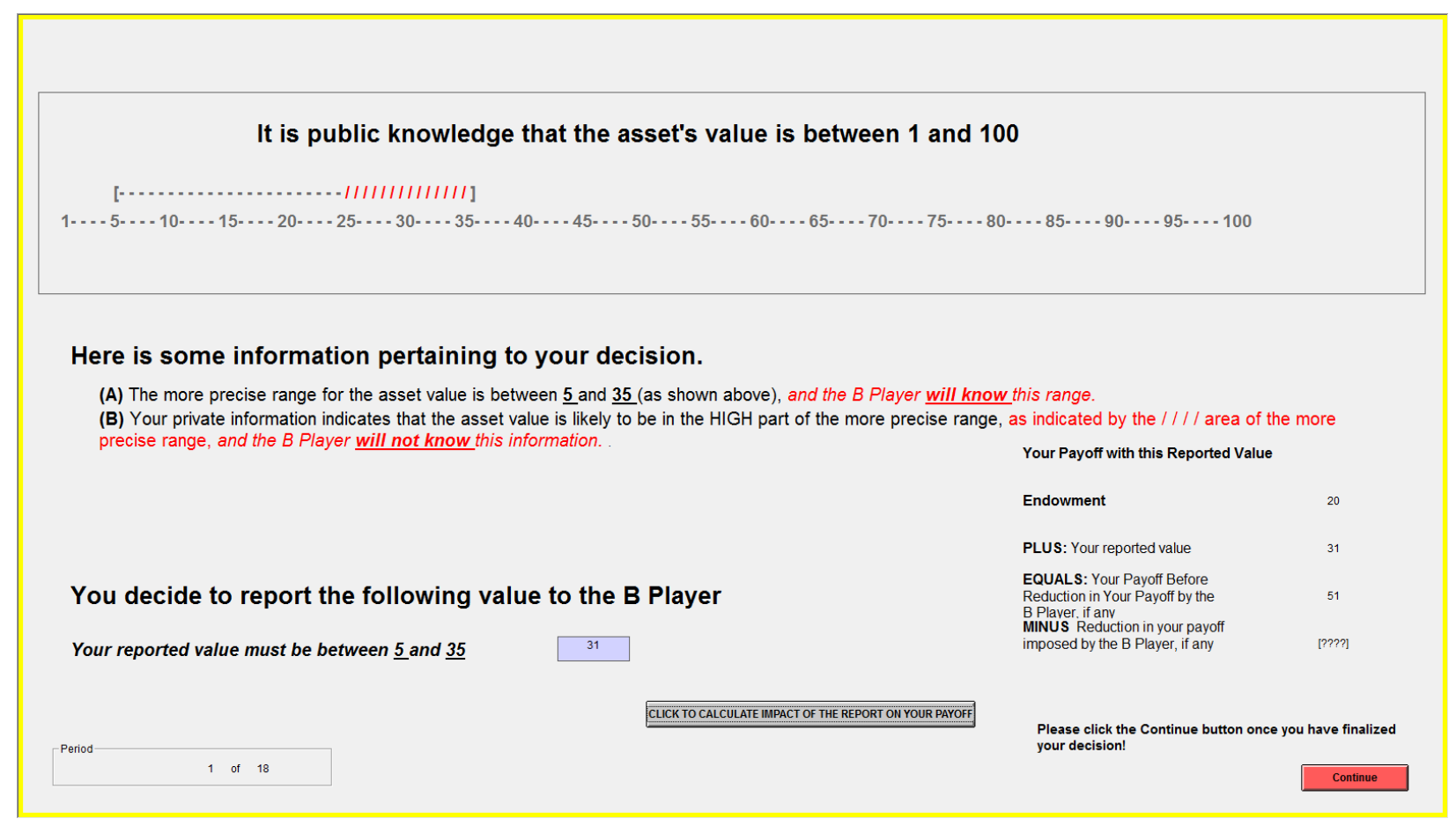


Manager Reporting Decision Screen - After Calculation (No Range Disclosure Condition)

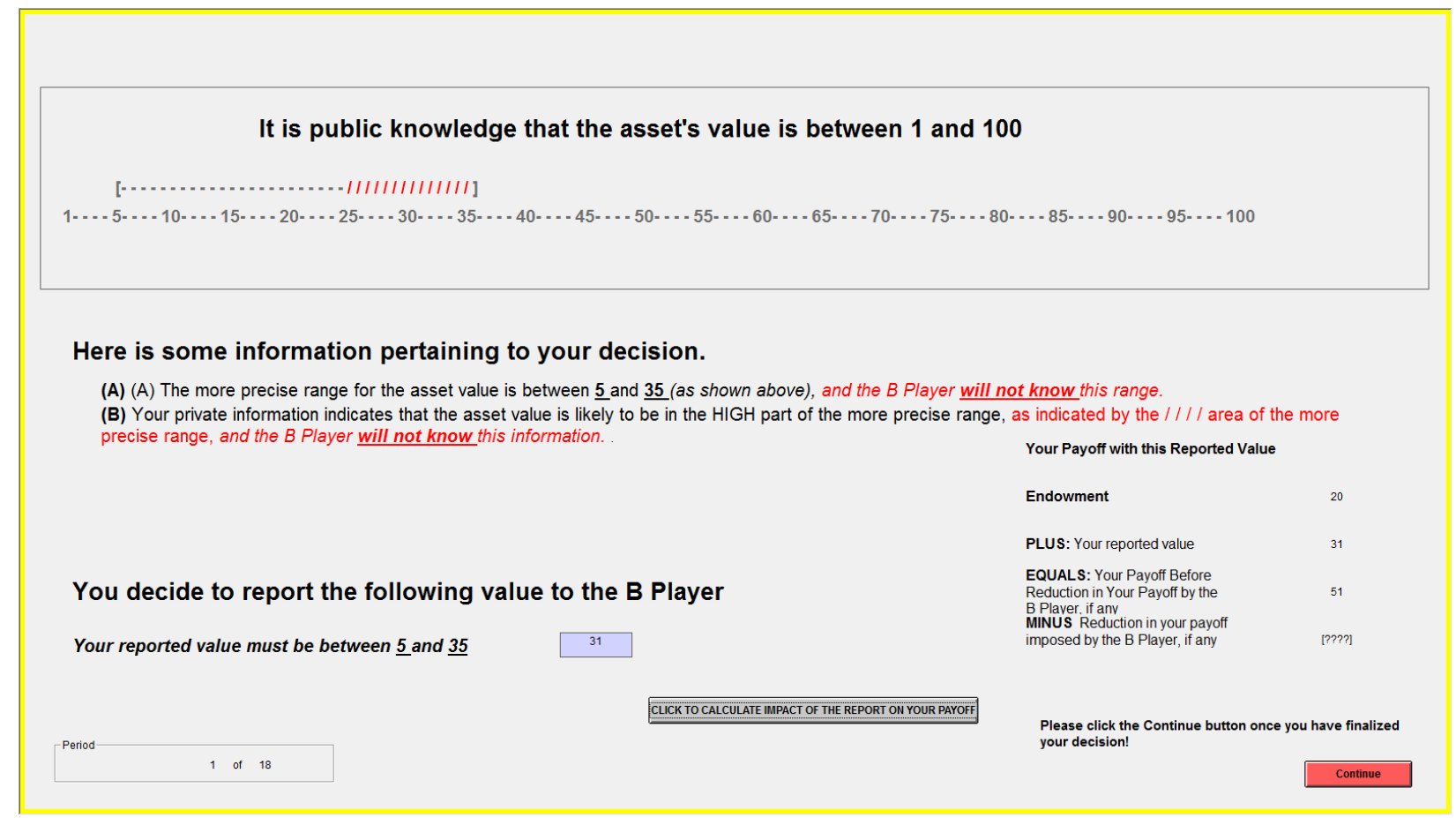

Initial Screen - Investor Action Decision (Range Disclosure Condition)

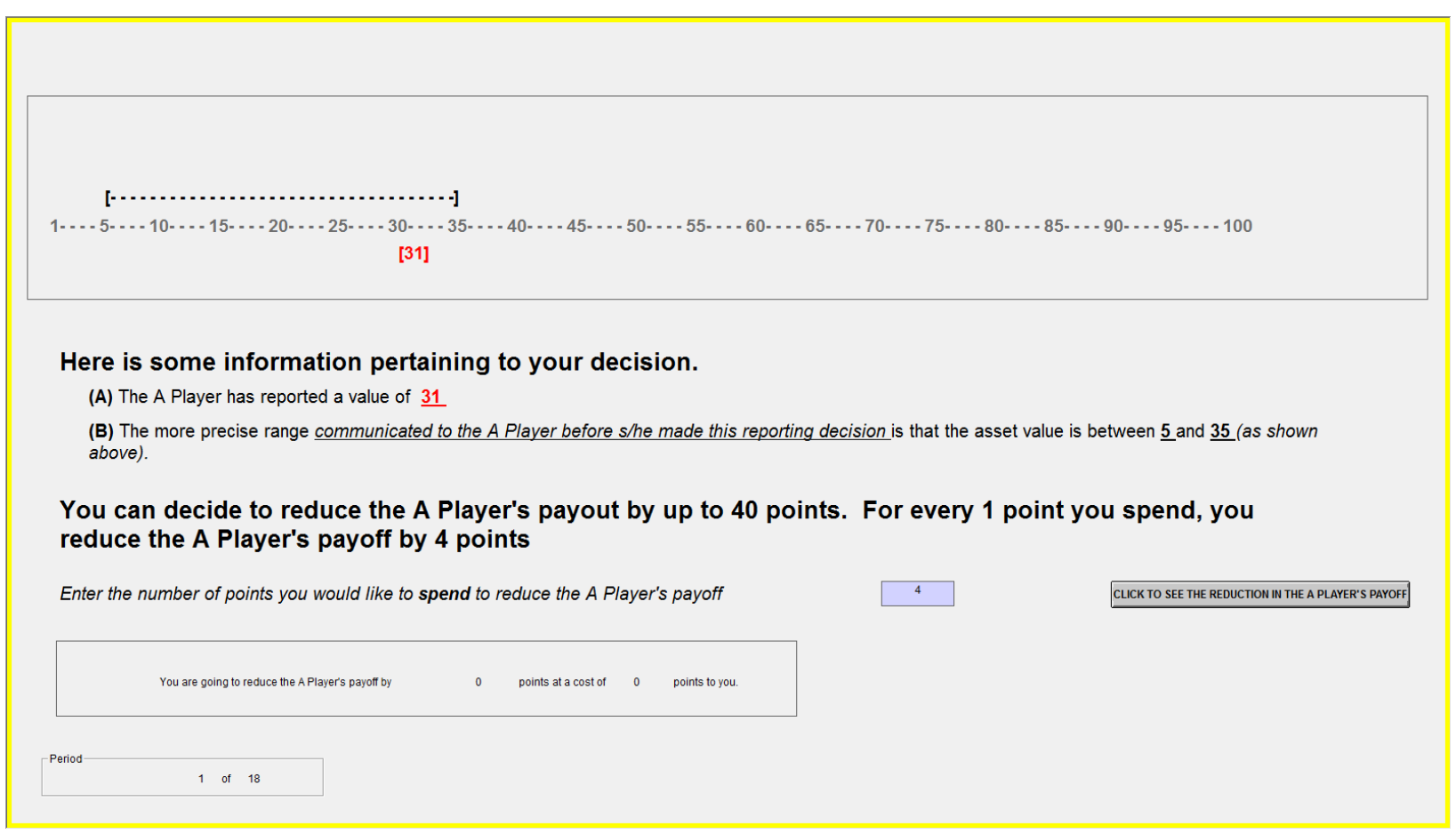


Initial Screen - Investor Action Decision (No Range Disclosure Condition)

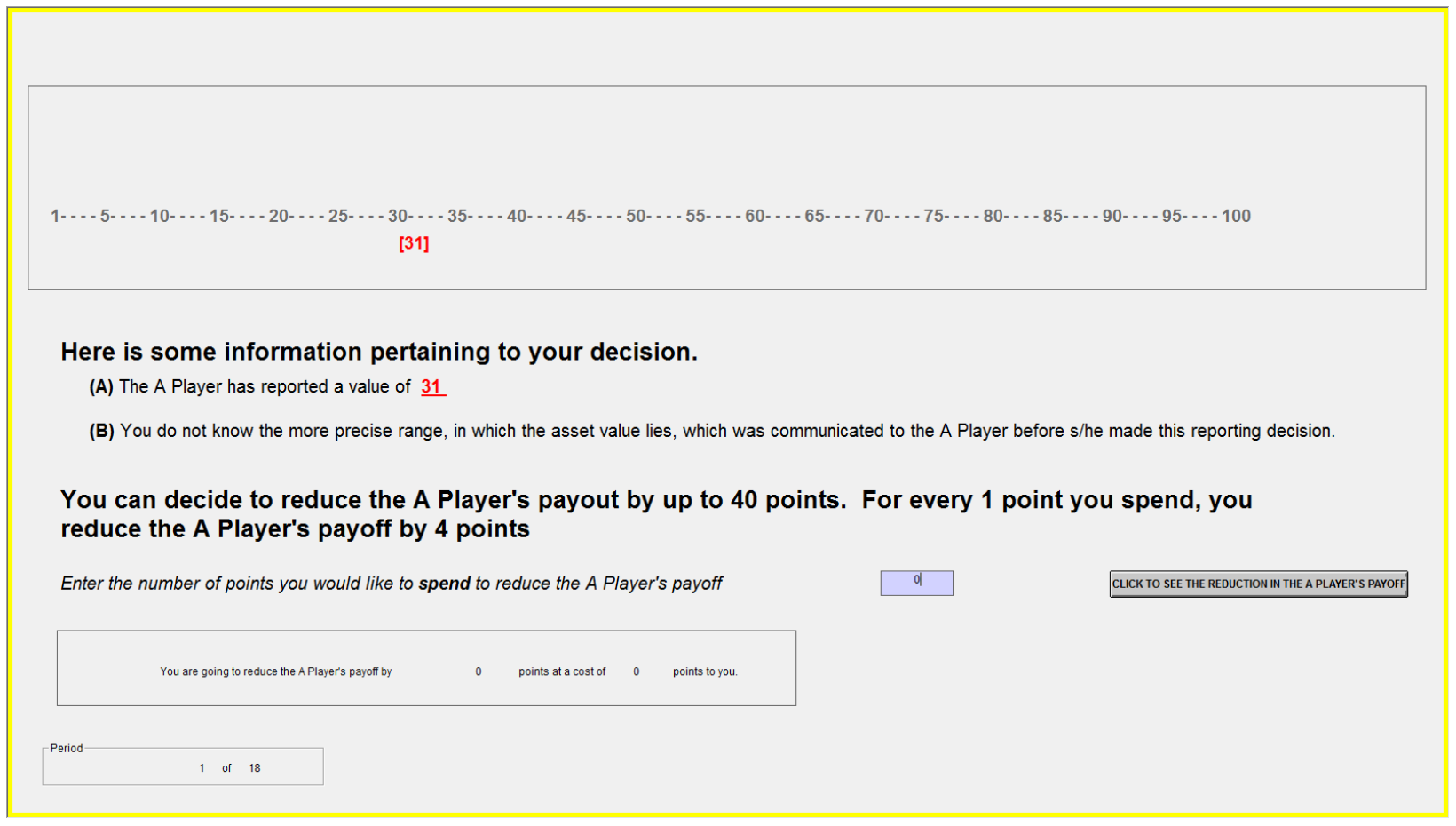

\section{Investor Action Decision Screen - After Calculation (Range Disclosure Condition)}

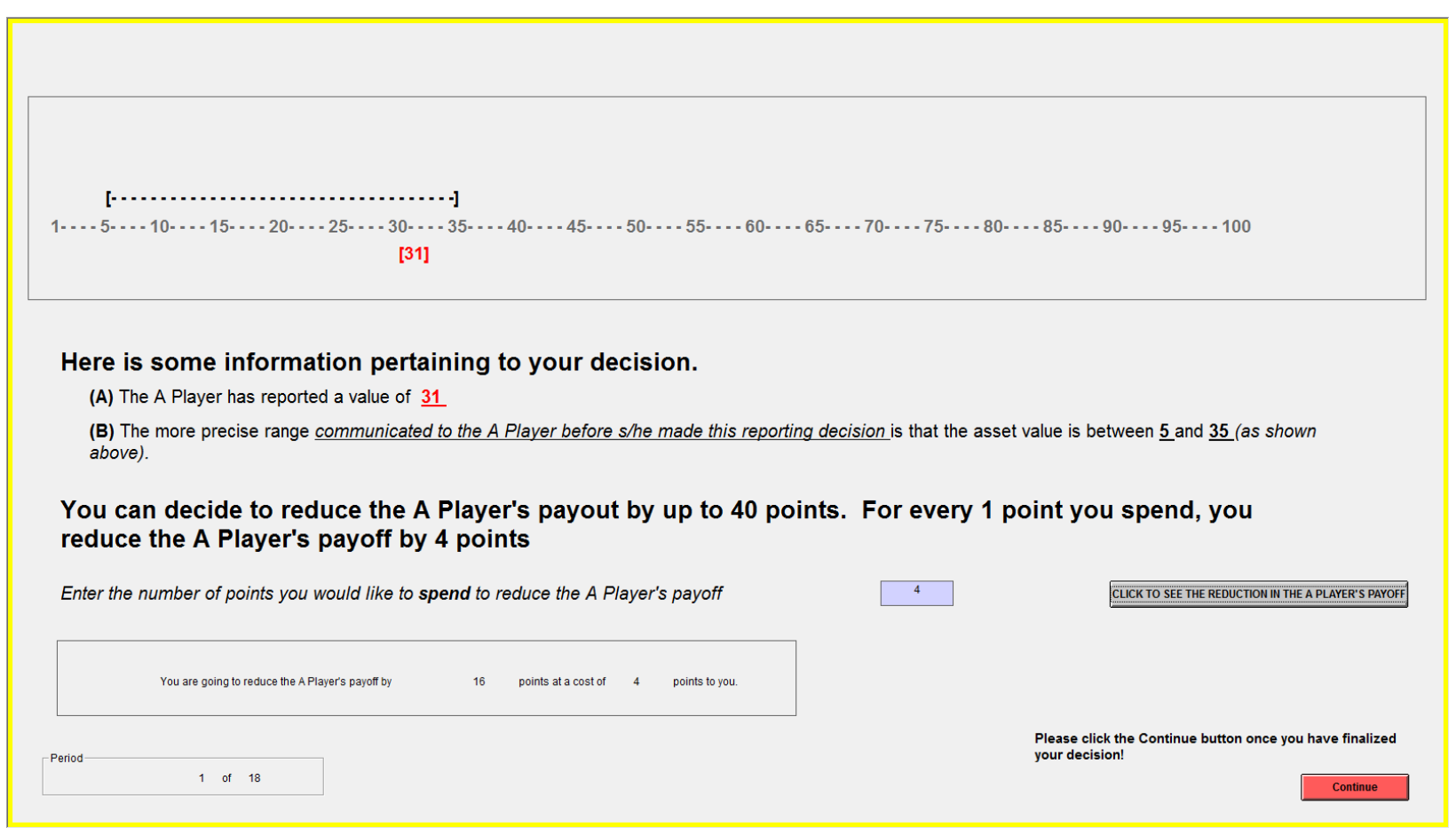




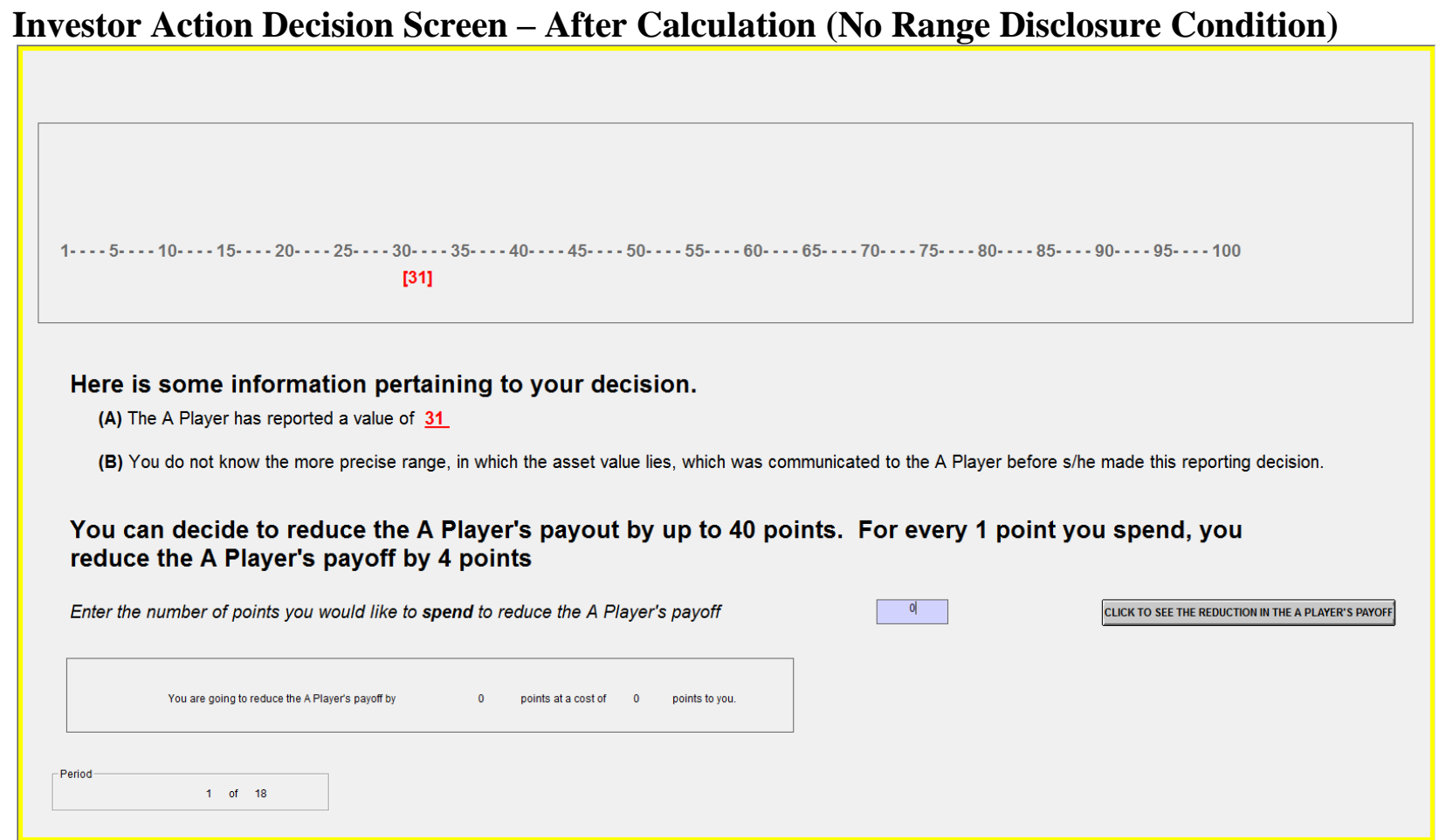

\section{Manager Feedback Screen on Investor Actions (All Conditions)}

The B Player has reduced your payoff by 16 points, which cost the B Player 4 points. Please click the Continue button to move to the next period of the experiment. 


\section{Screen Displayed While Managers and Investors Complete Questionnaire}

Please complete the questionnaire handed out by the experimenter.

Please DO NOT click the OK button until instructed by the experimenter .

\section{Initial Payout Screen - Managers}

\section{Congratulations on Finishing the Experiment!}

The results of each period are listed in the below table.

\begin{tabular}{|l|l|l|l|l|l|l|l|l|l|l|l|l|l|l|l|l|l|l|}
\hline YOUR PAYOFF: & P01 & P02 & P03 & P04 & P05 & P06 & P07 & P08 & P09 & P10 & P11 & P12 & P13 & P14 & P15 & P16 & P17 & P18 \\
\hline Base Compensation & 20 & 20 & 20 & 20 & 20 & 20 & 20 & 20 & 20 & 20 & 20 & 20 & 20 & 20 & 20 & 20 & 20 & 20 \\
\hline PLUS: Reported Value & 31 & 52 & 22 & 83 & 17 & 78 & 62 & 48 & 52 & 27 & 22 & 78 & 53 & 82 & 20 & 53 & 87 & 91 \\
\hline LESS: Reduction in your Payoff & 16 & 4 & 4 & 4 & 0 & 0 & 16 & 0 & 4 & 8 & 4 & 0 & 8 & 8 & 0 & 8 & 12 & 16 \\
\hline Your Total Payoff & 35 & $\mathbf{6 8}$ & $\mathbf{3 8}$ & $\mathbf{9 9}$ & $\mathbf{3 7}$ & $\mathbf{9 8}$ & $\mathbf{6 6}$ & $\mathbf{6 8}$ & $\mathbf{6 8}$ & $\mathbf{3 9}$ & $\mathbf{3 8}$ & $\mathbf{9 8}$ & $\mathbf{6 5}$ & $\mathbf{9 4}$ & $\mathbf{4 0}$ & $\mathbf{6 5}$ & $\mathbf{9 5}$ & $\mathbf{9 5}$ \\
\hline
\end{tabular}

Please enter in the rounds for which you will compensated, as determined by the random draw: 


\section{Initial Payout Screen - Investors}

\section{Congratulations on Finishing the Experiment!}

The results of each period are listed in the below table.

\begin{tabular}{|l|l|l|l|l|l|l|l|l|l|l|l|l|l|l|l|l|l|l|}
\hline YOUR PAYOFF: & P01 & P02 & P03 & P04 & P05 & P06 & P07 & P08 & P09 & P10 & P11 & P12 & P13 & P14 & P15 & P16 & P17 & P18 \\
\hline Base Compensation & 20 & 20 & 20 & 20 & 20 & 20 & 20 & 20 & 20 & 20 & 20 & 20 & 20 & 20 & 20 & 20 & 20 & 20 \\
\hline PLUS: True Asset or Reported Value & 31 & 47 & 22 & 40 & 29 & 73 & 51 & 83 & 23 & 61 & 19 & 84 & 17 & 80 & 47 & 86 & 77 & 80 \\
\hline LESS: Overreport Amount, if any & 0 & 5 & 0 & 22 & 5 & 5 & 0 & 0 & 3 & 0 & 3 & 1 & 3 & 2 & 0 & 8 & 2 & 0 \\
\hline LESS: Cost of Payoff Reduction & 4 & 1 & 1 & 6 & 4 & 0 & 0 & 2 & 2 & 4 & 0 & 2 & 0 & 2 & 0 & 10 & 0 & 0 \\
\hline Your Total Payoff & $\mathbf{4 7}$ & $\mathbf{6 1}$ & $\mathbf{4 1}$ & $\mathbf{3 2}$ & $\mathbf{4 0}$ & $\mathbf{8 8}$ & $\mathbf{7 1}$ & $\mathbf{1 0 1}$ & $\mathbf{3 8}$ & $\mathbf{7 7}$ & $\mathbf{3 6}$ & $\mathbf{1 0 1}$ & $\mathbf{3 4}$ & $\mathbf{9 6}$ & $\mathbf{6 7}$ & $\mathbf{8 8}$ & $\mathbf{9 5}$ & $\mathbf{1 0 0}$ \\
\hline
\end{tabular}

Please enter in the rounds for which you will compensated, as determined by the random draw:

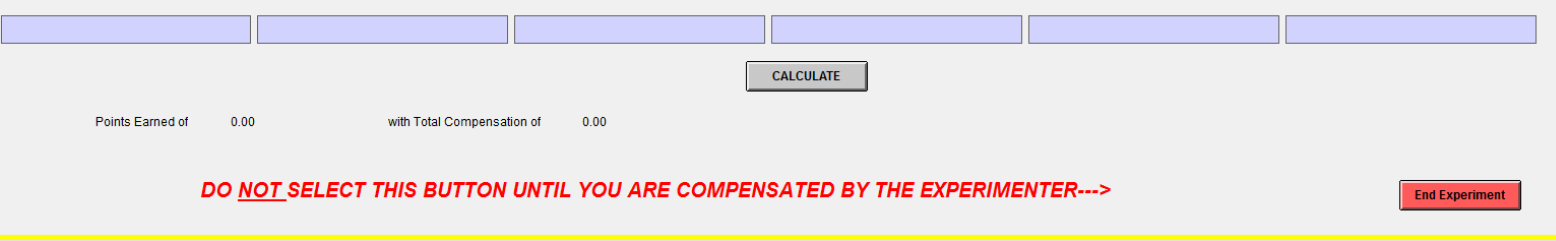

\section{Payout Screen After Rounds Have Been Entered - Managers}

\section{Congratulations on Finishing the Experiment!}

The results of each period are listed in the below table.

\begin{tabular}{|l|l|l|l|l|l|l|l|l|l|l|l|l|l|l|l|l|l|l|}
\hline YOUR PAYOFF: & P01 & P02 & P03 & P04 & P05 & P06 & P07 & P08 & P09 & P10 & P11 & P12 & P13 & P14 & P15 & P16 & P17 & P18 \\
\hline Base Compensation & 20 & 20 & 20 & 20 & 20 & 20 & 20 & 20 & 20 & 20 & 20 & 20 & 20 & 20 & 20 & 20 & 20 & 20 \\
\hline PLUS: Reported Value & 31 & 52 & 22 & 83 & 17 & 78 & 62 & 48 & 52 & 27 & 22 & 78 & 53 & 82 & 20 & 53 & 87 & 91 \\
\hline LESS: Reduction in your Payoff & 16 & 4 & 4 & 4 & 0 & 0 & 16 & 0 & 4 & 8 & 4 & 0 & 8 & 8 & 0 & 8 & 12 & 16 \\
\hline Your Total Payoff & 35 & $\mathbf{6 8}$ & $\mathbf{3 8}$ & $\mathbf{9 9}$ & $\mathbf{3 7}$ & $\mathbf{9 8}$ & $\mathbf{6 6}$ & $\mathbf{6 8}$ & $\mathbf{6 8}$ & $\mathbf{3 9}$ & $\mathbf{3 8}$ & $\mathbf{9 8}$ & $\mathbf{6 5}$ & $\mathbf{9 4}$ & $\mathbf{4 0}$ & $\mathbf{6 5}$ & $\mathbf{9 5}$ & $\mathbf{9 5}$ \\
\hline
\end{tabular}

Please enter in the rounds for which you will compensated, as determined by the random draw:

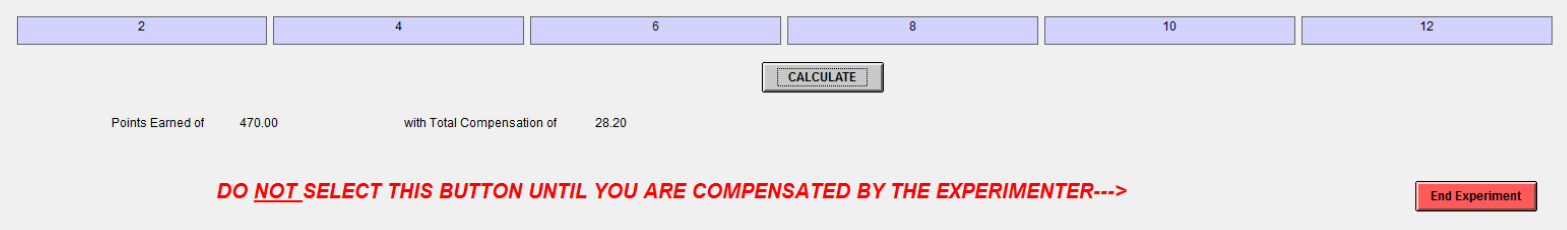




\section{Payout Screen After Rounds Have Been Entered - Investors}

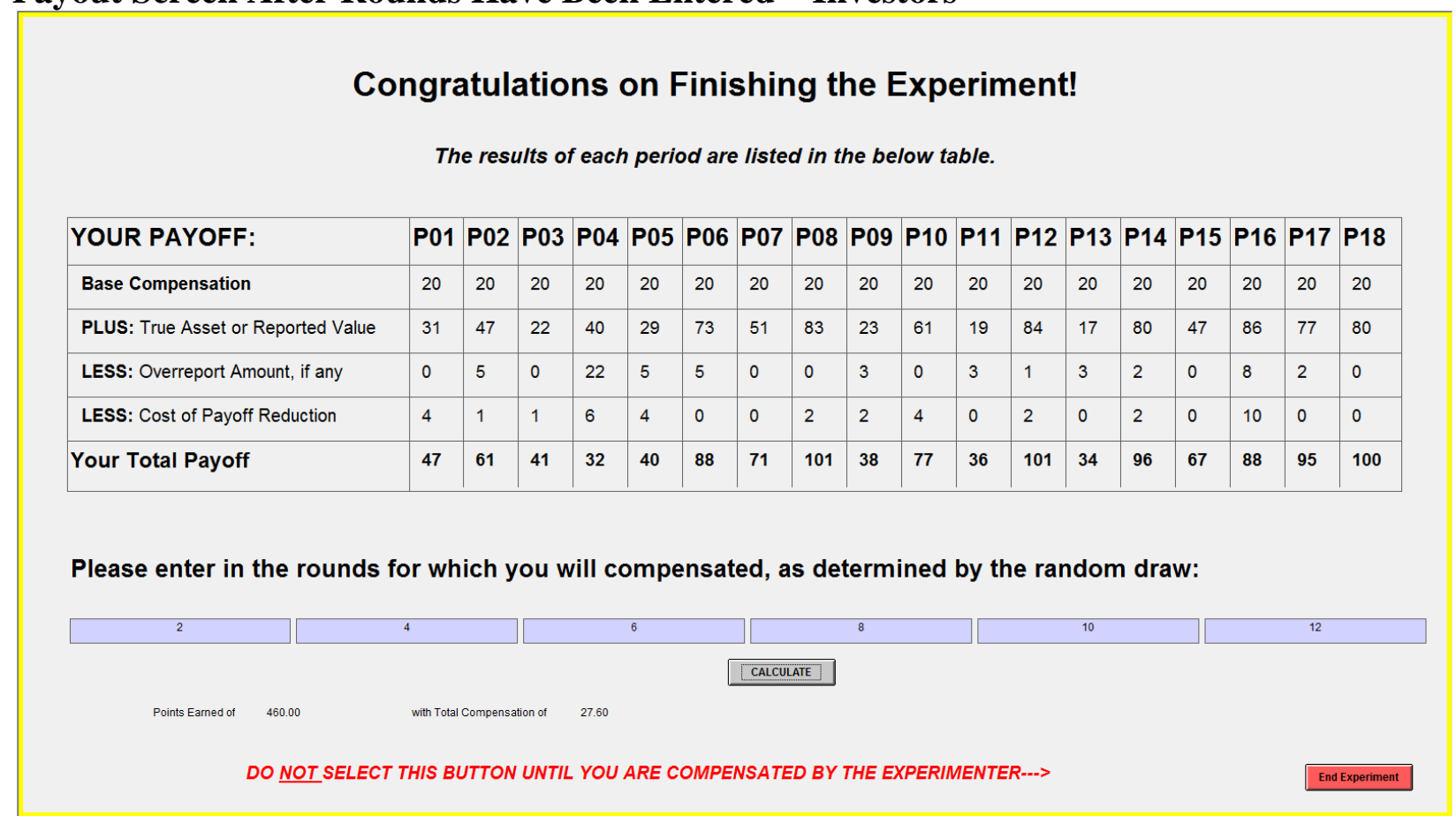




\section{References}

Babiak, P. and R.D. Hare. 2006. Snakes in Suits: When Psychopaths Go to Work. New York: HarperCollins Publishers Inc.

Babiak, P., C. Neumann, and R.D. Hare. 2010. Corporate Psychopathy: Talking the Walk. Behavioral Sciences and the Law. 28(2): 174-193.

Bailey, C. 2013. Psychopathy and Accounting Students' Attitudes Towards Unethical Behaviors. Working Paper, University of Memphis.

Bamber, L., J. Jiang, and I. Wang. 2010. What's My Style? The Influence of Top Managers on Voluntary Corporate Financial Disclosures. The Accounting Review. 85(4): 1131-1162.

Bell, T. and J. Griffin. 2012. Commentary on Auditing High-Uncertainty Fair Value Estimates. Auditing: A Journal of Practice and Theory. 31(1): 147-155.

Bereczkei, T., A. Deak, P. Papp, G. Perlaki, and G. Orsi. 2013. Neural Correlates of Machiavellian Strategies in a Social Dilemma Task. Brain and Cognition. 82(1): $108-116$.

Berg, J., J. Dickhaut, and K. McCabe. 1995. Trust, Reciprocity, and Social History. Games and Economic Behavior. 10(1): 122-142.

Blake, K., J. Carcello, N. Harrison, M. Head, B. Roper, A. Simpson, T. Sondhi, R. Tarola, L. Turner, W. Williams, and A. Yerger. 2012. Response of a Subgroup of the PCAOB's Investor Advisory Group to the PCAOB's Concept Release Concerning Reports on Audited Financial Statements and Related Amendments to PCAOB Standards. Current Issues in Auditing. 5(2): C21-C50.

Bloomfield, R. 1996. The Interdependence of Reporting Discretion and Informational Efficiency in Laboratory Markets. The Accounting Review. 71(4): 493-511.

Bowlin, K. 2011. Risk-Based Auditing, Strategic Prompts, and Auditor Sensitivity to the Strategic Risk of Fraud. The Accounting Review. 86(4): 1231-1253.

Boylan, S.J. and G.B. Sprinkle. 2001. Experimental Evidence on the Relation Between Tax Rates and Compliance: The Effects of Earnings vs. Endowed Income. The Journal of American Taxation Association. 23(Spring): 75-90. 
Bratten, B., L. Gaynor, L. McDaniel, N. Montague, and G. Sierra. 2013. The Audit of Fair Values and Other Estimates: The Effects of Underlying Environmental, Task, and Auditor-Specific Factors. Auditing: A Journal of Practice and Theory. 32(Supplement 1): 7-44.

Brown, T., K. Rennekamp, N. Seybert, and W. Zhu. 2013. Who Stands at the Top and Bottom of the Slippery Slope? Working Paper, University of Illinois at UrbanaChampaign, University of Maryland.

Brunell, A., W. Gentry, W. Campbell, B. Hoffman, K. Kuhnert, and K. DeMarree. 2008. Leader Emergence: The Case of the Narcissistic Leader. Personal and Social Psychology Bulletin. 34(12): 1663-1676.

Chatterjee, A. and D. C. Hambrick. 2007. It's All About Me: Narcissistic Chief Executive Officers and Their Effects on Company Strategy and Performance. Administrative Science Quarterly. 52(3): 351-386.

Christensen, B., S. Glover, and D. Wood. 2012. Extreme Estimation Uncertainty in Fair Value Estimates: Implications for Audit Assurance. Auditing: A Journal of Practice and Theory. 31(1): 127-146.

Christie, R. 1970. Scale Construction. In: Christie, R. and F.L. Geis. 1970. Studies in Machiavellianism. New York: Academic Press. 10-34.

Christie, R. and F.L. Geis. 1970. Studies in Machiavellianism. New York: Academic Press.

Cleckley, H. 1941. The Mask of Sanity. St. Louis, MO: Mosby.

Cleckley, H. 1976. The Mask of Sanity. St. Louis, MO: Mosby. $5^{\text {th }}$ edition.

Corzine, J. B. 1997. Machiavellianism and Management: A Review of Single-Nation Studies Exclusive of the USA and Cross-National Studies. Psychological Reports. 80: 291-304.

Downing, C. 1975. Sigmund Freud and the Greek Mythological Tradition. Journal of the American Academy of Religion. 43(1): 3-14.

Eagly, A. and S. Chaiken. 1975. An Attribution Analysis of the Effect of Communicator Characteristics on Opinion Change: The Case of Communicator Attractiveness. Journal of Personality and Social Psychology. 32(1): 136-144. 
Eagly, A., W. Wood, and S. Chaiken. 1978. Causal Inferences About Communicators and Their Effect on Opinion Change. Journal of Personality and Social Psychology. 36(4): 424-435.

Emmons, R.A. 1984. Factor Analysis and Construct Validity of the Narcissistic Personality Inventory. Journal of Personality Assessment. 48(3): 291-300.

Fehr, B., D. Samsom, and D.L. Paulhus. 1992. The Construct of Machiavellianism: Twenty Years Later. In C.D. Spielberger and J.N. Butcher (Eds.), Advances in Personality Assessment (Volume 9, pp. 77-116). Hillsdale, NJ: Erlbaum.

Fischbacher, U. 2007. Z-Tree: Zurich Toolbox for Readymade Economic Experiments. Experimental Economics. 10 (June): 171-178.

Furnham, A., S. Richards, and D. Paulhus. 2013. The Dark Triad of Personality: A 10 Year Review. Social and Personality Psychology Compass. 7(3): 199-216.

Ghosh, D. and T. Crain. 1996. Experimental Investigation of Ethical Standards and Perceived Probability of Audit on Intentional Noncompliance. Behavioral Research in Accounting. 8(Supplement): 219-244.

Giammarco, E, B. Atkinson, H. Baughman, L. Veselka, and P. Vernon. 2013. The Relation Between Antisocial Personality and the Perceived Ability to Deceive. Personality and Individual Differences. 54(2): 246-250.

Gillan, S. and L. Starks. 2007. The Evolution of Shareholder Activism in the United States. Journal of Applied Corporate Finance. 19(1): 55-73.

Griffith, E., J. Hammersley, and K. Kadous. 2013.Auditing Complex Estimates: Understanding the Process Used and Problems Encountered. Working Paper, Emory University, University of Georgia.

Gunnthorsdottir, A., K. McCabe, and V. Smith. 2002. Using the Machiavellianism Instrument to Predict Trustworthiness in a Bargaining Game. Journal of Economic Psychology. 23(1): 49-66.

Hales, J., J. Hobson, and R.Resutek. 2012. The Dark Side of Socially Mediated Rewards: How Narcissism and Social Status Affect Managerial Reporting. Working Paper, Georgia Institute of Technology, University of Illinois at Urbana-Champaign, Dartmouth College.

Hare. R. 1980. A Research Scale for the Assessment of Psychopathy in Criminal Populations. Personality and Individual Differences.1(2): 111-119. 
Hare, R. 1985. Comparison of Procedures for the Assessment of Psychopathy. Journal of Consulting and Clinical Psychology. 53(1): 7-16.

Hare, R. 1991. The Hare Psychopathy Checklist-Revised (PCL-R). Toronto, ON: MultiHealth Systems.

Hare, R. and C. Neumann. 2008. Psychopathy as a Clinical and Empirical Construct. Annual Review of Clinical Psycology. 4: 217-246.

Hare, R. 2012. The Wall Street Ten Percenters. Comments by Dr. Robert Hare. Available at: http://www.hare.org/comments/comment2.html.

Hartmann, F. and V. Maas. 2010. Why Business Unit Controllers Create Budget Slack: Involvement in Management, Social Pressure, and Machiavellianism. Behavioral Research in Accounting. 22(2): 27-49.

Haynes, C. M., and S. J. Kachelmeier. 1998. The Effects of Accounting Contexts on Accounting Decisions: A Synthesis of Cognitive and Economic Perspectives in Accounting Experimentation. Journal of Accounting Literature. 17: 97-136.

Hirst, E., L. Koonce, and P. Simko. 1995. The Effect of Financial Statement Classification of Hybrid Financial Instruments on Financial Analysts' Stock Price Judgments. Journal of Accounting Research. Autumn: 335-351.

Hirst, E., L. Koonce, and J. Miller. 1999. The Joint Effect of Management's Prior Forecast Accuracy and the Form of Financial Forecasts on Investor Judgment. Journal of Accounting Research (Supplement). 37: 101-124.

Hobson, J. and S. Kachelmeier. 2005. Strategic Disclosure of Risky Prospects: A Laboratory Experiment. The Accounting Review. 80(3): 825-846.

Hodge, F., P. Hopkins, and J. Pratt. 2006. Management Reporting Incentives and Classification Credibility: The Effects of Reporting Discretion and Reputation. Accounting, Organizations and Society. 31(7): 623-634.

International Auditing and Assurance Standards Board. 2012a. Agenda Item 4-A: Auditor Reporting - Insights. Available at: http://www.ifac.org/sites/default/files/meetings/files/20120312-IAASBAgenda_Item_4A-Auditor_Reporting_Insights-v8_0.pdf. 
International Auditing and Assurance Standards Board. 2012b. Improving the Auditor's Report. Available at:

http://www.ifac.org/sites/default/files/publications/files/Auditor_Reporting_Invita tion_t_Comment-final_0.pdf.

International Auditing and Assurance Standards Board. 2013. Proposed International Standard on Auditing (ISA) 701 Communicating Key Audit Matters in the Independent Auditor's Report. Available at: http://www.ifac.org/sites/default/files/meetings/files/20130624-IAASBAgenda_Item_2A-Auditor_Reporting-Proposed_ISA_701_Clean-final.pdf.

Jakobwitz, S. and V. Egan. 2006. The Dark Triad and Normal Personality Traits. Personality and Individual Differences. 40(2): 331-339.

Johnson, E.N., J.R. Kuhn, B.A. Apostolou, and J.M. Hassell. 2013. Auditor Perceptions of Client Narcissism as a Fraud Attitude Risk Factor. Auditing: A Journal of Practice and Theory. 32(1): 203-219.

Jonason, P., N. Li, G. Webster, and D. Schmitt. 2009. The Dark Triad: Facilitating a Short-Term Mating Strategy in Men. European Journal of Personality. 23(1):518.

Jonason, P., N. Li, and D. Buss. 2010a. The Costs and Benefits of the Dark Triad: Implications for Mate Poaching and Mate Retention Tactics. Personality and Individual Differences. 48(4): 373-378.

Jonason, P., N. Li, and E. Teicher. 2010b. Who is James Bond? The Dark Triad as an Agentic Social Style. Individual Differences Research. 8(2): 111-120.

Jonason, P. and G. Webster. 2010. The Dirty Dozen: A Concise Measure of the Dark Triad. Psychological Assessment. 22(2): 420-432.

Jonason, P., S. Slomski, and J. Partyka. 2012. The Dark Triad and Work: How Toxic Employees Get Their Way. Personality and Individual Differences. 52(3): 449453.

Jones, D.N. and D.L. Paulhus. 2009. Machiavellianism. In Leary, M.R. and R.H. Hoyle (Eds.), Individual Differences in Social Behavior. 93-108. New York: Guilford.

Jones, D.N. and D.L. Paulhus. 2011. Differentiating the Dark Triad Within the Interpersonal Circumplex. In L.M. Horowitz and S. Strack, Handbook of interpersonal psychology: Theory, Research, Assessment, and Therapeutic interventions. 249-269. New York: Wiley and Sons. 
Jones, D.N. and A.J. Figueredo. (in press). The Core of Darkness: Uncovering the Heart of the Dark Triad. European Journal of Personality.

Jones, D.N. and D.L. Paulhus. (in press). Introducing the Short Dark Triad (SD3): A Brief Measure of Dark Personality Traits. Assessment.

Jones, G. and M. Kavanagh. 1996. An Experimental Examination of the Effects of Individual and Situational Factors on Unethical Behavior Intentions in the Workplace. Journal of Business Ethics. 15(5): 511-523.

Judge, T.A., R.F. Piccolo, and T. Kosalka. 2009. The Bright and Dark Side of Leader Traits: A Review and Theoretical Extnsion of the Leader Trait Paradigm. The Leadership Quarterly. 20(6): 855-875.

Kachelmeier, S.K. and R. R. King. 2002. Using Laboratory Experiments to Evaluate Accounting Policy Issues. Accounting Horizons. 16(3): 219-232.

Kennedy, J., T. Mitchell, and S. Sefcik. 1998. Disclosure of Contingent Environmental Liabilities: Some Unintended Consequences? Journal of Accounting Research. 36(2): 257-277.

King, R. 1996. Reputation Formation for Reliable Reporting. The Accounting Review. 71(3). 375-396.

Lee, K. and M. Ashton. 2005. Psychopathy, Machiavellianism, and Narcissism in the Five-Factor Model and the HEXACO Model of Personality Structure. Personality and Individual Differences. 38(7): 1571-1582.

Lynam, D. and K. Derefinko. 2005. Psychopathy and Personality. In C.J. Patrick (Eds.) Handbook of Psychopathy (pp. 133-155). New York: Guilford.

Maccoby, M. 2000. Narcissistic Leaders: The Incredible Pros, the Inevitable Cons. Harvard Business Review. January-February.

Mathieu, C., R. Hare, D. Jones, P. Babiak, and C. Neumann. 2013. Psychological Assessment. 25(1): 288-293.

Mayhew, B. 2001. Auditor Reputation Building. The Journal of Accounting Research. 39(6): 599-618.

Mazar, N., O. Amir, and D. Ariely. 2008. The Dishonesty of Honest People: A Theory of Self Concept Maintenance. Journal of Marketing Research. 45(6): 633-644. 
McHoskey, J. 1999. Machiavellianism, Intrinsic Versus Extrinsic Goals, and Social Interest: A Self-Determination Theory Analysis. Motivation and Emotion. 23(4): 267-283.

Murphy, P. 2012. Attitude, Machiavellianism, and the Rationalization of Misreporting. Accounting, Organizations, and Society. 37(4): 242-259.

Nagel, R. 1995. Unraveling in Guessing Games: An Experimental Study. The American Economic Review. 85(5): 1313-1326.

Nikiforakis, N. and H. Normann. 2008. A Comparative Statics Analysis of Punishment in Public-Good Experiments. Experimental Economics. 11(4): 358-369.

Paulhus, D.L. and K. Williams. 2002. The Dark Triad of Personality: Narcissism, Machiavellianism, and Psychopathy. Journal of Research in Personality. 36: 556563.

Paulhus, D.L., C.S. Neumann, and R.D. Hare (in press). Manual for the Self-Report Psychopathy scale. Toronto: Multi-Health Systems.

Public Company Accounting Oversight Board (PCAOB). 2011. Concept Release on Possible Revisions to PCAOB Standards Related to Reports on Audited Financial Statements and Related Amendments to PCAOB Standards. Available at: http://pcaobus.org/Rules/Rulemaking/Docket034/Concept_Release.pdf.

Public Company Accounting Oversight Board (PCAOB). 2012. Briefing Paper: The Auditor's Reporting Model. Available at: http://pcaobus.org/News/Events/Pages/11152012_SAGMeeting.aspx.

Public Company Accounting Oversight Board (PCAOB). 2013. Proposed Auditing Standards: The Auditor's Report on an Audit of the Financial Statements When the Auditor Expresses an Unqualified Opinion; The Auditor's Responsibilities Regarding Other Information in Certain Documents Containing Audited Financial Statements and the Related Auditor's Report; And Related Amendments to PCAOB Standards. Available at: http://pcaobus.org/Rules/Rulemaking/Docket034/Release_2013-005_ARM.pdf.

Ramanna, K. and R. Watts. 2012. Evidence on the Use of Unverifiable Estimates in Required Goodwill Impairment. Review of Accounting Studies. 17(4):749-780.

Raskin, R. and C. Hall. 1979. A Narcissistic Personality Inventory. Psychological Reports. 45(2): 590-590. 
Raskin, R. and H. Terry. 1988. A Principal-Components Analysis of the Narcissistic Personality Inventory and Further Evidence of Its Construct Validity. Journal of Personality and Social Psychology. 54(5): 890-902.

Ray, J. and J. Ray. 1982. Some Apparent Advantages of Subclinical Psychopathy. The Journal of Social Psychology. 117(1): 135-142.

Rijsenbilt, A. and H. Commandeur. 2012. Narcissus Enters the Courtroom: CEO Narcissism and Fraud. Journal of Business Ethics. 1: 1-17.

Robins, R. and D. Paulhus. 2001. The Character of Self-Enhancers: Implications for Organizations. In B. Roberts and R. Hogan (Eds.), Personality Psychology in the Workplace (pp. 193-222). Washington D.C.: American Psychological Association.

Roth, A. Bargaining Experiments. In: The Handbook of Experimental Economics. Princeton: Princeton University Press, 1995. Ed. Hagel, J. and A. Roth. 253-342.

Securities and Exchange Commission (SEC). 2011. Transcript of the Inaugural Public Roundtable for Financial Reporting Series on November 8, 2011 (Roundtable Subject: "Measurement Uncertainty in Financial Reporting"). Available at: http://www.sec.gov/about/offices/oca/frs/ocafrseries110811-transcript.txt.

Shultz, C. 1993. Situational and Dispositional Predictors of Performance: A Test of the Hypothesized Machiavellianism Structure Interaction Among Sales Persons. Journal of Applied Social Psychology. 23(6): 478-498.

Spitzer, M., U. Fischbacher, B. Herrnberger, G. Gron, and E. Fehr. 2007. The Neural Signature of Social Norm Compliance. Neuron. 56(1): 185-196.

Stahl, D. and P. Wilson. 1995. On Players' Models of Other Players: Theory and Experimental Evidence. Games and Economic Behavior. 10(1): 218-254.

Stewart, A. and E. Stewart. 2006. The Preference to Excel and Its Relationship to Selected Personality Variables. Journal of Individual Psychology. 62(3): 270 284.

Swann, W.B. Jr. and J. Bosson. Self and Identity. In S. Fiske, D. Gilbert, and G. Lindzey (Eds.), Handbook of Social Psychology (5 ${ }^{\text {th }}$ Edition, pp. 589-628). New York: McGraw-Hill.

Thaler, R. 1988. Anomalies: The Ultimatum Game. Journal of Economic Perspectives. Autumn. 2(4): 195-206. 
Tversky, A. and D. Kahneman. 1974. Judgment Under Uncertainty: Heuristics and Biases. Science. 185: 1124-1131.

Tversky, A. and D. Kahneman. 1991. Loss Aversion in Riskless Choice: A ReferenceDependent Model. The Quarterly Journal of Economics. 106(4): 1039-1061.

Williams, K.M., D.L. Paulhus, and R.D. Hare. 2007. Capturing the Four-Factor Structure of Psychopathy in College Students Via Self Report. Journal of Personality Assessment.. 88(2): 205-219.

Zimbelman, M.F. and W.S. Waller. 1999. An Experimental Investigation of AuditorAuditee Interaction Under Ambiguity. Journal of Accounting Research. 37(Supplement): 135-155. 


\section{Vita}

Tracie McDonald Majors was born in Raleigh, North Carolina. She is married to Edward Alan Majors. After graduating from Jesse O. Sanderson High School in 1999, she attended Wake Forest University in Winston-Salem, North Carolina, earning a Bachelor of Science in Analytical Finance and a Masters of Accountancy in 2004. She worked at PricewaterhouseCoopers LLP, as an auditor in the Charlotte office from 2004 to 2006 and a senior associate in Transaction Services in the Dallas office from 2007 to 2008. In June of 2008, Tracie entered the doctoral program at The University of Texas at

Austin. Tracie's research uses experimental methods to investigate auditing and financial reporting issues.

This dissertation was typed by the author. 